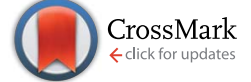

Cite this: RSC Adv., 2017, 7, 4580

\title{
Carbon steel corrosion: a review of key surface properties and characterization methods
}

\author{
Deepak Dwivedi, ${ }^{a}$ Kateřina Lepková ${ }^{\star a}$ and Thomas Becker ${ }^{b}$
}

Corrosion is a subject of interest to interdisciplinary research communities, combining fields of materials science, chemistry, physics, metallurgy and chemical engineering. In order to understand mechanisms of corrosion and the function of corrosion inhibitors, the reactions at the interfaces between the corrosive electrolyte and a steel surface, particularly at the initial stages of the corrosion process, need to be described. Naturally, these reactions are strongly affected by the nature and properties of the steel surfaces. It is however seen that the majority of recent corrosion and corrosion-inhibition investigations are limited to electrochemical testing, with ex situ analysis of the treated steels (post-exposure analysis). The characterization of materials and their surface properties, such as texture and morphology, are not being considered in most studies. Similarly, in situ investigations of the initial stages of the corrosion reactions using advanced surface characterization techniques are scarce. In this review, attention is brought to the importance of surface features of carbon steels, such as texture and surface energy, along with defects dislocation related to mechanical processing of carbon steels. This work is extended to a critical review of surface analytical techniques used for characterization of carbon steels in corrosive media with particular focus on examining steel surfaces treated with corrosion inhibitors. Further, emerging surface analysis techniques and their applicability to analyse carbon steels in corrosive media are discussed. The importance of surface properties is commonly addressed by surface scientists as well as researchers in other chemistry fields such as nanotechnology, fuel cells, and catalysis. This article is expected to appeal to a broad scientific community, including but not limited to corrosion scientists, material chemists, analytical chemists, metal physicists, corrosion and materials engineers.

Received 11th October 2016 Accepted 22nd November 2016 DOI: $10.1039 / c 6 r a 25094 g$ www.rsc.org/advances
${ }^{b}$ Nanochemistry Research Institute, Department of Chemistry, Faculty of Science and Engineering, Curtin University, Western Australia, Australia
${ }^{a}$ Curtin Corrosion Engineering Industry Centre, Department of Chemical Engineering, Curtin University, Western Australia, Australia. E-mail: k.lepkova@ curtin.edu.au

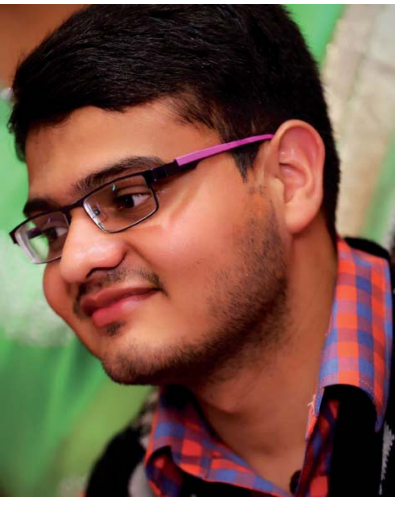

Deepak Dwivedi is currently pursuing research in Department of Chemical Engineering at Curtin University. He obtained his $B E$ in Metallurgical Engineering from $O$. P. Jindal Institute of Technology, India with university merit position for academic excellence and moved to Indian Institute of Technology (IIT) for research with the designation of "Junior Research Fellow". He has been awarded with prestigious "Balshree award" by the President of India H.E. Ms Pratibha Patil. His scientific competency has also been recognised by the Department of Science and Technology, Government of India and he has been awarded as a "Child Scientist" twice (2006 and 2007) and by Institution of Engineers (Raipur Chapter). His current interest involves the investigation of corrosion inhibition mechanism.

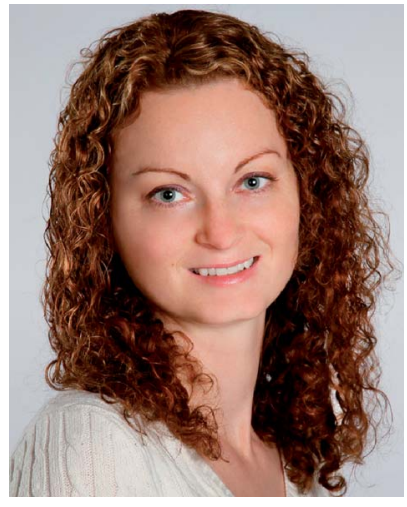

Katerina Lepková obtained an $\mathrm{MSc}$ in chemical engineering from the University of Chemistry and Technology Prague and completed a PhD in physical chemistry (electrochemistry) in the Materials and Surface Science Institute at the University of Limerick. She was awarded an Early Career Research Fellowship at Curtin University in 2009. She is currently a Research Fellow at the Curtin Corrosion Engineering Industry Centre where she leads corrosion inhibition research through several PhD projects. Her research interests are focused on understanding of the mechanisms of carbon steel corrosion and its inhibition for applications in the oil and gas industry and mining sector. 


\section{Introduction}

The high cost of corrosion affects numerous industries, domestic applications and public sectors worldwide and highlights the need for improved corrosion measures. Effective corrosion inhibition has a high economic value as the annual corrosion cost is estimated to reach $3-4 \%$ GDP in developed countries. ${ }^{1}$ In the oil, gas and chemical industries alone, corrosion is one of the most challenging tasks, and it is assumed that it costs 170 billion USD per year. ${ }^{2,3}$ It is not only the high cost of corrosion, but also the health and environmental risks associated with potential failure of the oil and gas equipment that drive the developments of corrosion resistant materials and improved corrosion mitigation strategies worldwide.

Low-cost carbon steels are used as the preferred construction material across industries and are considered the more economical option than the costly corrosion-resistant alloys. Carbon steels typically contain less than $1.5 \%$ carbon content along with the minute presence of $\mathrm{Mn}, \mathrm{Si}, \mathrm{P}$ and $\mathrm{S}$. Based on the percentage of carbon, the classification is further divided into three forms, namely low carbon steels $(<0.25 \% \mathrm{C})$, medium carbon steels $(0.25-0.70 \% \mathrm{C})$ and high carbon steels (0.70$1.05 \% \mathrm{C})$. Variation of the percentage of carbon content allows to attain different mechanical properties such as strength, ductility, hardness, etc. Based on the steel properties, related to carbon content, plain carbon steels are further divided into certain grades, such as grade 1008 (0.08 wt\% C), which is good for forming and has good ductility; grade 1018 (0.18 wt\% C), useful for general application and good for welding; grade 1030 $(0.30 \mathrm{wt} \% \mathrm{C})$, which has low hardenability; grade 1045 (0.45 wt\% C), which has applications in power transmission and shafting; and X-65, which is a seamless grade and weldable.

Carbon steels are used in a wide range of applications, such as structural components, industrial pipes, and kitchen appliances. With regards to applications in the oil and gas industry, the two major forms of corrosion are carbon dioxide $\left(\mathrm{CO}_{2}\right)$

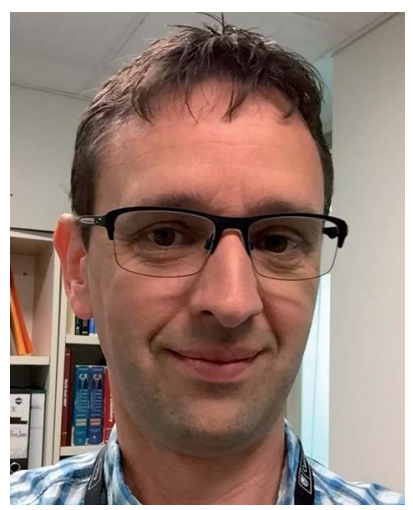

Thomas Becker studied Physics at the University of Ulm in Germany and obtained his PhD from the University of Twente (The Netherlands) in 2005. He joined the Nanochemistry Research Institute/Department of Chemistry at Curtin University in Perth, Australia, in 2005 where he manages the Scanning Probe Microscopy Facility. His research interests focus on sample characterisation with scanning probe microscopy techniques and confocal Raman microscopy. He is currently involved with a number of University based research projects from different disciplines such as corrosion research, hydrogels, health sciences as well as with collaborations with the industry. corrosion, which is also known as sweet corrosion, and hydrogen sulphide $\left(\mathrm{H}_{2} \mathrm{~S}\right)$ corrosion, which is most commonly known as sour corrosion. ${ }^{4}$ Among these two, $\mathrm{CO}_{2}$ corrosion brought a lot of attention to researchers since 1949 because oil wells normally contain $\mathrm{CO}_{2} \cdot{ }^{5,6}$

In this review, we discuss carbon steel as the most employable material for construction of pipelines that supply gas and oil. ${ }^{7}$ Most of the corrosion issues occurring in the oil and gas industries are related to pipelines and the conditions of exposure of the carbon steel that define the selection of the suitable type of carbon steel. For example, minutely added alloying elements such as $\mathrm{Cr}$ and $\mathrm{Ni}$ in carbon steels are sometimes used in the oil and gas sector. Based on the chemical composition and manufacturing procedures, different properties are gained for the steels such as texture (hot rolled texture, cold rolled texture), defects, grain sizes, dislocation densities, etc. that affect the limits for applications of the selected material.

Carbon steels in general are susceptible to corrosion under the conditions at industrial operations and high levels of corrosion inhibition are important for safe and cost-effective operations that extent the limits of use of carbon steels alone. In oil and gas industries, corrosion inhibition can occur naturally through crude oils due to the presence of certain chemical species such as nitrogen, sulphur, aromatic resins, etc. ${ }^{\mathbf{8 9}}$ The most utilized corrosion inhibition measure is however the use of organic or inorganic inhibitors that protect the steel surface by forming a protective film of a passive nature. ${ }^{10}$ Corrosion inhibitors typically contain nitrogen, sulphur and oxygen, and hydrophobic hydrocarbon chains in their structures. Corrosion inhibitors adsorb on the steel surface (either through physical or chemical adsorption) and change the surface and interface free energies. It is postulated from earlier studies that inhibitors alter the wettability of a surface. ${ }^{\mathbf{1 1}}$ Physical adsorption is an electrostatic change whereas chemical adsorption occurs through a bond formation by sharing an electron.

As the use of inhibitors for preventing corrosion of carbon steels is often the most economical option, it is of significant interest to the industry to define the application limits of filmforming corrosion inhibitors. Commercial inhibitor formulations virtually never use a single molecule due to observed synergistic effects that enhance their performance. However, there is no clear explanation in the open literature as to how chemical components of the corrosion inhibitor formulations self-assemble on metal surfaces to protect synergistically against corrosion. Most importantly, the formation of corrosion-protective films is expected to be strongly affected by the nature of the metallic substrate, i.e. carbon steel. It is clear that a definition of limits and potential extension of the use of carbon steels in different corrosive environments is only achievable with a detailed understanding of the mechanisms of carbon steel corrosion and its inhibition.

This review therefore focuses on the importance of texture, surface morphology, surface energy and defects for the corrosion of carbon steels. We discuss in detail the methods of analysis of carbon steel surfaces under corrosive conditions, and in the absence and presence of corrosion inhibitors. In particular, we assess the applicability and limitations of 
analytical methods that have been utilized on carbon steels; and those that have been applied to other metallic substrates, but could have potential applications for studies at carbon steel substrates. Furthermore, the corrosion inhibitor compounds that are presently being used by the oil and gas sector or which could be the prominent emerging candidates for corrosion inhibition (such as green inhibitors) are reviewed, including those specific to internal pipeline corrosion under carbon dioxide conditions.

\section{Role of texture in corrosion of carbon steels}

Surface texture, also addressed as preferred orientations, is one of the important parameters investigated in relation to corrosion. Surface texture develops in alloys and metals during their mechanical deformation such as rolling, forging, drawing, etc. and the established preferred orientations can introduce significant changes to the material properties, including changes in friction and wear properties. Besides mechanical deformation, texture development can occur also during phase transformation, recrystallization, grain growth, etc. ${ }^{\mathbf{1 2 , 1 3}}$ Surface texture can also be associated with special morphology and roughness of the surface, but this review uses the term surface texture with relation to crystallographic orientation.

The importance of texture in corrosion investigations lies in its relation to corrosion resistivity of the materials. It is an established fact that the activation energy for dissolution of a densely packed surface is higher than that of a loosely packed surface. The opposite effect is known for surface energy; with a dense plane having a lower surface energy than a loosely packed surface. It is expected that dense planes dissolve at relatively slow rates compared to the low dense (loose) planes. ${ }^{\mathbf{1 4}}$ It has been established that crystals oriented towards low surface energy (i.e. highly dense planes) can result in increase in corrosion resistance. ${ }^{15}$

Texture is also important for welded structures as crystallographic orientation and crystallite interface are strongly correlated with corrosion resistance. The microstructural difference in the weld nugget and the surrounding area, due to precipitation, affects the texture of the steel through microstructural gradient generation. As many failures in the industry are related to the corrosion at welded areas, it is highly desirable to understand and examine the texture at weldments in corrosion investigations. ${ }^{16,17}$ Similarly, texture is an important parameter in surface chemical reactions as highly textured crystal faces promote the solid-liquid interfacial reactions. ${ }^{\mathbf{1 8 - 2 0}}$ The significance of texture in corrosion has been proven by numerous researchers. This review focuses on establishing the role of texture in corrosion behaviour of plain carbon steels in corrosive environments.

Kandeil et al. ${ }^{21}$ offered a way to classify the surface parameters such as (a) amplitude parameters (peak and valley on surface), (b) spacing parameter (spacing between irregularities in surface) and (c) hybrid parameters (combination of (a) and (b)). It is an established fact that corrosion behaviour is mostly related to the amplitude parameter.
Bateni et $a .^{22}$ investigated the effect of carbon-steel texture on the corrosion process. Under corrosive conditions, the $\{111\}$ $<011>$ fibre texture and $\{001\}<110>$ cube texture developed, which was different to the texture developed in dry wear test, i.e. $<016><100>$ goss texture and $\{111\}$ gamma fibre. In a corrosive environment, $\mathrm{NaCl}$ behaved as a lubricant and developed a different orientation distribution function (ODF) by reducing the metallic contact. It is noticed that the same load (9.6 N) applied for dry wear test and the test under corrosive media depicted different ODF. It was stated that shear stress reduction leads to less shear texture formation and resulted in the disappearance of goss and brass texture in corrosion wear situation. This is due to $\mathrm{NaCl}$ acting as a lubricant and reducing frictional force. It was also observed that the weight loss rate under corrosive wear condition was lower than the dry wear condition because of the same lubrication formation by $\mathrm{NaCl}$.

Venegas et $a l^{23}$ studied the role of texture in hydrogeninduced corrosion of pipeline steel and observed that the steel with $\{111\}$ ND fibre texture developed through warm texture offered good resistance against hydrogen induced corrosion, whereas $\{000\} \mathrm{ND}$ and random texture caused hydrogen induced corrosion. This study concludes the importance of crystallographic texture and grain boundary engineering, showing that low angle grain boundary and $\{111\}$ ND texture provide good corrosion resistance. The role of grain boundary was further investigated by Arafin et al. ${ }^{24}$ The authors observed that intergranular stress corrosion cracking depends on texture and grain boundary. High angle grain boundaries are prone to corrosion but sometimes cracks might be getting arrested at high angle grain boundaries. The association of the crack boundary with $\{100\} / / \mathrm{RP}$ texture in this work provides evidence for the link between crack boundary and texture, and highlights the importance of texture in material failure investigations.

Recently, Baik et al. ${ }^{25}$ studied sulphide stress corrosion cracking of carbon steels with the help of strain rate measurement and found strong correlation between sulphide stress corrosion cracking and strain rate test results, which is indirectly related to the surface texture. This is because the movement of dislocations is easier at a certain plane of crystals, known as dense pack plane ((111) for FCC metals with high atomic density) in BCC iron. This is in agreement with an earlier study showing that pit initiation occurs in sequence of (110) > $(100)>(111)$ whereas pit propagation takes place in the following order $(100)>(110)>(111) .^{24}$

Shkatulyak et al. ${ }^{26}$ studied the role of crystallographic texture in corrosion of carbon steel, which were produced through hot rolling and observed double cylindrical axial texture, i.e. $<100>$ and $\langle 110\rangle$. They illustrated the importance of carbon content as well as texture for anisotropy of electro-chemical corrosion. The study concluded that medium and high carbon content in steels affects the structural texture and invites the anisotropy in electrochemical corrosion. In low carbon steels, the rate of dissolution of facets, such as $\{100\}$ and $\{110\}$ was different and this highlights the importance of surface energy of crystals (alloys or metals), which will be discussed later. ${ }^{27}$ Similarly, the importance of mechanical processing of metals or alloys with respect to texture, which is further related to corrosion 
inhibition or corrosion resistance has been shown by Hallen et al. ${ }^{28}$ Steel samples with the same morphology, but different textures were analysed and warm rolled/recrystallized steels had higher resistance for hydrogen induced corrosion (HIC) than cold and hot rolled steels. This observation was linked to grain boundary distribution and texture. Warm rolling offered $\{111\}$ $\mathrm{ND} /\{112\}$ ND fibre texture with significant amount of low angle grain boundary which is highly resistive for HIC. HRB (hot rolled with $50 \%$ thickness reduction, $1000{ }^{\circ} \mathrm{C}$ rolling temperature) exhibited significant fraction of low angle boundaries with $\{001\}$ ND grain orientation, which reduced the resistance of this sample to hydrogen induced cracking and supported intergranular crack propagation along $\{001\}$ cleavage plane. This phenomenon illustrated the importance of texture in rolled pipes as far as the durability and mechanical performance of pipes are concerned, whereas CRA (cold rolled with 50\% thickness reduction, $27{ }^{\circ} \mathrm{C}$ rolling temperature) and HRA (hot rolled with $75 \%$ thickness reduction, $1040{ }^{\circ} \mathrm{C}$ rolling temperature) showed isotropic texture, which was completely different to that of HRB and warm rolled samples (WRA - with $75 \%$ thickness reduction, $800{ }^{\circ} \mathrm{C}$ rolling temperature, WRB - with $75 \%$ thickness reduction, $600{ }^{\circ} \mathrm{C}$ rolling temperature).

Texture generation can be influenced by numerous factors, such as impurities, stacking fault, inherently stored deformation energy, casting and rolling conditions, grain size and shape, grain boundary angle, shear bending, precipitation. Rabbe et al..$^{27}$ observed cube type fibre orientation in low carbon steels and showed that active slip system steel which got hot rolled in the austenitic regime shows random austenitic texture and texture gradient across the thickness, and undergoes recrystallization due to low stacking fault energy. It has been observed that $\mathrm{Si}$ and $\mathrm{Cr}$ affect the texture in terms of the generation of alpha fibre.

Park et al. ${ }^{29}$ investigated corrosion of steels samples, alloyed with $\mathrm{Cu}$ and $\mathrm{Sb}$, under aggressive corrosion environment (16.9 vol\% $\mathrm{H}_{2} \mathrm{SO}_{4}$ and $0.35 \mathrm{vol} \% \mathrm{HCl}$ at $60{ }^{\circ} \mathrm{C}, \mathrm{pH} 0.3$ ). The authors compared corrosion properties of the steels formed by hot rolling and cold rolling. The interesting facts revealed by this study were that the corrosion rate of cold rolled steel was higher than the hot rolled steel (Fig. 1). This study again proved the importance of mechanical deformation in corrosion behaviour of steels as well as alloys. This was linked closely with the texture of steel as in cold rolled steel the grain refinement and orientation were the key factors for corrosion. ${ }^{28}$ It was observed that a large number of grains were oriented with $\{001\}$ along with $\{101\}$ and $\{111\}$ in cold rolled steel whereas in case of hot rolled steel $\{111\}$ crystallographic orientation was found dominant along with $\{101\}$ and $\{001\}$. Lower corrosion resistance of cold rolled steel compared to hot rolled steel is related to the high surface energy in $\{100\}$ direction as low surface energy plane offers slow dissolution rate of atoms due to its closed atomic packing and results in high corrosion resistance.

It has been demonstrated that deformation conditions, such as hot rolling and cold rolling parameters affect the texture development in steel. Rolling schedule, rolling temperature, reheating time and temperature, etc. are some of the important parameters to consider for texture development. Texture varies over the entire thickness of the specimen. For example hot rolled ultra-low carbon steels exhibit diffused texture due to the dynamic recrystallization and phase transformation from austenite to alpha phase. Shear texture $(\{225\}<554>)$ appears at the close vicinity of the surface, whereas a weak texture $(\{001\}$ $<110>$ ) is found towards the mid-section..$^{30}$

Cold rolled low carbon steel was studied by Xu et al. ${ }^{31}$ with four different microstructures, namely ferritic, acicular ferritic, coarse polygonal ferritic and bainitic. All specimens were cold rolled and annealed in the range of 853-953 K. Polygonal ferrite exhibited string texture along $\{223\}<110>$, similarly acicular and bainitic showed string texture along $\{001\}<110>$ and during annealing all samples exhibited fibrous texture $(\{111\}<u v w>)$ (with $70-90$ reduction). This study elucidated the importance of microstructure and deformation condition with texture.

The deformation procedure affects corrosion such as cold rolled steel, showing low corrosion resistance due to externally applied tension as well as due to texture. Cold deformation often introduces deformation twinning and dislocation arrays, which are accepted as one-dimensional crystal defects. The defects generated on the surface during cold deformations may be more important than texture for cold rolled steels. Cold worked stainless steel (316 type)
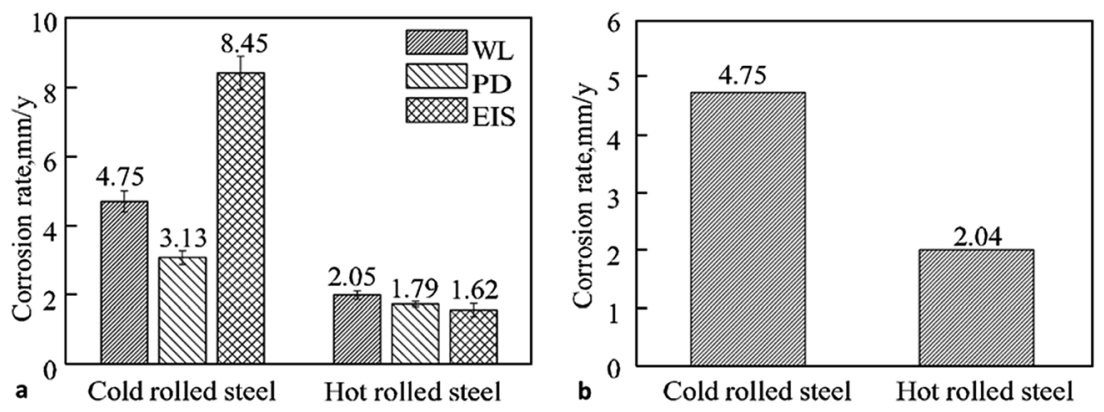

Fig. 1 (a) Comparison of the corrosion rates of cold and hot rolled steel by weight loss (WL), potentiodynamic polarization (PD) and electrochemical impedance spectroscopy (EIS) measurements; (b) comparison of weight loss measurements for cold and hot rolled steel after $6 \mathrm{~h}$ immersion in 16.9 vol\% $\mathrm{H}_{2} \mathrm{SO}_{4}$ and 0.35 vol\% $\mathrm{HCl}$ solution at $60{ }^{\circ} \mathrm{C}(\mathrm{pH}-0.3) .{ }^{29}$ Reprinted from ref. 29 with permission of Springer. Pleiades Publishing, Ltd., 2014. 
exhibits high diffusivity for $\mathrm{Cr}$ and easy carbide nucleation by offering low free energy barrier. Earlier explanations in this section already established the relation between the deformation process with texture and corrosion resistance. ${ }^{32}$ Deformation conditions also affect stacking fault energy. This is responsible for the change in the phase stability and phase transformation. Volume fraction and distribution of phases are other specific parameters that affect corrosion properties of steels.

The importance of phases in the structure of carbon steels is further highlighted by their effect on the inhibitor applications for enhanced corrosion resistance. Oblonsky et al. ${ }^{33}$ explained the importance of phases in the inhibitor molecules attachment to carbon steel, showing that octadecyldimethyl benzylammonium chloride (ODBAC) attached to ferritic-pearlitic microstructures through physical adsorption, but did not adsorb to the martensitic phase in the carbon steel.

Naderi et al. ${ }^{34}$ studied the effect of inhibitors on differently heat treated steels and found slightly lower corrosion in pearlitic steel due to the protective oxide film formation compared to martensitic steel in $1 \mathrm{M} \mathrm{HCl}$ solution, whereas in the presence of inhibitors $N, N^{\prime}$-ortho-phenylen acetyle acetone imine (S1) and 4-[(3-\{[1-(2-hydroxy phenyl)methylidene]amino\}propyl)ethanemidol]-1,3-benzenediol (S2), pearlitic steel exhibited better adsorption of inhibitors than martensitic steel. This study highlights the importance of microstructure for corrosion inhibitor applications and proves the significance of the substrate's microstructure for the corrosion inhibition phenomenon.

The effect of texture on inhibitor adsorption could be very useful to study in the near future as Herrera et al. ${ }^{35}$ have shown that heat treatment affects texture evolution. It was observed that cold rolling with large thickness reduction changed the texture of steel (SAE 1050) such as gamma $<111>/ / \mathrm{ND}$, alpha $<110>/ / \mathrm{RD}$ and gamma prime $<223>/ / \mathrm{ND}$, whereas after annealing with 50 and $80 \%$ reduction, gamma and gamma prime were completely invisible. As explained earlier, heat treatment affects corrosion resistance and this could be related to texture evolution and the adsorption of inhibitors might be influenced by certain specific textures. This highlights the need for extensive investigations in this area in order to get deep insights into the mechanism of corrosion inhibitor adsorption.

Kandeil et $a l .^{36}$ investigated the effect of surface texture on corrosion behaviour of carbon steel and developed a regression equation for corrosion potential and polarization potential, correlating the corrosion rate, corrosion potential and polarization potential with surface properties.

In the assessment of texture and its role in corrosion, one needs to consider dislocation effects. Dislocations are considered as one dimensional defects in materials and are closely related to the texture development as high dislocation density introduced by tensile deformation causes weakening of the crystallographic orientation. This phenomenon is closely related to corrosion as high corrosion rates were obtained at sites where dislocations intersect the surface.

\section{Effects of surface energy and morphology on corrosion of carbon steels}

In the previous section, we have described the importance of texture for corrosion of carbon steels and also proposed the ways through which texture could be controlled. There are however other parameters such as microstructure, chemical composition, defects (e.g. stacking fault energy, dislocation, precipitates, point defects) and surface energy of crystal planes, etc. that also affect the corrosion properties of steel. Section 2 (ref. 29 and 33) addressed the relationship of texture with microstructure, phase composition and the relation of texture with stacking fault and defects. Passive films contain a number of point defects such as interstitial cations (donors) and oxygen vacancies (donor) and/or cation vacancies (acceptor). Movement of cations through the oxide film contribute to the formation of a passive film and increased oxygen leads to an incompact passive film. An interstitial cation can render a metal more easily dissolvable, resulting in decreasing corrosion resistance. ${ }^{37,38}$ Corrosion, texture and surface energy are interrelated as shown in case of aluminium alloys, where $\mathrm{Al}$ (110) surface energy was at maximum when low corrosion resistance was observed. ${ }^{39}$ Crystallographic planes with high surface energy offer adsorption sites for atoms and thus assist with the development of surface films. Film formation could occur due to the effect of the surface energy or through variations in the surface texture as shown by Perlovich et al. ${ }^{\mathbf{4 0}}$ It has been observed that texture-induced stress results in formation of a film on the steel substrate. A high surface energy (low atomic density) crystallographic plane offers sites for water adsorption or proton adsorption and causes hydrogen evolution (hydrogen reaction process), whereas a low surface energy plane (high atomic density) presents a site for hydrogen-reduction reaction. ${ }^{\mathbf{4 1}}$ Adsorption of hydrogen in a high surface energy plane causes corrosion with dissolution of atoms in that plane. Also, the evolution of hydrogen leads to development of pores on surface, which is detrimental for corrosion resistance of the steel substrate. Calculations done by Song et $a .^{42}$ have proven that adsorption of hydrogen in bcc and fcc iron stabilizes its $\{100\}$ facets by lowering the surface energy of $\{100\}$. Similarly, an increase in the carbon content in grain boundary increases the chances of cleavage fracture by increasing the surface energy. The surface energy of pure austenite was found higher than that of pure ferrite, whereas in the case of a hydrogen-containing system, a decrease in surface energy was observed for both austenite and ferritic phases (Fig. 2a). This study described the role of chemical constituents of steel in the surface energy as well as the durability of a steel's relation with the surface energy as incorporation of carbon in austenitic steel widely affected its surface energy, but had lesser effect on ferritic steel (Fig. 2b).

Surface energy can be altered by alteration of texture, as discussed earlier, which in turn influences the corrosion resistivity of the steel substrate. Another aspect of addressing surface energy is hydrophobicity. A well-established concept of hydrophobicity is very important for corrosion studies of metals or 

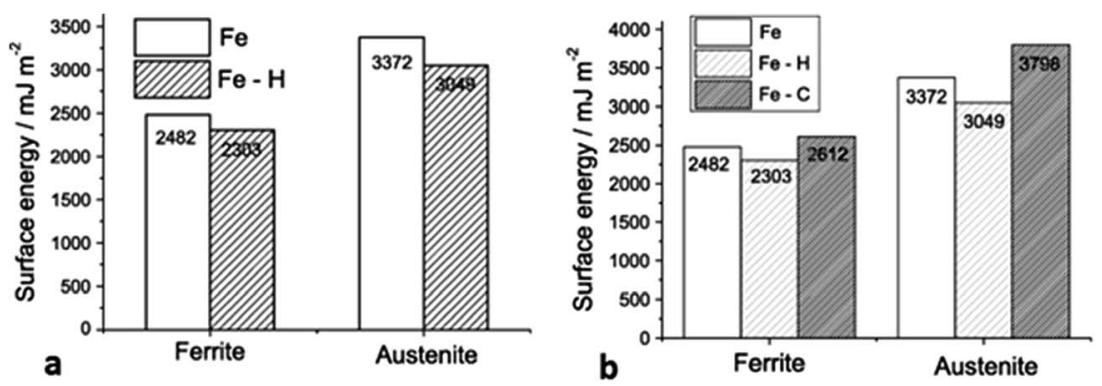

Fig. 2 (a) Comparison of ferrite and austenite surface energy under hydrogen and hydrogen free condition, exhibiting hydrogen addition caused reduction on surface energy for both ferrite and austenite; (b) computed surface energy of ferrite and austenite [under pure (metallic form) and hydrogen, carbon containing system] exhibited lower surface energy for hydrogen containing system for ferrite and austenite than Fe and Fe-C system. ${ }^{42}$ Reprinted with permission from ref. 42. Copyright 2013, Elsevier B. V.

alloys. It is proven that high hydrophobicity prevents liquid from staying on the solid surface for an extended period of time and leads to less exposure of solid surface with liquid by decreasing the contact area between them. Therefore, it is required to understand the surface energy and morphology effects for corrosion studies. Hydrophobicity is related to surface energy as high hydrophobicity requires low surface energy. ${ }^{43}$ It is however important to understand that low surface energy alone cannot be considered as the deciding factor for a super-hydrophobic surface. There are other factors, such as surface morphology, including hierarchical morphology as described earlier in this section, ${ }^{43-45}$ surface roughness as increasing surface roughness causes high hydrophobic surface generation. ${ }^{46,47}$

For corrosion protection, it is necessary that a steel surface has little contact with corrosive media and a surface must have hydrophobic characteristics that can be developed either by increasing the roughness of a surface, which has low surface energy or by low surface energy material coatings on a rough
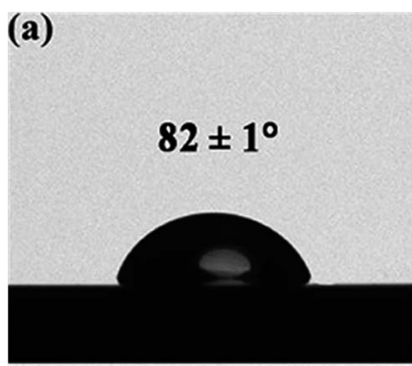

(c)

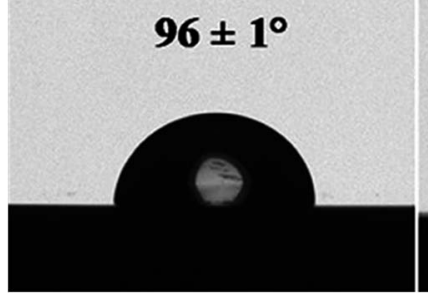

Fig. 3 Contact angle measurements on (a) the bare steel, (b) the textured steel, (c) the modified bare steel, and (d) the modified textured steel. Modification of textured steel depicted its hydrophobic nature. ${ }^{49}$ Reprinted with permission from ref. 49. Copyright 2015, Elsevier B. V. surface. However, a study by Yu et al. ${ }^{48}$ showed that superhydrophobic surfaces cannot always prevent corrosion. Certain rolling characteristics should be maintained. Rolling is a mechanical deformation process, which is a well-known process for texture development of materials as discussed in previous section, but its relation to surface energy in terms of hydrophobicity has not been largely addressed.

The development of a hydrophobic surface film using filmforming corrosion inhibitors is nowadays rather a conventional way of increasing resistivity of carbon steel surfaces. An important emerging alternative to the conventional formation of corrosion-protective surface films is morphological modification of the steel and the consequent development of hierarchical morphology generation. Zhang et al. ${ }^{49}$ developed a superhydrophobic surface in steel by texturing with the help of a hydrogen fluoride (HF) and a hydrogen peroxide $\left(\mathrm{H}_{2} \mathrm{O}_{2}\right)$ solution mixture and the super-hydrophobicity was examined by contact angle measurements (Fig. 3), which depicts the transformation of hydrophilic bare steel surface to hydrophobic surface. Morphological observation through scanning electron microscopy (Fig. 4) revealed that the surface contained islands

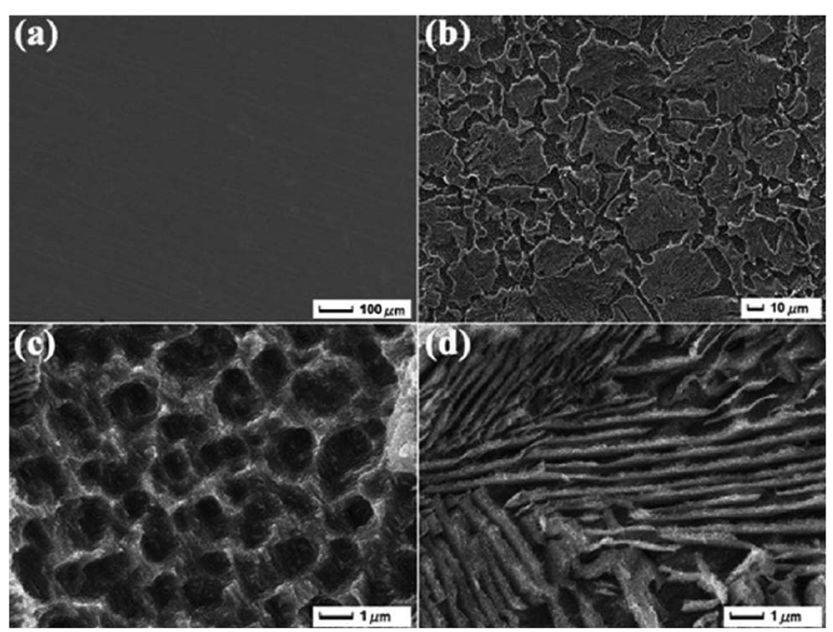

Fig. 4 Morphological images recorded via SEM clearly elucidate the differences for (a) the bare steel and (b) the textured steel surface. (c and d) Magnified images of (b) ${ }^{49}$ Reprinted with permission from ref. 49. Copyright 2015, Elsevier B. V. 


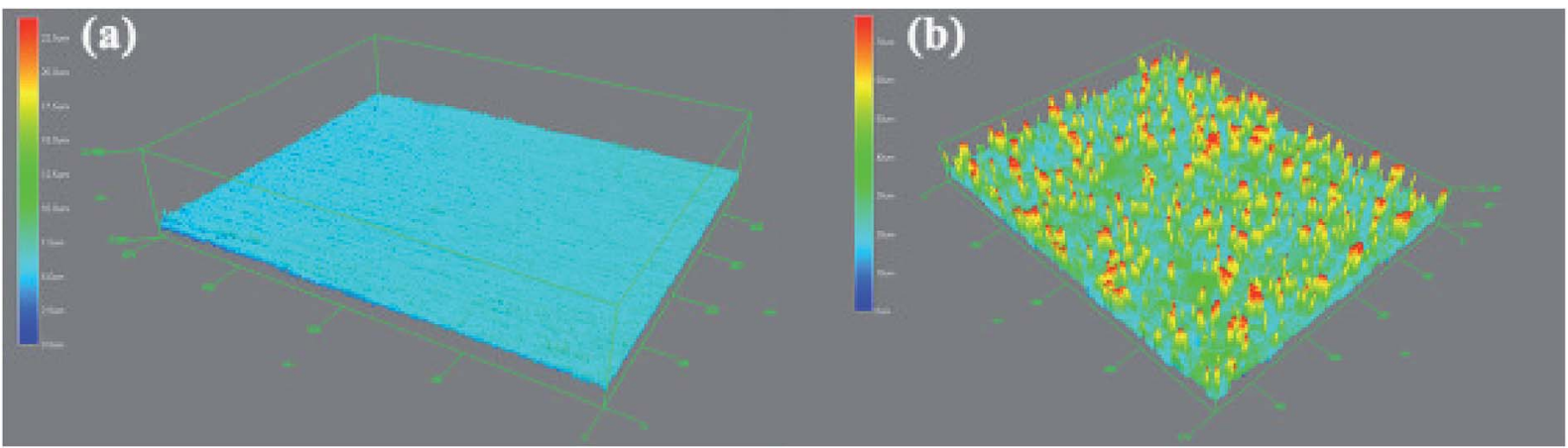

Fig. 5 Surface profile variations in (a) the bare steel and (b) the textured steel surface ${ }^{49}$ Reprinted with permission from ref. 49. Copyright 2015, Elsevier B. V.
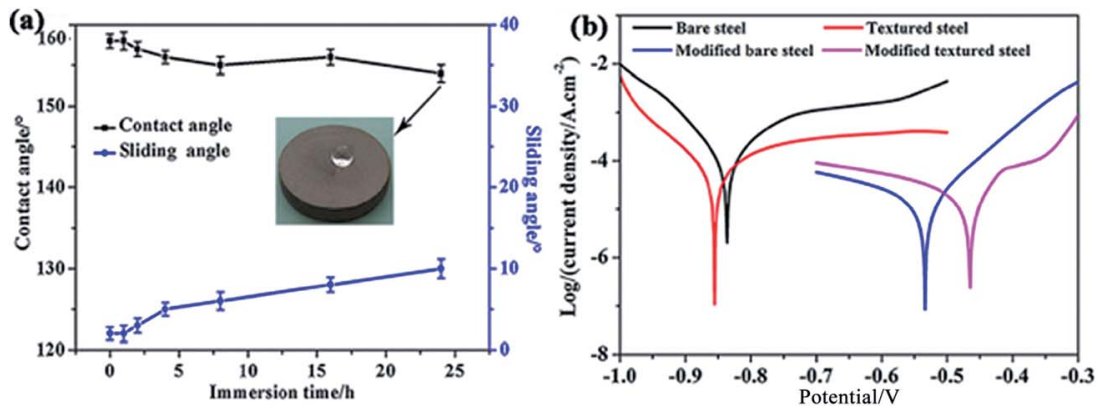

Fig. 6 (a) Establishing relationship between the contact angle and sliding angle of the superhydrophobic surface with the immersion time (3.5\% $\mathrm{NaCl}$ solution); (b) exhibited the effect of surface modification on polarization behaviour as polarization curves for the bare steel, the textured steel, the modified bare steel, and the modified textured steel are found different. ${ }^{49}$ Reprinted with permission from ref. 49. Copyright 2015 , Elsevier B. V.

covered with nanoflakes that lead to the hierarchical-surface generation, which is very important for securing hydrophobic nature of the surface. A hierarchical surface is a surface of multiple roughness, which is the origin for the observed hydrophobicity of this surface (Fig. 5). After 24 hour immersion of textured (modified) steel in $3.5 \% \mathrm{NaCl}$ solution, the contact angle was not significantly changed $\left(158^{\circ}\right.$ to $\left.154^{\circ}\right)$ (Fig. 6a), which suggested stability of the surface for long duration, while Fig. $6 \mathrm{~b}$ shows high corrosion resistance of modified steel surface due to the "cushion" and capillarity effect. Super hydrophobic textured steel does not allow water and $\mathrm{Cl}^{-}$to reach the bare steel surface.

A similar approach, involving a template and chemical etching of the substrate was adopted by Yuan $e t$ al. ${ }^{50}$ This study is beyond the scope of this review as it dealt with iron, but is highly significant as it establishes chemical etching as an important technique for the development of hydrophobic surfaces. It has been observed that the hydrophobic surface had a hierarchical structure. ${ }^{49}$

Wu et al. ${ }^{51}$ protected mild steel by a one-step electrodeposition process of a $\mathrm{SiO}_{2}$ film, which was hydrophobic in nature. Deposition was done through sol-gel process with tetra-ethoxy silane and dodecyltriethoxysilane precursors. A rough surface with low surface energy was achieved and this study brought attention towards the importance of surface roughness in corrosion science. Atomic force microscopy is a technique suitable for identification of the surface roughness, which is further discussed in this review.

The importance of morphology of the protective surface layer as well as its hydrophobicity have been established. A surface layer with significant roughness and less surface energy that is hierarchically structured can increase the corrosion resistivity of the steel. The adherence of the surface film to the substrate (an alloy or metal) also plays a significant role as low adherence of the surface film to the steel substrate always causes high interface energy and thus provides instability of the interface. This highlights the importance of understanding the interface behaviour in terms of adherence of film to the substrate, analysis of which, using atomic force microscopy, is addressed later in this review.

Ramachandran et al.52 investigated corrosion resistive properties of a super-hydrophobic surface of cast iron and identified the relation between surface energy and electric potential by application of the Lippmann law of electro-wetting and Lechatelier principle. This study described the behaviour of a hydrophobic surface in terms of corrosion potential as a decreasing corrosion potential for hydrophobic surfaces was observed. The methodology could be adopted for plane carbon steels when investigating the behaviour of a hydrophobic surface in terms of corrosion potential. 
As far as the mechanism of corrosion prevention through hydrophobic surface formation is concerned, it has been documented that a super-hydrophobic surface can trap air in its structure, due to its hierarchical nature. This leads to improved corrosion protection of the underneath surface through restricting the corrosive ions to strike the surface of the steel substrate. ${ }^{53}$ Similarly, corrosion prevention can be achieved through the capillary effect due to the Laplace pressure, as a super-hydrophobic surface $\left(>150^{\circ}\right)$ of a magnesium alloy was shown to remain resistant to sea water. ${ }^{54}$

Along with various experimental surface studies, significant theoretical investigations have also been carried out in order to examine surface characteristics and morphology of carbon steels. This has been done either through specific surface morphological studies or through inhibitor's adsorption investigations (see for example Durnie et al. ${ }^{55}$ or Shahabi et $a l .{ }^{56}$ ). Similarly, the performance of corrosion inhibitors 1,3thiazole (TA), 2-amine-1,3-thiazole (2-ATA) and 4-amine-1,3thiazole (4-ATA) on mild steel in acidic medium was investigated by theoretical analysis of corrosion inhibitors by Guo et al. ${ }^{57}$ Inhibitor properties were analysed through DFT, whereas adsorption properties were studied by molecular dynamic simulation. Besides defining the preferred corrosion inhibitor based on comparison of reactivity of the studied compounds, the authors also calculated surface energy of Fe crystal and showed that the (110) surface has low surface energy.

Further, $(Z)$-5-(4-Chlorobenzylidene)-3-(benzo[d]thiozol-2-yl)2-(4-methoxyphenyl)thiazolidine-4-one (CBTMT) and (Z)-5-(4methoxybenzylidene)-3-(benzo[d]thiazol-2-yl)-2-(4-methoxyphenyl)thiazolidine-4-one (MBTMT) inhibition performances were checked both theoretically and experimentally. Higher efficiency of MBTMT was observed over CBTMT because of a low band gap energy and the high dipole moment contributes to adsorption on the mild steel surface. ${ }^{58}$

Khaled et $a{ }^{59}$ performed theoretical studies using Monte Carlo simulation and molecular dynamics to investigate adsorption of $Z$-( $p$-toluidinylmethyl)-5-methylfuron (Inh A), 2-( $p$ toluidinyl methyl)-5-nitro furon (Inh B) and 2-( $p$-toluidinyl methyl)-5-bromo furan (Inh C) on mild steel. Monte Carlo simulations identified various adsorption sites on mild steel through selection of the preferential low energy adsorption sites, whereas MD simulation was shown useful for the simulation of the inhibitor adsorption on mild steel. Ethyl 3-hydroxy8-methyl-4-oxo-6-phenyl-2-( $p$-toly)-4,6-dihydroprrimido-[2,1-6][1,3]thiazine-7-carboxylate (PT) was used as a corrosion inhibitor for carbon steel corrosion prevention by Larouj et $a{ }^{6}{ }^{60}$ in $\mathrm{HCl}$ media. It is an established fact that low $\Delta E\left(E_{\text {lumo }}-E_{\text {homo }}\right)$ causes high efficiency of an inhibitor. The Monte Carlo simulation technique was also adopted by Tan et al. ${ }^{61}$ for 3-indobutyric acid (IBA) inhibitor for mild steel in $\mathrm{H}_{2} \mathrm{SO}_{4}$ solution with $\mathrm{Fe}$ (110) surface. It was observed that with the increasing number of IBA molecules the adsorption energy increases, resulting in high surface coverage and good contact with the mild steel surface through parallel orientation of the IBA molecules at the steel surface.

The review of the open literature currently available reveals that extensive research has not been carried out to establish the mechanism of corrosion inhibition through formation of hydrophobic surfaces. It is certainly an emerging field in corrosion science to determine the behaviour of carbon steel morphology and texture with respect to both the surface energy and interface energy. Furthermore, we realize that a clear relationship between the hydrophobicity and rolling texture of carbon steels has not been established. As discussed earlier in this review, hydrophobicity of the steel substrate does not prevent corrosion as a sole factor. We observe from the literature that hierarchical morphology of surface films improves corrosion resistance due to the multiple-roughness structure. Hierarchical structures can be developed through residue ${ }^{62}$ or particle deposition. Another method of generating hierarchical structures is to modify the steel surface, which is typically achieved through etching. ${ }^{63}$ It is also important to note that the mechanical stability and phase stability of the films and structures have not been investigated, but are of significance to the mechanistic studies on corrosion inhibition of carbon steels. Mechanical stability of hierarchical films or morphology could be determined using atomic force microscopy (AFM), where the force required to remove surface film with the AFM tip is measured (scratch test), whereas phase stability could be determined through X-ray diffraction spectroscopy (XRD) or high-temperature XRD.

Another area which is yet to be investigated is the effect of the metallic, non-metallic inclusions and intermetallic phases on the hierarchical structure development. These areas demand extensive investigation as far as carbon steel corrosion is considered. Furthermore, the mechanistic investigations into the formations of the hierarchical structures at steel surfaces and their corrosion-inhibition properties should consider other influencing factors, such as porosity and surface roughness, already described for development of surface films (of nonhierarchical structure) at carbon steels. It has been shown for example that the formation of iron carbonate layer at carbon steel exposed to carbon dioxide media is affected by the velocity of the carbon dioxide gas. This in effect changes the porosity of the iron carbonate surface film and its protectiveness against corrosion. ${ }^{64}$ This study shows the importance of gas media velocity (such as for example $\mathrm{CO}_{2}$ ) in the development of surface morphology of film with significant amount of porosity. Future developments of hydrophobic carbon steel surfaces and the mechanistic studies on their formations and modifications will require advanced investigations that consider the properties of carbon steel structures addressed in this review. Such advanced studies combined with the competent theoretical techniques could reveal the mechanisms involved in the process of corrosion of carbon steels.

\section{Surface characterization techniques}

This section of the article discusses the use of surface analytical techniques for the characterization of carbon steel surfaces with and without treatments (e.g. corrosion inhibitors) under corrosive conditions. The factors influencing the applicability of certain 
techniques to the carbon-steel corrosion studies, such as for example high surface roughness under corrosive conditions, are considered in the discussions. The techniques are also classified by the mode of their applications, i.e. ex situ vs. in situ studies; and techniques using conventional $v s$. synchrotron-sourced signals.

The importance of surface morphology, texture, surface energy and surface defects (including stacking fault, dislocation and point defects) and their significant contributions to the corrosion of carbon steels has been discussed in the previous section. To determine the effects that these parameters impose, the use of surface characterization analytical tools is essential. It has been discussed earlier in this work that the considerable surface roughness of corroded carbon steels often hinders the investigations of thin surface films on these substrates. In the following section, we describe analytical methods available to determine surface structure and the chemical nature of the surface films. This part is divided into two parts, dedicated to (1) analytical techniques that have been applied in corrosion science more commonly, and (2) emerging analytical techniques, some of which are yet to be applied on carbon steels.

\subsection{Conventional characterization techniques}

4.1.1. Atomic force microscopy (AFM). Atomic force microscopy allows for analysis of surface topography, including surface roughness measurements. It has always been difficult to comment on the adherence of the inhibitor film or corrosive film on the substrate (base metal or alloys) by only recording the topographical images. In addition, recording of topographical images can be difficult due to the rough film formation. Therefore, AFM current images and force $v s$. distance curves are also being utilized and provide the additional information on properties of the surface films, for example on the adhesion of corrosion inhibitors and coatings. ${ }^{65,66}$ AFM provides the advantage to operate in liquid conditions and allows surface monitoring under corrosive environments in realtime. ${ }^{67,68}$

Majid Sababi et al. ${ }^{69}$ established the importance of AFM phase imaging for determining densely packed films in their study on composite film of $\mathrm{B}$ mussel adhesive protein with $\mathrm{CeO}_{2}$ nanoparticles at carbon steel. Topography and line profile measurements demonstrated the formation of a film with nanoparticles (20-40 nm), and phase imaging indicated a densely packed nanostructure. Ji et al. ${ }^{70}$ used AFM to obtain molecular information, i.e. surface topography, defects and local surface roughness on carbon steel with a green inhibitor, "Musa paradisiaca". Numerous studies have utilized AFM to determine the nature of the surface film formed on carbon steel surfaces, which can be related to its protectiveness of the metal substrate against corrosion. Jevremovic et al. ${ }^{71}$ investigated inhibitor film formation of tall oil diethylenetriamine imidazoline $(20 \mathrm{ppm})$ on mild steel under the $\mathrm{CO}_{2}$ saturated $\mathrm{NaCl}$ solution $(3 \% \mathrm{NaCl})$ and observed self-assembly of the inhibitor molecules on mild steel. Similarly, imaging of surface films and their characterization, including force mapping can be applied to the analysis of biofilms. Chen et al. ${ }^{72}$ utilized atomic force microscopy for investigation of the effect of dodecylamine on carbon steel and observed a significant decrease in the conductivity of carbon steel due to the adsorption of dodecyl amine on carbon steel with the help of AFM current images. At the same time, the nature of the film was revealed with the help of AFM force measurements. The thickness of the film can also be measured using the AFM. ${ }^{73}$ It was shown that the difference in force $v s$. distance curve can be used to measure thickness of liquid layer on ice and the study suggested application of the AFM for film thickness measurement.

From a corrosion science point of view, not only the nature of the film, but also the mechanical properties of corrosionprotective films are very important as they are closely related to the persistency of the protective film under specific conditions of exposure to corrosive media. AFM can be used to measure the force required to penetrate a surface film. This knowledge on the penetration force can be correlated with the sustainability of the film under certain mechanical loading and can assist in designing surface films for specific applications. Xiong et al. ${ }^{74}$ observed that removal of a bi-layer film of tall oil fatty acid (TOFA) imidazolium chloride required more force compared to a monolayer. AFM lateral force microscopy was used to determine the shear force required to remove the surface film. The study concluded that 50-100 MPa shear stress is required to remove film from the surface and the authors agreed that a corrosion-inhibitor film could not be removed from mild steel pipe walls due to fluid flow because fluid flow velocity in the pipeline is $<1 \mathrm{kPa}$ even under severe hydrodynamic conditions. It was also noticed that the lateral force required to remove a film from a substrate is independent of the film thickness. Film removal depends on the force between the hydrophilic head group in the inhibitor molecule and the substrate. This study investigated mica, gold and X-65 steel as substrates, exposed to deionised water and the corrosion inhibitor. Shear force measurements may be useful for removing the corrosion-product film on the substrate, but the uncertainty regarding the contact area of the AFM probe with the sample can lead to an error in the shear stress calculation.

Corrosion research considers in situ studies as a popular choice that eliminate possible erroneous measurements caused by the exposure to a different environment when samples are treated ex situ. This was shown in a study by Zhang et al. ${ }^{75}$ where mussel adhesive protein films on carbon steel were studied using in situ AFM. The study showed flake shape protein aggregates, whereas ex situ AFM analysis exhibited a compact film (multilayer), which could be stabilized in $\mathrm{NaCl}$ solution through cross linking. The in situ AFM study identified visible holes present in the protein film. The degree of aggregation and multilayer film formation of protein molecules depending on the $\mathrm{pH}$ has also been established and the study elucidated that maximum adsorption was attained faster at $\mathrm{pH} 9$ than at lower $\mathrm{pH}$.

In situ AFM provides high spatial resolution and is therefore used for inhibitor film formation studies. Phase shift and adhesion enhanced contrast can be achieved by tapping mode AFM. ${ }^{76-78}$ A more complex approach has been introduced by Paulson et al. ${ }^{79}$ who carried out in situ AFM investigation of localized and general corrosion at carbon steel. It was observed that size and location of pitting affect the electrochemical signal and the role of inclusion is significant. A similar approach has 
been adopted by Li et $a .^{80}$ with solvent generated alkyd composite coating (with nano-clay) and nano-clay dispersion. Local aggregation was observed on the surface of the carbon steel with the help of AFM imaging while in situ AFM analysis confirmed the stability of coating, also detecting pin holes and defects, through which water and other corrosive media could reach to the parent metal or alloy and cause corrosion. ${ }^{\mathbf{8 1 , 8 2}}$

For corrosion scientists it is always beneficial to see the simultaneous changes in the morphology of the inhibitor film on the surface of the substrate, along with electrochemical observations that provide information on the rates of corrosion.
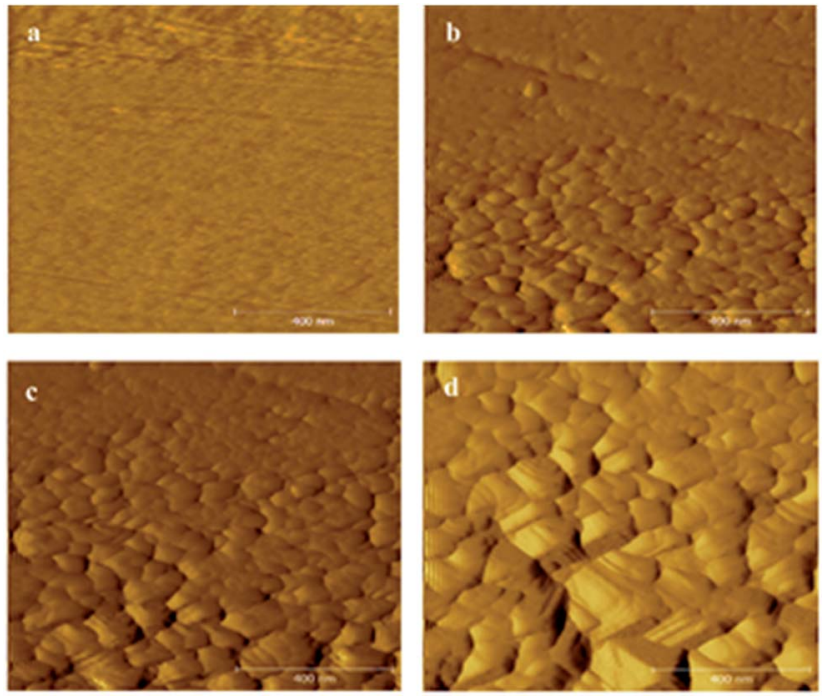

Fig. 7 In situ AFM topographical images of (a) untreated (bare) carbon steel before immersion, and in brine containing DPC (500 ppm) after (b) $5 \mathrm{~min}$, (c) $30 \mathrm{~min}$, and (d) $4 \mathrm{~h}$ immersion. ${ }^{83}$ Reprinted with permission from ref. 83. Copyright 2014, American Chemical Society.
Pandarinathan et $a .^{83}$ provided a correlation between the morphology of the surface films of a corrosion inhibitor, namely 1-dodecylpyridinium chloride (DPC), acquired with in situ AFM and their protectiveness against corrosion, which was derived from electrochemical measurements. The formation of hemispherical and cylindrical structures of the DPC inhibitor formed at carbon steel are shown in Fig. 7 and the electrochemical response associated with these formation processes is shown in Fig. 8. In this study, however, the in situ AFM and electrochemical measurements were not conducted simultaneously within one test cell. Such methodology for in situ AFM and electrochemical measurements is required for kinetic studies of the film-formation processes. The methodology has been developed for corrosion environment, carbon-dioxide saturated brine solution mimicking conditions in oil and gas industry, but corrosion inhibition is yet to be investigated with this test method.

The in situ electrochemical study was further performed by $\mathrm{Li}$ et $a .^{84}$ on acrylic composite coatings with $\mathrm{CeO}_{2}$ nanoparticles for corrosion protection of carbon steel. Cerium based inhibitors are considered as green inhibitors and in situ AFM analysis revealed precipitation of the $\mathrm{CeO}_{2}$ particles through ejection from the coating. It was also observed that the inhibition effect of $\mathrm{CeO}_{2}$ nanoparticles originates from the nanoparticles stabilization through acetic acid. Recently, Li et al. ${ }^{85}$ utilized in situ AFM, intermodulation AFM and electrochemical controlled AFM with combination of cyclic voltammetry, FTIR etc. in order to investigate the mechanism of self-healing properties of a composite coating, PTSA (P-toluene sulfonic acid) doped with polyaniline (PANI) (Fig. 9).

The continuous progress in the developments and applications of the AFM analysis, particularly in situ AFM to carbon steel surfaces confirms the significance of this method in corrosion studies. The identified gaps in the currently available
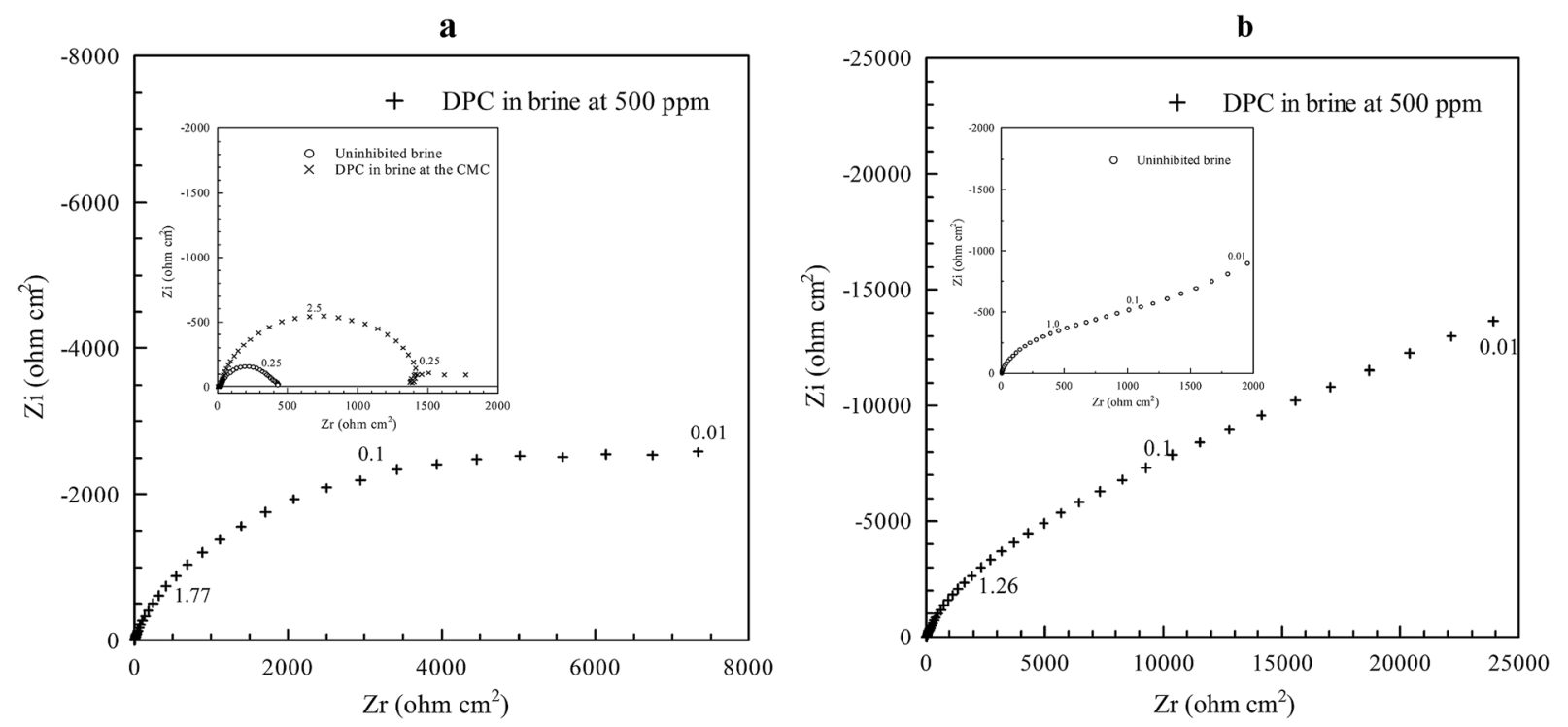

Fig. 8 Electrochemical impedance spectroscopy Nyquist plots for (a) $\mathrm{CO}_{2}$-saturated brine with 500 ppm DPC (inset: uninhibited brine and DPC at the CMC) and (b) $\mathrm{N}_{2}$-saturated brine with 500 ppm DPC for carbon steel after $4 \mathrm{~h}$ immersion. ${ }^{83}$ Reprinted with permission from ref. 83. Copyright 2014, American Chemical Society. 

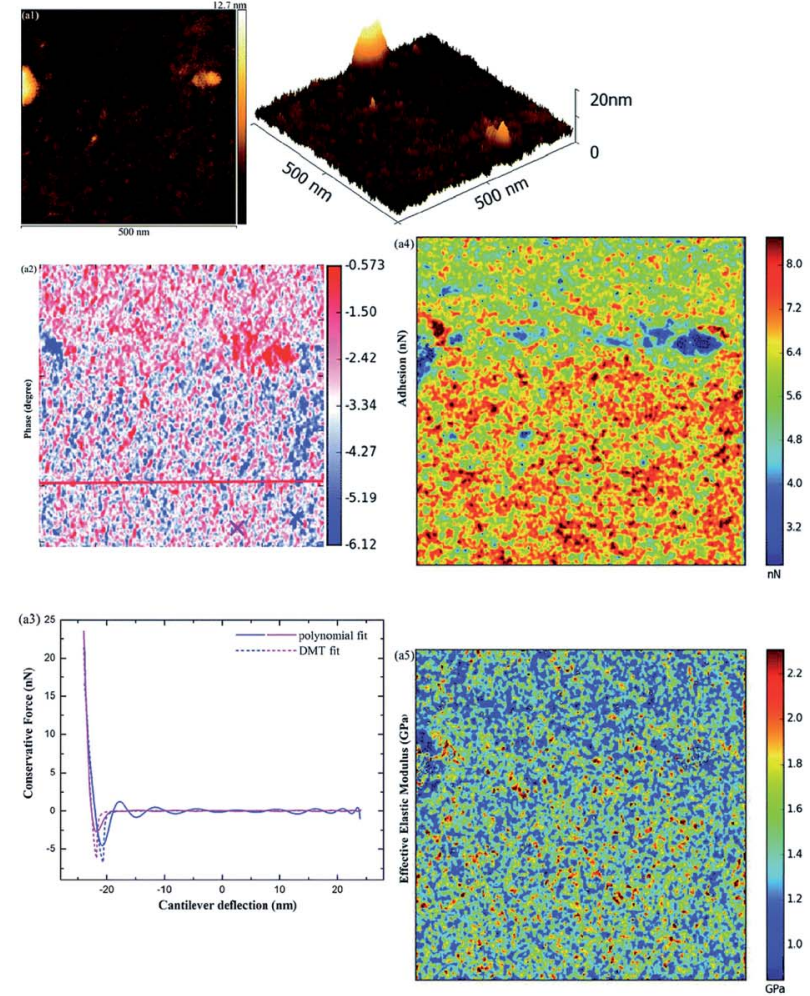
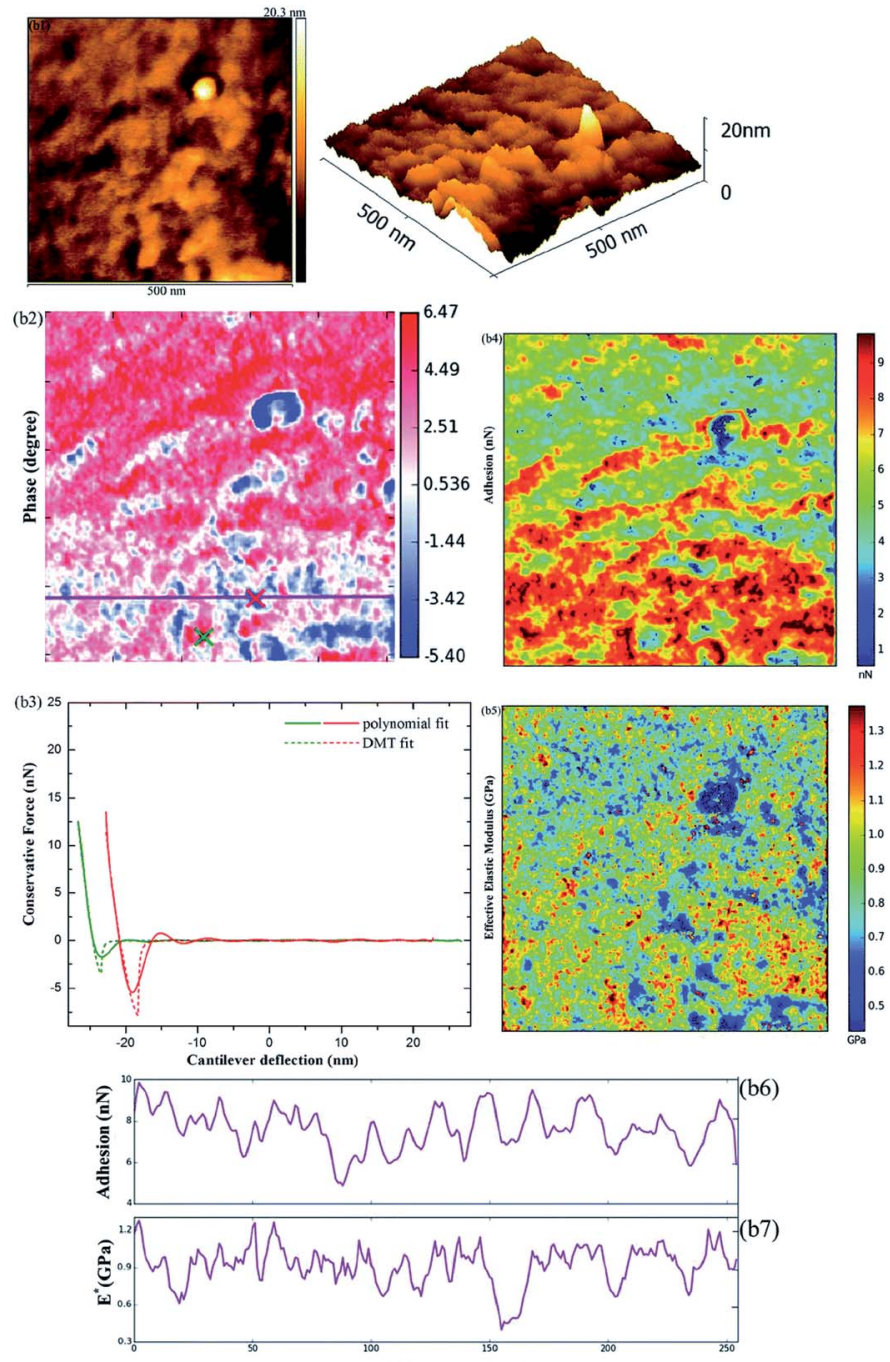

Distance (nm)
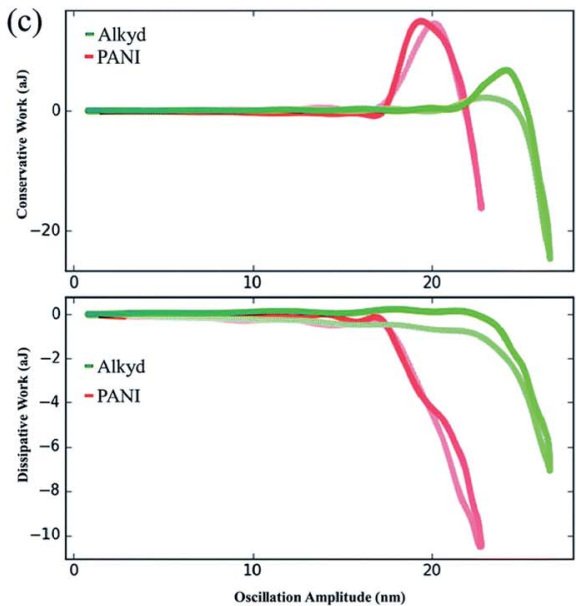

Fig. 9 AFM mapping of reference coating and composite coating showing 2D and 3D morphology (a1) and (b1) respectively, phase mapping (a2) and (b2) and force curves (solid lines) between the tip and the reference (a3 and b3) with DMT model fitting (dotted lines) along with adhesion force ( $\mathrm{a} 4$ and b4) and effective elastic modulus measurements ( $\mathrm{a} 5$ and b5). Adhesion force $v$ s. distance curve has been plotted for reference ( $\mathrm{a} 7$ ) and composite coating (b7) along with the effective elastic modulus ( $\left.E^{*}\right)$ vs. distance curve for reference (a7) and composite (b7). (c) Represents conservative and dissipative work as the function of oscillation amplitude (measured at marked areas in (b2)). ${ }^{85}$ Reprinted with permission from ref. 85. Copyright 2016, Royal Society of Chemistry. 
methodology are the unavailability of accurate lateral shear force measurements applied to carbon steels under corrosive media as well as a methodology for simultaneous (a single-cell system) in situ AFM and electrochemical analysis of thin films of corrosion inhibitors on carbon steels.

4.1.2. X-ray diffraction spectroscopy (synchrotronsourced). It has been documented that grazing-angle X-ray diffraction spectroscopy (GI-XRD) allows examining the surface chemistry of a solid-liquid interface. The conventional GI-XRD however generates a poor signal to noise ratio, which could lead to misleading information on the phase formation. The use of conventional GI-XRD on carbon steels is particularly limited for investigations of thin films, such as corrosioninhibitor films, due to the increased surface roughness of carbon steels under corrosive conditions, and the consequent low signal detected with the GI-XRD. Synchrotron-sourced XRD overcomes the issue of the GI-XRD with a conventional source, as it provides sufficient signal to noise ratio for examining film formations on carbon steels under corrosive conditions. Synchrotron radiation XRD (SR-XRD) is popular among the crystallographers as it gives good resolution with the help of a parallel beam that assists to eliminate low-angle peak broadening, a result of the focussing geometry. Other advantages include the availability of high brightness, high intensity, high collimation, high polarization and low emittance. It is also important to consider the changes which corrosion products can undergo under different conditions and perform corrosion experiments in situ. ${ }^{86}$ It has been observed, for example, that under $\mathrm{CO}_{2}$ conditions (oxygen-free conditions) carbon steel produces iron carbonate as a corrosion product. While exposed to atmospheric conditions (oxygenated conditions), iron carbonate may undergo oxidation.

Combination of in situ SR-GI-XRD with other electrochemical techniques such as cyclic voltammetry, electrochemical impedance spectroscopy, etc. has been shown suitable for mechanistic studies of electrochemical processes on copper surfaces. ${ }^{87,88}$

The first study combining in situ SR-XRD analysis and electrochemical measurements on carbon steel was performed by
De Marco et $a .^{89}$ under carbon-dioxide conditions and corrosion products of $\mathrm{Fe}_{2}(\mathrm{OH})_{2} \mathrm{CO}_{3}, \mathrm{Fe}_{2} \mathrm{O}_{2}\left(\mathrm{CO}_{3}\right), \mathrm{Fe}_{6}(\mathrm{OH})_{12}\left(\mathrm{CO}_{3}\right)$ and $\mathrm{Fe}_{6}(\mathrm{OH})_{12}\left(\mathrm{CO}_{3}\right) \cdot 2 \mathrm{H}_{2} \mathrm{O}$ were identified. It was shown that the surface films had sufficient thickness but due to their porosity corrosion continued by the ingression of electrolyte. This study revealed the importance of SR-XRD as a powerful in situ technique that allows to determine the appearance of a corrosion product at specific sites of the steel surface, either anodic or cathodic. De Marco et al. ${ }^{90}$ later utilized SR-GI-XRD (Si (111) monochromator with $0.6^{\circ}$ incidence angle) in combination with electrochemical impedance spectroscopy to study $\mathrm{CO}_{2}$ corrosion of mild steel in the presence of acetate (Fig. 10 and 11). A wavelength of $1.00 \AA$ was selected for reducing attenuation in air and electrolyte. It was observed that the absence of acetate led to the formation of thick scale during $\mathrm{CO}_{2}$ corrosion of mild steel. The study concludes that acetate assists the formation of a passive film, i.e. corrosion protection on mild steel.

Ingham et al. ${ }^{91}$ examined carbon steel during $\mathrm{CO}_{2}$ corrosion in a chlorinated solution at $90{ }^{\circ} \mathrm{C}$ with in situ SR-XRD. The scale formed on the surface of the carbon steel with a majority of siderite phase. The crystallite size and thickness of scale decreased with temperature, amino trimethylene phosphonic acid (ATMPA) was included in some tests. Siderite was observed as major corrosion product and an increased scale formation rate with increased temperature was noticed. High concentration of ATMPA inhibits the nucleation of siderite and prevents formation of spherical siderite, leading to development of a smooth scale. Further, Ingham et al. ${ }^{92}$ performed experiments with $\mathrm{NaCl}$ and $\mathrm{MgCl}_{2}$ solution at $80{ }^{\circ} \mathrm{C}$ for $\mathrm{CO}_{2}$ corrosion of carbon steel and observed $\mathrm{FeCO}_{3}$ phase in $\mathrm{NaCl}$ solution whereas $\mathrm{FeCO}_{3}$ and $\mathrm{Fe}(\mathrm{OH})_{2} \mathrm{CO}_{3}$ formed in $\mathrm{MgCl}_{2}$ solution. This means that $\mathrm{MgCl}_{2}$ solution imposed higher precipitation than $\mathrm{NaCl}$ solution by offering low critical supersaturation for precipitation. A significant effect of $\mathrm{Mg}^{2+}$ and $\mathrm{Ca}^{2+}$ ion was noted whereas no carbonate species of these ions were observed in the phase analysis. Ko et al. ${ }^{93}$ extended this work by investigating two scale inhibitors, amino trimethylene phosphonic acid and polyethyleneimine, in $\mathrm{CO}_{2}$ corrosion of carbon steel using SR-GI-XRD. The study depicted the effect of inhibitor on
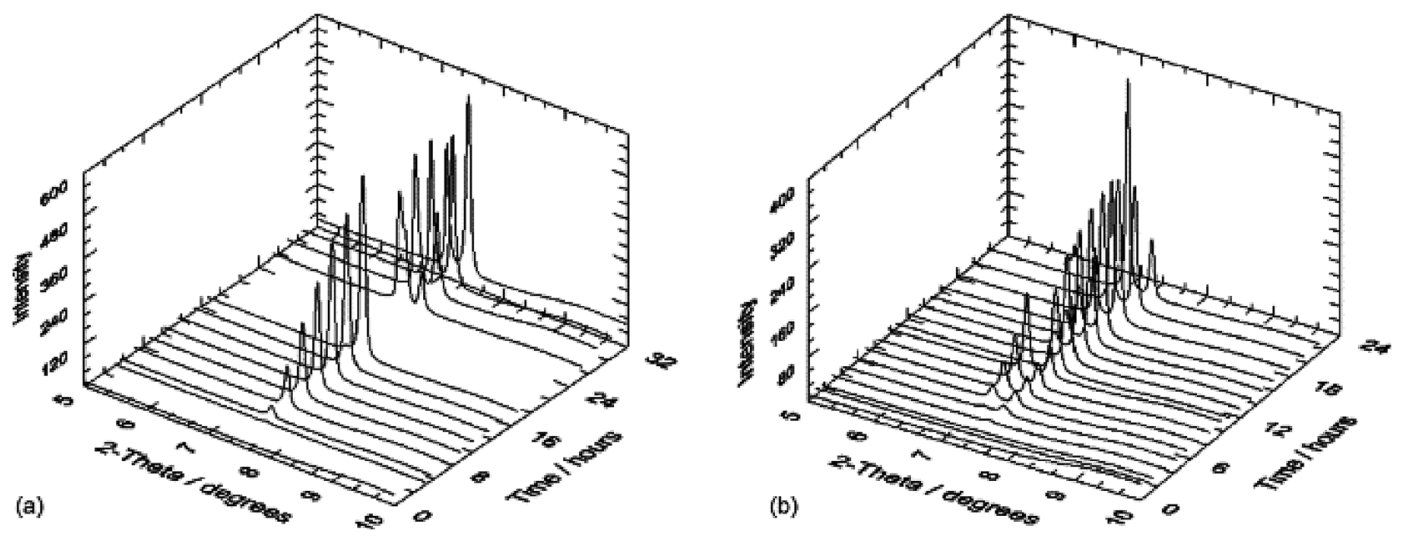

Fig. 10 In situ SR-GIXRD results for a polished mild steel electrode immersed in $3 \%(\mathrm{w} / \mathrm{v}) \mathrm{NaCl}$ saturated with high purity carbon dioxide (at atmospheric pressure (adjusted to $\mathrm{pH} 4.75$ )) without (a) and with acetic acid (b) $200 \mathrm{mg} \mathrm{L}^{-1}$ of acetic acid..$^{90}$ Reprinted with permission from ref. 90. Copyright 2007, Elsevier B. V. 

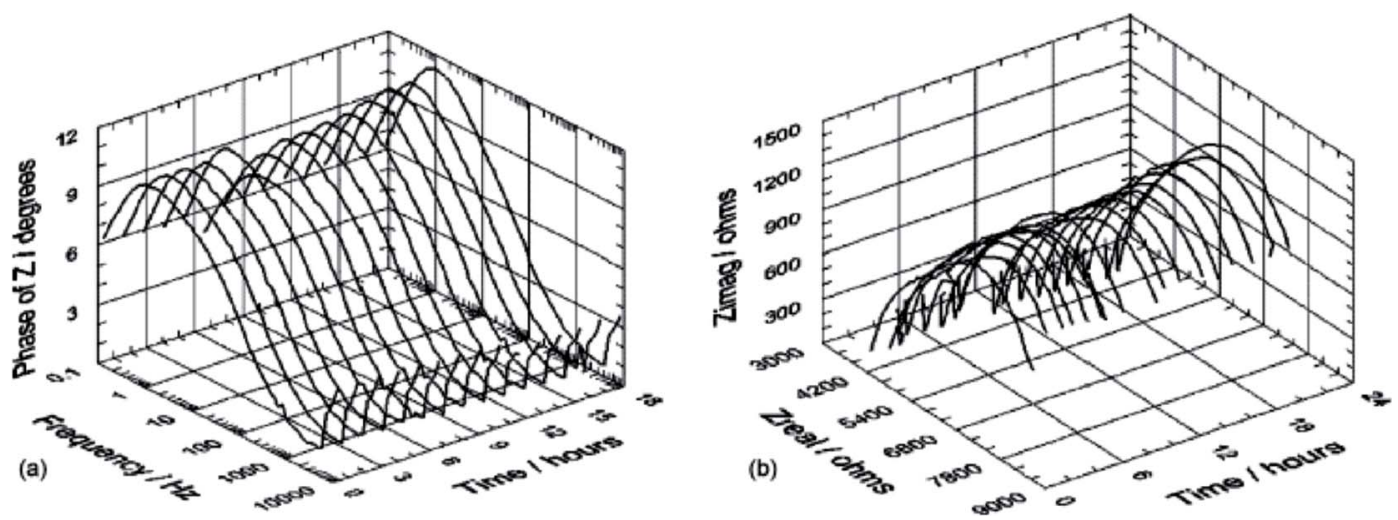

Fig. 11 In situ (a) EIS Bode phase angle and (b) complex-plane impedance plots data for a polished mild steel electrode immersed in 3\% (w/v) $\mathrm{NaCl}$ saturated with high purity carbon dioxide at atmospheric pressure (adjusted to $\mathrm{pH} 4.75$ ). ${ }^{90}$ Reprinted with permission from ref. 90 . Copyright 2007, Elsevier B. V.

the nucleation and growth of siderite. The development of cubic crystals of siderite was dependent on the partial pressure of the $\mathrm{CO}_{2}$ and this proved the importance of partial pressure of $\mathrm{CO}_{2}$ in the corrosion product morphology evolution. The corrosion rate was found lower at high temperature $\left(80-100^{\circ} \mathrm{C}\right)$ whereas it was significantly higher at $60^{\circ} \mathrm{C}$ because the networking of the cubic crystal morphology of siderite was not fully developed. Ko et al. ${ }^{94}$ also applied in situ SR-XRD in $\mathrm{CO}_{2}$ corrosion of pipeline steel (carbon steel) and observed a significant effect of roughness and microstructure of the steel on the corrosion process. It was shown that during $\mathrm{CO}_{2}$ corrosion scale starts nucleating on the surface, which consists of siderite and chukanovite phases. Changes in $\mathrm{pH}$ and local conditions define the growth of chukanovite. It was also noticed that the siderite phase had grown faster in steel containing higher carbon $(0.25 \mathrm{wt} \% \mathrm{C})$ than the steel containing low carbon $(0.06 \mathrm{wt} \% \mathrm{C})$. The study elucidated the importance of siderite, which acted as the nuclei for chukanovite and growth rates of siderite and chukanovite are interlinked with each other. Local precipitation of siderite was strongly dependent on the microstructural variation (variation of different $\mathrm{Cr}$ containing phases).

The few available studies presented in this section have confirmed the applicability of the SR-XRD to corrosion investigations at carbon steels. Future studies could follow the investigations conducted by De Macro et al. ${ }^{95}$ who combined SR-XRD studies with AFM for ion selective electrode surface characterization. Such an approach could be adopted for surface characterization of carbon steels along with their phase analysis. Furthermore, the use of SR-XRD data in correlation with Raman spectroscopy and X-ray absorption techniques could be interesting to study the simultaneous compositional variation in the phase formations.

4.1.3. X-ray photoelectron spectroscopy (XPS). XPS is considered a quantitative spectroscopic technique which provides information about the elemental composition, in parts per thousand level, based on the elemental electronic and chemical state of the studied surface.

This technique has been widely adopted by corrosion scientists for surface composition characterization, especially for corrosion product analysis. This has for example been demonstrated on carbon steel exposed to sea-water. ${ }^{96}$ A 3dimensional structure of a film was studied. Since an iron peak was absent at the spectrum, it was suggested that substrate was fully covered with corrosion products. The presence of iron in metallic state, and iron in oxidized state was related to the oxide formation and was further confirmed by other techniques such as Raman spectroscopy and X-ray diffraction spectroscopy. Similarly, qualitative analysis of surface films and analysis of corrosion products, further related to the protectiveness of the film against corrosion has been determined by employing XPS. These studies include the formation of iron carbonate on carbon steel surfaces ${ }^{97}$ and a study on the presence of $\mathrm{OH}^{-}$in the film which could be useful for investigating compactness of surface film and evaluation of its protective properties. ${ }^{98}$

Furthermore, the compositional evaluation using XPS can be used in mechanistic studies. Galicia et al. ${ }^{99}$ studied 1018 carbon steel surface composition exposed to alkaline medium ( $\mathrm{NaCN})$ as a function of immersion time and confirmed film formation on the steel surface through XPS quantitative analysis of the atoms of oxygen, iron and carbon. XPS was also used to study film purity as $\mathrm{C}$ was present in the film as impurity $(\mathrm{C}-\mathrm{H})$ and its counts decreased with increasing immersion time, due to the reduced gas trapping in the film with increased time of exposure.

The formation and quantitative analysis of iron carbonate at carbon steel in respect to the structure of the carbon steel has been evaluated by XPS in the study by Ochoa et al., ${ }^{100}$ who examined $\mathrm{CO}_{2}$ corrosion resistance of carbon steel with $0.5 \mathrm{M}$ $\mathrm{NaCl}$, loaded with $\mathrm{CO}_{2}$ with four different microstructures: banded, normalized, quenched and tempered, and annealed. XPS study showed that the annealed sample contained $\mathrm{FeCO}_{3}$ in much larger quantity than the other samples, which corresponded to the highest corrosion resistance observed for the annealed sample, whereas lowest resistance was found for the banded structure. Precipitation of siderite was strongly dependent on the local $\mathrm{pH}$ and the corrosion rate was affected by the distribution and morphology of cementite, which controls the galvanic coupling between ferrite and pearlite. The lowest corrosion rate was observed for annealed steel due to abundant siderite formation whereas high corrosion rates were found for 


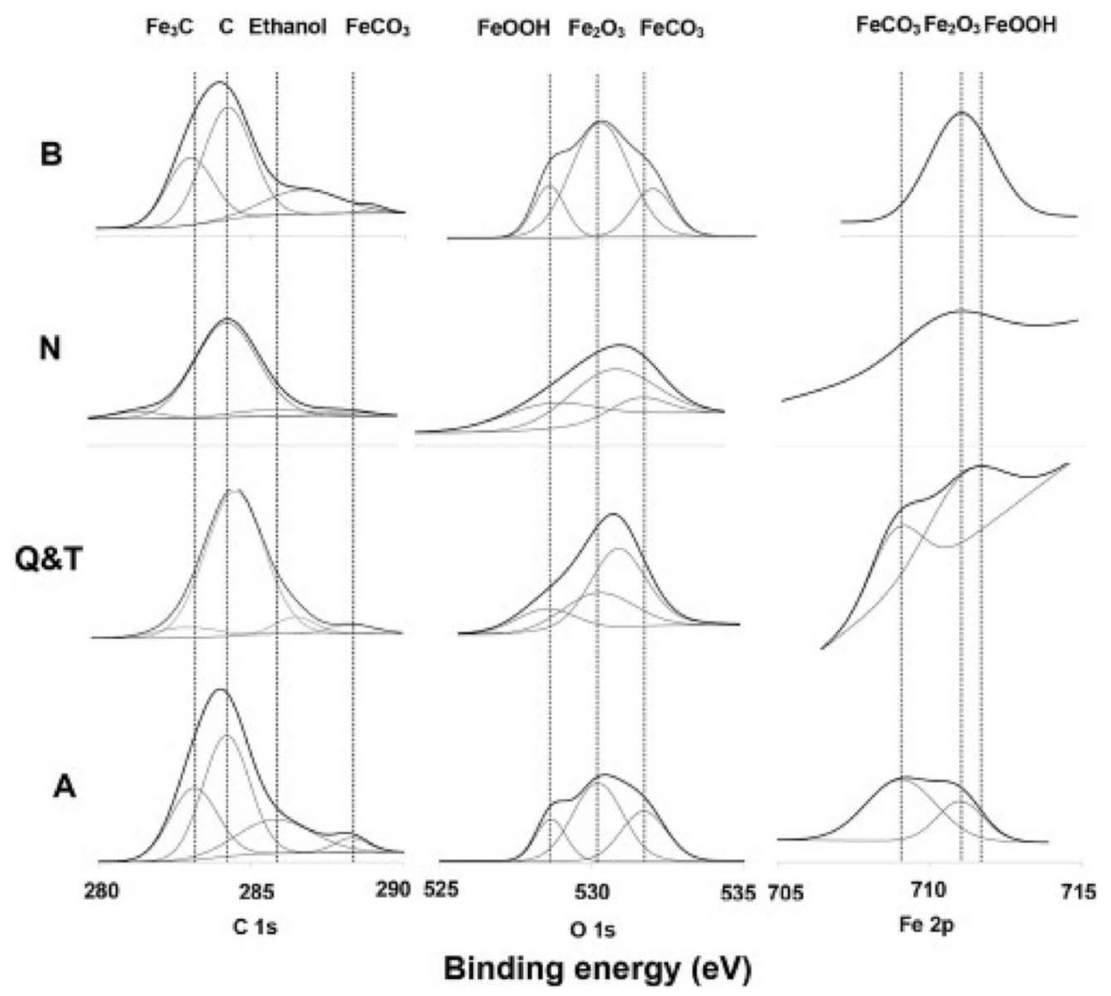

Fig. 12 Presence of $C, O$ and Fe has been confirmed due to the appearance of $C 1 s, O$ s and Fe $2 p$ regions in XPS high resolution spectra recorded from corroded steel surfaces with different microstructures. ${ }^{100}$ Reprinted with permission from ref. 100. Copyright 2015 , Elsevier B. V.

banded steel. This is because in banded steel, siderite forms in the outer part of the cementite structure which is distinct from the metal. The surface composition and microstructures are presented in Fig. 12 and 13.

The importance of XPS for corrosion inhibition mechanism identification of carbon steel is clearly evident. Additional studies to those presented in detail in this work, involving XPS characterizations of carbon and stainless steel, demonstrate the importance of the XPS as a surface characterization tool in the present era. ${ }^{101-105}$

XPS applied to corrosion inhibition on carbon steels is typically used to study the adsorption mechanisms of the inhibitor molecules, and the XPS data are often combined with electrochemical measurements that provide information on the protectiveness of the inhibitor film against corrosion, and with thermodynamic calculations. Tourabi et al. ${ }^{106}$ utilized XPS for the study of 3,5-bis(2-thienylmethyl)-4-amino-1,2,4-triazole corrosion inhibitor for carbon steel in $\mathrm{HCl}$ medium and included electrochemical studies such as electrochemical impedance spectroscopy and polarization techniques. XPS concluded the chemisorption of inhibitor molecules with the presence of nitrogen species on carbon steel surface and these results were consistent with thermodynamic calculation. This study highlighted XPS as an important tool for investigation of adsorption of the inhibitor molecules and composition evaluation of the formed surface film. XPS was also used to investigate the inhibitor performance, from the point of view of the surface structure, of ternary inhibitor containing $\mathrm{N}, \mathrm{N}$ - bis(phosphono methyl)glycine (BPMG), Zn ion and citrate ion. XPS confirmed the presence of chemical species and hydroxide, which contributes to deriving a possible mechanism of corrosion inhibition. ${ }^{107}$ Carbon steel was exposed to $\mathrm{HCl}$ solvent with 3,6-bis(3-pyridyl)pyridazine inhibitor by Bentiss et al. ${ }^{108}$ and XPS results along with the electrochemical studies allowed to determine the corrosion inhibition mechanism. Zarrok et al. ${ }^{109}$ used XPS study for corrosion control of carbon steel in phosphoric atmosphere, which is present in the fertilizer industry. They combined XPS with EIS and electrostatic adsorption of purplad (4-amino-3 hydrazino-5-mercapto-1,2,4-triazole) (AHMT) on carbon steel was confirmed through XPS which was further supported using thermodynamic calculations. Lopez et al. ${ }^{110}$ utilized XPS to study corrosion layers on carbon steel corroded with deoxygenated $\mathrm{NaCl}(5 \%)$ at pH 6 and under $\mathrm{CO}_{2}$-saturated conditions. Benzimidazol was used as an inhibitor and the authors aimed to detect the inhibitor molecules on the corroded sample, but could not detect $\mathrm{FeCO}_{3}$ due to the chemisorption of water or oxygen.

One of the advantages of XPS is that it can be used for film thickness measurements when metal is detected in the spectra. But due to sputtering with heavy ion such as $\mathrm{Ar}^{+}$, the surface may undergo chemical and compositional changes, which may result in roughening etc. XPS can also provide information about the oxidation state of elements but one needs to be careful as sputtering causes a decrease in the oxidation state of elements in oxides (Fe, $\mathrm{Cu}$ and $\mathrm{Nb}$, etc.). ${ }^{111}$ Angle resolved XPS analysis is difficult for corrosion products because these 

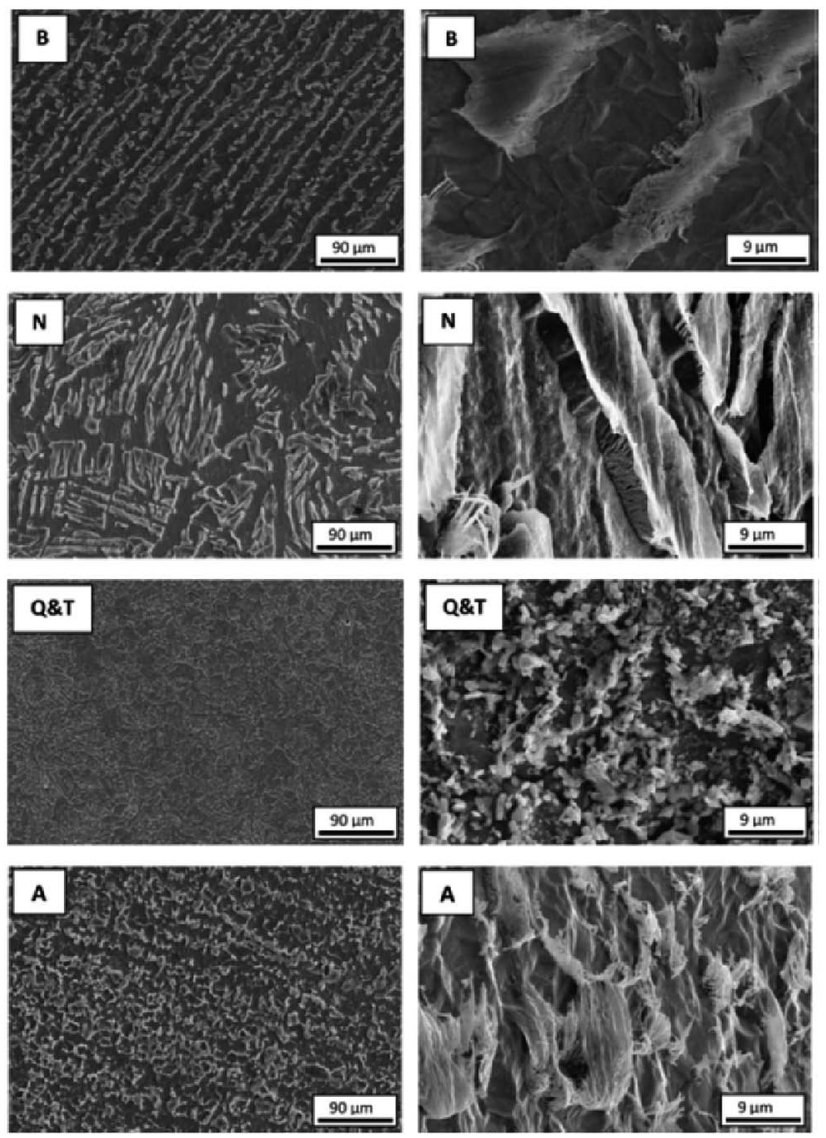

Fig. 13 Appearance of morphological differences after corrosion (with hold time of $6 \mathrm{~h}$ in $0.5 \mathrm{M} \mathrm{NaCl}$ solution saturated with $\mathrm{CO}_{2}$ ) of banded $(B)$, normalized $(N)$, quenched and tempered ( $Q \& T)$ and annealed $(A)$ steels shown by SEM morphological images with two different magnifications. ${ }^{100}$ Reprinted with permission from ref. 100. Copyright 2015, Elsevier B. V.

products are often associated with roughness, large variation in the cluster size and shape and inhomogeneity, which makes data interpretation complicated as the angle-resolved XPS (ARXPS) peak intensity depends on these factors. However, conventional XPS can also provide information through inelastic loss structure analysis. ${ }^{112}$

The significance of in situ investigations of corrosion processes has been highlighted in the previous sections of this work, as it provides valuable information on the kinetics of adsorption and composition of the initial corrosion-product films that can differ from those detected at later stages of the corrosion processes. Despite the wide use of XPS in corrosion and corrosion-inhibition studies at carbon steel surfaces, in situ XPS is yet to be applied in this field. In situ XPS has been limitedly used in other research areas. ${ }^{113}$

4.1.4. Raman spectroscopy. Raman spectroscopy has been established as an important surface characterization tool for corrosion studies, and can be used for either single layer or multi-layer surface characteristics evaluation. Raman spectroscopy provides information about the surface bonds (vibrational information) and thus reveals structural information about the interface between a corrosion inhibitor and the metal. The changes in vibrational information can be used to assess phase transformation. There are only few techniques available which are sensitive enough to characterize surface-inhibitor interaction directly. ${ }^{114}$

The importance of Raman spectroscopy for studying the products of carbon steel corrosion was highlighted by Fabis et $a{ }^{115}$ His team studied weathering corrosion products on steels and compared the Raman results with infrared spectroscopy. They described Raman spectroscopy as a complementary technique to XRD and electron based diffraction techniques without any compulsion of crystalline product formation as Raman spectroscopy could also be used for amorphous products analysis. Nie et al. ${ }^{\mathbf{1 1 6}}$ used Raman spectroscopy for the characterization of corrosion products on carbon steel and established the surprising fact that carbon steel, which was corroded through soil containing $10 \mathrm{wt} \%$ water has shown high corrosion rate with localized nature and promoted the formation of $\mathrm{FeOOH}, \mathrm{Fe}_{2} \mathrm{O}_{3}$ and $\mathrm{Fe}_{3} \mathrm{O}_{4}$ thin layer, whereas solids containing $20 \mathrm{wt} \%$ and $34 \mathrm{wt} \%$ water led to nonlocalized corrosion with formation of alpha-FeOOH. Corrosion of carbon steel under aerobic conditions was studied by Sherar et al. ${ }^{117}$ and the composition of the corrosion product layer was determined by Raman spectroscopy along with energy dispersive spectroscopy (EDS). Raman spectroscopy confirmed the presence of goethite (alpha-FeOOH) and magnetite. Choi et al. ${ }^{118}$ investigated the carbon steel corrosion in $\mathrm{CO}_{2}$ saturated water and water-saturated $\mathrm{CO}_{2}$ to mimic the conditions of $\mathrm{CO}_{2}$ gas pipeline. The Raman spectroscopy data supported the hypothesis that $\mathrm{H}_{2} \mathrm{SO}_{4}$ was produced due to the acid regeneration that in turn caused a high corrosion rate. Molchan et al. ${ }^{\mathbf{1 1 9}}$ studied three different corrosion inhibitor molecules, such as 1alkyl-3-methylimidazolium tricynanomethanide (TCM) ionic liquid (where alkyl = ethyl, butyl and hexyl) for mild steel corrosion and utilized micro Raman spectroscopy to determine the formation of corrosion products that were magnetite and magnemite ferrites, developed due to the dissolution of MnS inclusion inherently present in mild steel.

Raman spectroscopy was utilized to understand the corrosion product formation in atmospheric corrosion and natural weathering of carbon steel. In a study by Kui et al., ${ }^{120}$ carbon steel was exposed to open atmosphere and lepidocrocite, goethite and maghemite formation was confirmed using Raman spectroscopy. Similarly, natural weathering of carbon steel was investigated using Raman spectroscopy by Antunes et $a .^{\mathbf{1 2 1}}$ who confirmed the presence of lepidocrocite, goethite and magnetite. Li et al. ${ }^{122}$ further exposed carbon steel to a marine atmosphere and utilized micro-Raman spectroscopy which provided layer by layer information of the formed corrosion products. The presence of lepidocrocite, goethite and akaganeite were observed due to the presence of $\mathrm{Cl}^{-}$. It was noticed that after the saturation of akganeite, $\mathrm{Cl}^{-}$contributed to the increasing corrosion rate which could be considered as an important unit step for the process of corrosion as delayed saturation with akaganeite delays corrosion.

Mendili et al. ${ }^{123}$ brought attention to the use of Raman spectroscopy to qualitatively define crystallinity of the phases. Using micro Raman spectroscopy for the determination of the 
mechanism of carbon steel corrosion in aerobic and anaerobic conditions, the authors identified magnetite after one week of the exposure of steel to corrosive media. The poor resolution of the obtained spectrum was related to the poor crystallinity of maghemite phase. Magnetite and maghemite were observed as major corrosion products under aerobic condition whereas mackinawite and pyrrhotite were observed under anaerobic condition.

Raman spectroscopy can also be used to study phase transformation of corrosion products. Hematite to magnetite phase transformation was observed in a microbial corrosion study conducted on carbon steel used in a fire-water distribution system. Raman spectroscopy showed the presence of lepidocrocite, goethite, magnetite and hematite, and allowed for establishing the importance of dissolved oxygen in water as a key parameter in this corrosion study. ${ }^{124}$ Qualitative information about the texture of the formed phases on the carbon steel surface can be obtained using Raman spectroscopy as shown by Genchev et al. ${ }^{125}$ The authors have shown that mackinawite (corrosion product) was highly textured along (001) and therefore $\mathrm{E}_{\mathrm{g}}$ mode was absent in the Raman spectrum, which was in agreement with the texture of this corrosion product (Fig. 14 and 15). FeS appeared with sharp intense peak.

The advances in Raman spectroscopy now allow for in situ Raman analysis of carbon steel surfaces. Zhang et al. ${ }^{126}$ exposed carbon steel to a $\mathrm{SO}_{4}{ }^{2-}$ and $\mathrm{Cl}^{-}$containing solution and observed a double layer of corrosion products, containing lepidocrocite and magnetite. It was shown that the presence of $\mathrm{SO}_{4}{ }^{2-}$ and $\mathrm{Cl}^{-}$ in the test solutions promoted formation of lepidocrocite.

Conventional Raman analysis applied to thin films on metallic substrates can give low signal which can be overcome by using surface enhanced Raman spectroscopy (SERS). SERS can generally be considered for the analysis of metal-inhibitor interactions on metallic substrates as it provides information about the chemical identity, bonding nature and structure of species on the metal-liquid (electrolyte) interface. ${ }^{127}$ Following the use of SERS on metallic substrates, Oblonsky et al. ${ }^{128}$ applied SERS on stainless steel to study pyridine adsorption. It has been noticed that intensity is a function of the thickness of the film, but the drawback of this technique could be the need of thin substrates (such as thin stainless steel substrate). Utilization of thin substrates could not replicate the real world scenario as thin substrates contain different texture, microstructure and also possess a different defect density compared to the bulk metal. Another aspect is the type of organic molecule on the substrate as $\pi$-bonded organic molecules are not sensitive for SERS. Application of SERS is limited as pyridinium compounds that are only bonded through nitrogen atom with the substrate can be identified through SERS, which limits our understanding as far as adsorption mechanism of inhibitor molecules are concerned. ${ }^{129}$

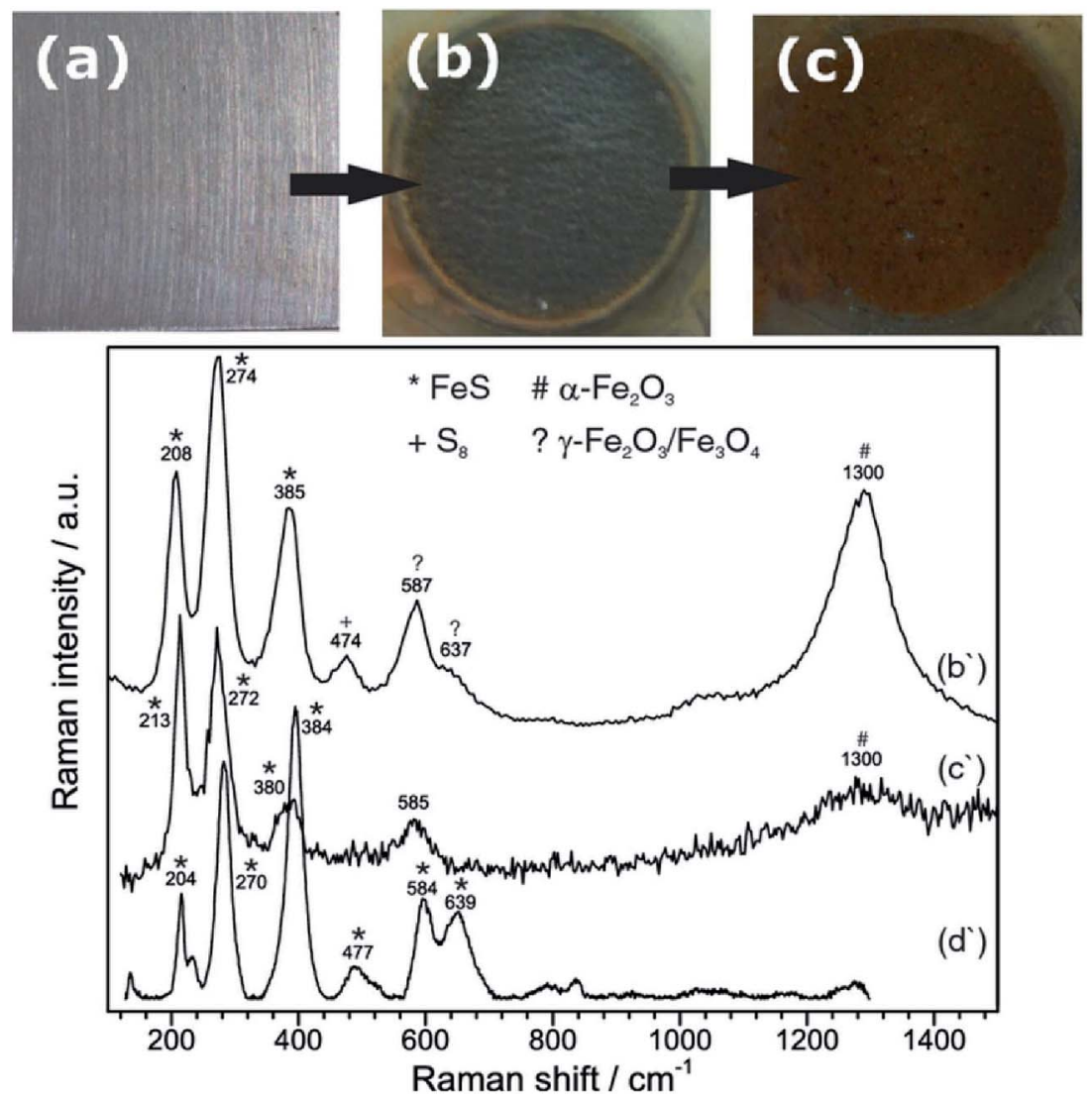

Fig. 14 Shows images of (a) bare metal before exposure to saline $\mathrm{H}_{2} \mathrm{~S}$ saturated acetic solution, (b) area of exposure after anodic polarization for $44 \mathrm{~h}$ at $200 \mathrm{mV}$ above $E_{\text {corr, }}$ with Raman spectrum (b'); and (c) corrosion products after aging in air for 90 d, with Raman spectrum (c'), along with the reference Raman spectrum for mackinawite (d'). ${ }^{125}$ Reproduced by permission of The Electrochemical Society. 

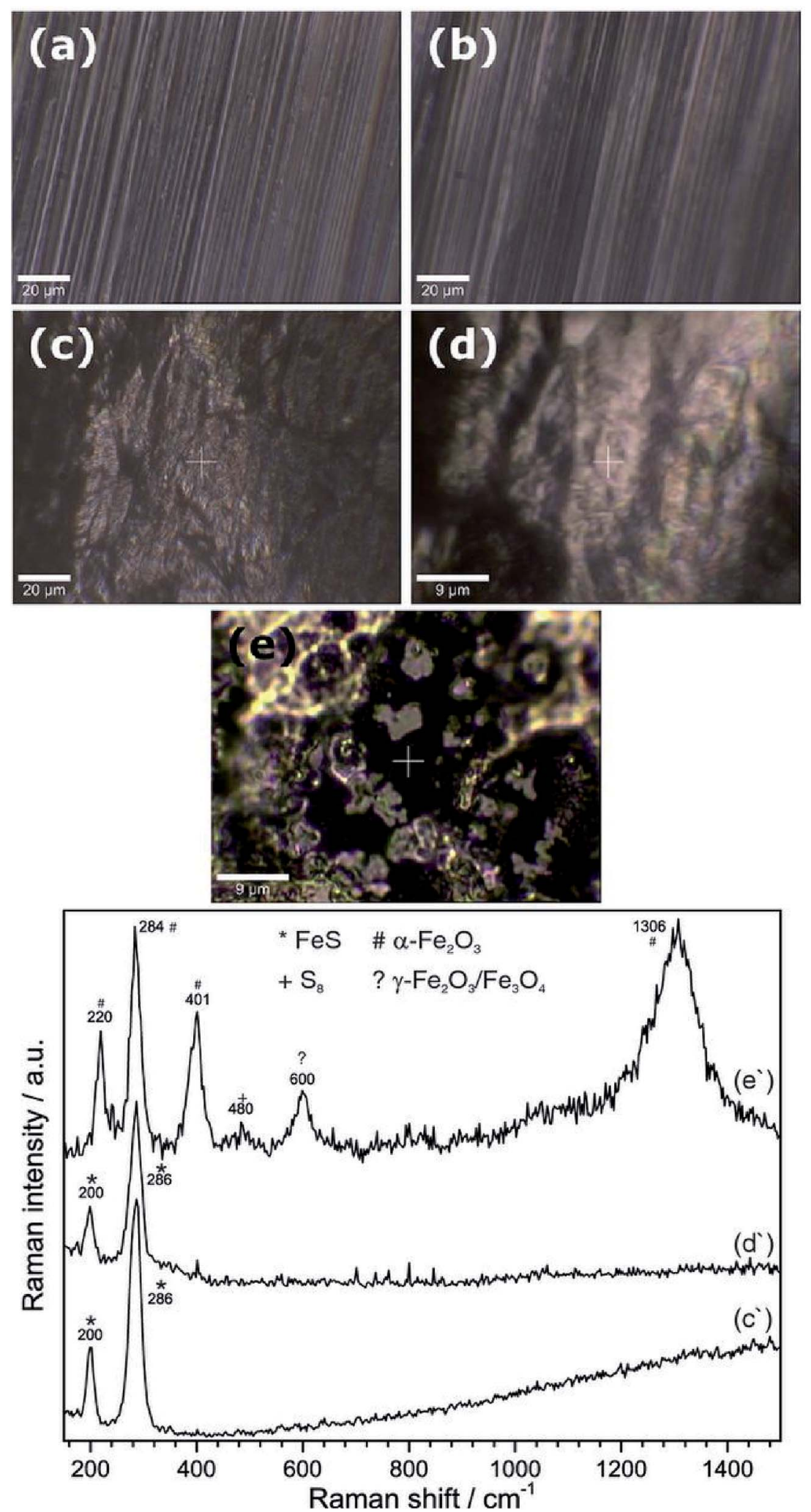

Fig. 15 Confocal microscopic images of substrate surface before (a) and after (b) introducing the $\mathrm{H}_{2} \mathrm{~S}$ saturated electrolyte, (c) substrate surface after starting the electrochemical treatment with corresponding Raman spectrum (c'); and (d) surface after polarization termination, with respective Raman spectrum (d'). (e) Shows corrosion products on substrate after removing from in situ cell and drying with nitrogen stream and (e') gives corresponding Raman spectrum. ${ }^{125}$ Reproduced by permission of The Electrochemical Society. 
An earlier proposed mechanism of adsorption suggested that aromatic ring's nitrogen and metal bonding leads to a nonparallel orientation of aromatic ring at the surface, whereas in another study the aromatic ring was found to be parallel to the substrate and the proposed mechanism was based on the $\pi$ electron interaction (metal substrate and aromatic ring). ${ }^{\mathbf{1 3 0 - 1 3 2}}$

$\mathrm{Gu}$ et $a l .{ }^{133}$ investigated the adsorption of pyridine on iron substrate in acidified $\mathrm{KCl}$ solution and addressed the effect of surface roughening on the SERS analysis. Surface roughness increases surface area and causes a weak SERS effect. The study suggested that pyridine adsorbed through nitrogen bonds with iron. This study highlighted the importance of surface pretreatment for SERS.

The use of Raman spectroscopy for surface analysis in terms of phase formation and phase transformation has been demonstrated in this section. Raman spectroscopy allows qualitative evaluation of surface films and their crystallinity. The surface enhanced Raman spectroscopy could be a potential technique for solid-liquid interaction behaviour evaluation. Developments in the applications of in situ Raman spectroscopy could bring novel insights into the mechanisms of interaction between the corrosion-inhibitor molecules and carbon steel.

4.1.5. Fourier transform infrared spectroscopy (FTIR). Based on the absorption and transmission of infrared radiation, unique finger prints of molecules can be generated. Quality and amount of specific components in samples (mixtures) can be identified through FTIR. Infrared spectroscopy (IR) known as dispersive IR technique was utilized in earlier studies. Nowadays, FTIR is extensively used as it offers several advantages, such as precise measurement, fast data collection, high sensitivity, non-destructive, no external calibration required, etc. Conventional FTIR, typically studied in mid-IR wavelength region has been successfully applied in investigations of surface films on carbon steel surfaces. The presence and/or absence of certain bands of the corrosion inhibitor molecule is related to the orientation of the molecule on the steel surface and/or within the inhibitor film. This allows to gain insight into the mechanisms of adsorption of the corrosion inhibitors on steel surfaces. For example, Alaneme et $a .^{\mathbf{1 3 4}}$ studied mild steel corrosion with Hunteria umbellata seed husk extract as an inhibitor and utilized FTIR to determine chemical nature of the inhibited surface, concluding that $\mathrm{O}-\mathrm{H}, \mathrm{C}-\mathrm{N}$ and unsaturated $\mathrm{C}=\mathrm{C}$ were related to the observed corrosion inhibition effect. They confirmed the interaction of extract and mild steel by observing a change in the spectra after immersing mild steel in extract-containing $\mathrm{HCl}$ solution. Awe et $a .^{\mathbf{1 3 5}}$ studied the inhibitive property of Boscia senegalensis on mild steel in $\mathrm{HCl}$ medium. The FTIR study revealed that $\mathrm{C}-\mathrm{N}$ and $\mathrm{C}=\mathrm{O}$ bonds were responsible for the inhibitor interaction with the surface of mild steel as those bonds were missing in the spectra. Similarly, a significant shift was observed for $\mathrm{OH}^{-}$and $\mathrm{N}-\mathrm{H}$ which suggested interaction between mild steel and inhibitor. A study performed by Sangeetha et al. ${ }^{136}$ used hydroxyl propyl alginate as inhibitor in acidic medium for mild steel corrosion and observed clear shifts in FTIR spectra in case of $\mathrm{OH}, \mathrm{CO}$ and carboxylate, which suggested adsorption of this inhibitor through these functional groups. Oguzie et al. ${ }^{137}$ used the extracts of piper guineense as an inhibitor for mild steel in acidic medium and investigated the role of $\mathrm{O}-\mathrm{H}, \mathrm{C}-\mathrm{N}$ and $\mathrm{C}=\mathrm{O}$ in metal-inhibitor interaction with the help of FTIR. Similarly, Michelia alba leaves extract (MALE) was investigated as an inhibitor for carbon steel, iron and stainless steel. Differences were observed, in terms of disappearance of vibration, including shifting bands in the FTIR spectrum, which could be due to the $\mathrm{Fe}^{2+}$-MALE complex formation. Major functional groups were $\mathrm{O}-\mathrm{H}, \mathrm{C}=\mathrm{O}, \mathrm{C}-\mathrm{N}, \mathrm{C}-\mathrm{O}$ and $\mathrm{C}=\mathrm{C}$ including epoxy group. ${ }^{138}$

A common approach in applications of FTIR is to define corrosion products on carbon steel surfaces. Perez et al. ${ }^{\mathbf{1 3 9}}$ investigated the effect of bi-carbonate solution in carbon steel corrosion and applied FTIR technique to define that the type of corrosion product formed depends on the bi-carbonate concentration, and includes $\mathrm{FeCO}_{3}$ (with $0.5-1.0 \mathrm{~mol} \mathrm{~L}^{-1}$ ) $\mathrm{Fe}_{6}(\mathrm{OH})_{12} \mathrm{CO}_{3}$ (with 0.02-0.05 mol L ${ }^{-1}$ ) and $\mathrm{Fe}_{2}(\mathrm{OH})_{2} \mathrm{CO}_{3}$ (with 0.01-0.2 $\left.\mathrm{mol} \mathrm{L}^{-1}\right)$. The FTIR correlated well with XRD analyses and also contributed to the conclusion that bicarbonate affects anodic dissolution of the carbon steel substrate. The effect of different corrosive conditions has been studied by Kumar et al. ${ }^{\mathbf{1 4 0}}$ by exposing mild steel to three different corrosive media such as $\mathrm{SO}_{2}, 3 \% \mathrm{NaCl}$ and distilled water. Gamma-FeOOH has been identified as corrosion product which was further confirmed through conversion electron Mössbauer spectroscopy (CEMS). Corrosion products of carbon steel (A-36) and weathering steels (A-588 and COR 420) were analysed for atmospheric corrosion through FTIR by Jaen et al. ${ }^{\mathbf{1 4 1}}$ The authors confirmed the presence of gamma and alpha-FeOOH, which has been further confirmed through other analytical techniques, such as XRD and Mössbauer spectroscopy. Recently, Chong et al. ${ }^{142}$ used the synergistic effect of imidazolinium and 4-hydroxycinnamate (organic salt) for corrosion inhibition of mild steel in $0.1 \mathrm{M} \mathrm{NaCl}$ and FTIR analysis confirmed the interaction between mild steel surface and 4hydroxycinnamate. This interaction resulted in formation of a corrosion-protective layer.

The use of FTIR in polymer science has been demonstrated for example by Baskar et al. ${ }^{143}$ who used photo-crosslinked polymers poly((E)-(1-(5-(4-(3-(4-chlorophenyl)-3-oxoprop-1-enyl) phenoxy)pentyl)-1H-1,2,3-triazol-4-yl)methyl acrylate) (Cl-5) and poly((E)-(1-(5-(4-(3-(4-chlorophenyl)-3-oxoprop-1-enyl)phenoxy) decyl)-1H-1,2,3-triazol-4-yl)methyl acrylate) (Cl-10) as corrosion inhibitors for mild steel. It was observed that C1-5 had a higher inhibition efficiency than C1-10.

The use of FTIR to obtain qualitative insight into crystallinity of the inhibitor film formed on the substrate and in depth understanding of mechanism of the inhibition reaction was presented by Atta et al., ${ }^{\mathbf{1 4 4}}$ who used crosslinked poly(sodium acrylate)-coated magnetite nanoparticles as an inhibitor for carbon steel and used FTIR to characterize the chemical structure of the composites. A band shift was observed for $\mathrm{Fe}-\mathrm{O}$ which could be due to the breaking of a large number of bonds at the surface. The oleic band was shifted towards the lower frequency due to the hydrocarbon chain in monolayer, which was surrounded by Fe nanoparticles and maintained the closely packed crystallinity. 
The use of FTIR on carbon steel surfaces can be limited in case of thin surface films adsorbed on carbon steels that undergo increased roughening upon exposure to corrosive media. Synchrotron-sourced FTIR provides a better signal to noise ratio compared to conventional FTIR instruments. Lepkova et al. ${ }^{145}$ studied an organic surfactant, namely 1-dodecylpyridinium chloride (DPC), on carbon steel in $\mathrm{CO}_{2}$-saturated brine. Using the synchrotron-sourced FTIR, the authors detected the adsorbed inhibitor film on the carbon steel, which was not possible with conventional FTIR. Furthermore, the orientation of the DPC molecule was defined as parallel to the steel surface, and absence of the pyridinium ring suggested the $\pi$ bonding of DPC with steel. Pandarinathan et al. ${ }^{\mathbf{1 4 6}}$ used synchrotron-sourced infrared micro-spectroscopy to identify corrosion products formed underneath silica sand layers deposited on carbon steel surfaces in $\mathrm{CO}_{2}$-saturated brine. It was shown that chukanovite $\left(\mathrm{Fe}_{2}(\mathrm{OH})_{2} \mathrm{CO}_{3}\right)$ is the prevalent corrosion product formed on the sand-deposited carbon steel whereas iron carbonate $\left(\mathrm{FeCO}_{3}\right)$ is the main product on depositfree carbon steel. The differences in corrosion products identified by FTIR combined with electrochemical measurements showed that the presence of chukanovite is related to the susceptibility of sand-deposited steel to localized corrosion.

FTIR studies in the far-infrared region have not been widely applied in corrosion science despite the theoretical possibility of identification of the absorption bands characteristic for corrosion products or corrosion inhibitors. Lepkova et al. ${ }^{\mathbf{1 4 7}}$ utilized synchrotron-sourced far-infrared spectroscopy to study carbon steel exposed to $\mathrm{CO}_{2}$-saturated brine in the presence and absence of a corrosion inhibitor, 2-mercaptopyrimidine (MPY). The study used variable grazing angle of incidence to optimize the experimental settings suitable for analysis of thin films on corrosion-roughened carbon steels. The selection of a grazing angle of incidence that is suitable for analysis of inhibitor-free steels with high surface roughness, and of inhibited steels with low surface roughness allowed the authors to detect corrosion products and inhibitor films. This study demonstrated the applicability of the synchrotron-sourced far-infrared spectroscopy in investigation corrosion at carbon steels.

We have discussed conventional FTIR along with the synchrotron-sourced infrared spectroscopy. There are areas which need to be addressed, such as the in situ use of this techniques along with the other surface analytical methods, for example synchrotron XRD, AFM, etc. which could provide good mechanistic insight into corrosion-product formation, along with the surface features (such as morphology and phases).

\subsection{Emerging future techniques for surface characterization}

4.2.1. Kelvin probe force microscopy (KPFM). KPFM has been established as an important tool for the characterization of the local potential on metallic surfaces, but lack of repeatability of results, accuracy and limited spatial resolution limits its application. This technique depends on contact potential measurement and work function in the nanometre regime. Amplitude modulation KPFM and frequency modulation KPFM are two types of detection techniques, which are based on the detection of electric force and electric force gradient. ${ }^{\mathbf{1 4 8}}$

The majority of studies have been performed at surfaces of alloys, but are presented here as they have relevance to potential studies at carbon steel surfaces. Apachitei et al. ${ }^{\mathbf{1 4 9}}$ has utilized tapping mode for collecting topographical image and lift mode (with $100 \mathrm{~nm}$ height) for Volta potential measurements and found large differences for Al-Mn-Fe intermetallic. Since the observed difference was positive, it suggested formation of noble particles with respect to matrix. The studied alloy system contained $\mathrm{Ca}, \mathrm{Sn}$ and $\mathrm{Sr}$, which suppressed the formation of $\mathrm{Mg}_{17} \mathrm{Al}_{12}$ and $\mathrm{Al}-\mathrm{Ca}(\mathrm{Sn}, \mathrm{Sr})$ particles elucidated lower Volta potential difference with matrix compared to the Volta potential difference between $\mathrm{Mg}_{17} \mathrm{Al}_{12}$-matrix. The KPFM topographic image exhibited larger height differences for Al-Mn-Fe particles $(322 \mathrm{~nm})$ than $\mathrm{Al}-\mathrm{Ca}(\mathrm{Sn}, \mathrm{Sr})$ particles $(98 \mathrm{~nm})$. This study opens a new door for investigating the intermetallic effect of carbon steel on corrosion resistance. As described earlier in this review, alloying elements such as Cr etc. could affect corrosion rate. Schmutz et al. ${ }^{150}$ utilized KPFM at AA 2024-T3 alloy, and predicted that localized corrosion can be caused by the intermetallic particles. Similar studies could be designed for carbon steels to see the behaviour of various alloying element's effect on localized corrosion. Interested readers could follow the respective paper for an elaborative description. ${ }^{150}$ The authors further extended their study to the AA 2024 T3 alloy-solvent interaction and observed that along with the surface compositions, other factors are also involved for generating Volta potential as the intermetallic phase was identified as a major source of Volta potential. SEM-EDS analysis also suggested the presence of intermetallic phase and investigation concluded association of higher potential of intermetallic phases. ${ }^{151}$ The study described the behaviour at the solid-liquid interface in terms of generation of Volta potential, which could lead to corrosion. Similar experiments could be useful for carbon steels too and could describe mechanisms of localized corrosion and its influencing factors. Intermetallics observed during experiments were $\mathrm{Al}-\mathrm{Cu}-\mathrm{Mg}$ containing particles (less spherical) and $\mathrm{Al}-\mathrm{Cu}-\mathrm{Mn}-\mathrm{Fe}$ containing particles (irregular shape). The Al$\mathrm{Cu}-\mathrm{Mg}$ containing particles offer low Volta potential, which describes high reactivity of the particles. The difference in Volta potential among the various phases leads to the corrosion and KPFM can be effectively utilized for localized corrosion examination along with the identification of intermetallics in alloys.

Kim et al. ${ }^{152}$ applied KPFM on carbon steel to study the effect of surface roughness on the electrochemical behaviour of the steel. It was found that corrosion resistance of carbon steel decreases with increasing surface roughness, which is caused by the micro-galvanic effect generated between surface sites with different Volta potentials, i.e. the high (valley) and low (peak) Volta potential sites. At a rough surface, a surface site with lower Volta potential (peak) acts as an anode and is more susceptible to corrosion (Fig. 16 and 17).

There is a scarcity of literature as far as the application of KPFM for the carbon steel corrosion is concerned and there is ample opportunity to collaborate this study with various electrochemical techniques in order to get an advanced view of 


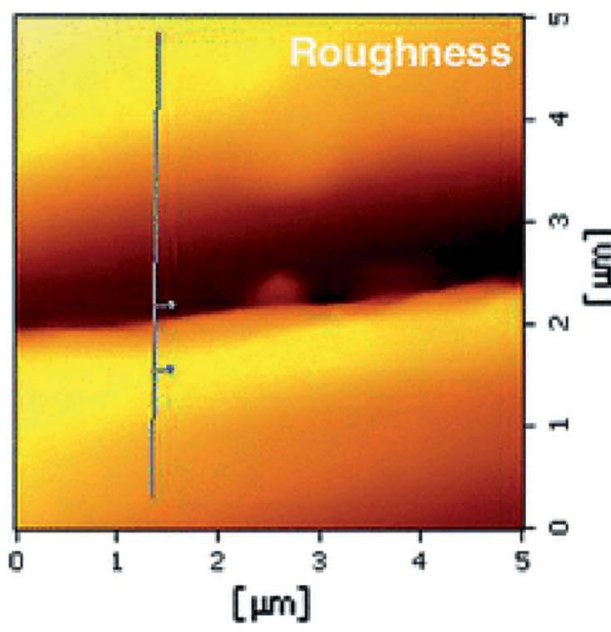

(a)

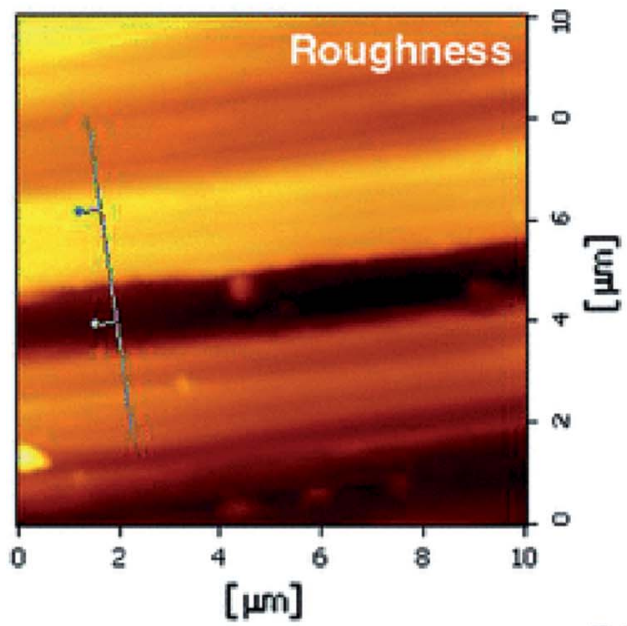

(b)

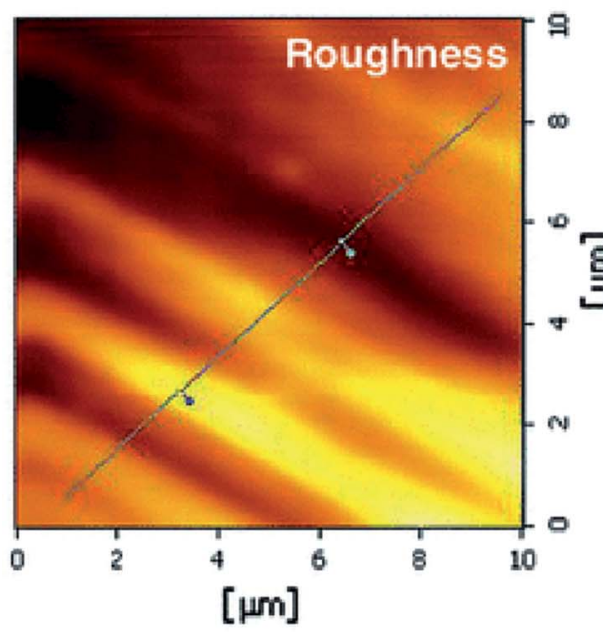

(c)
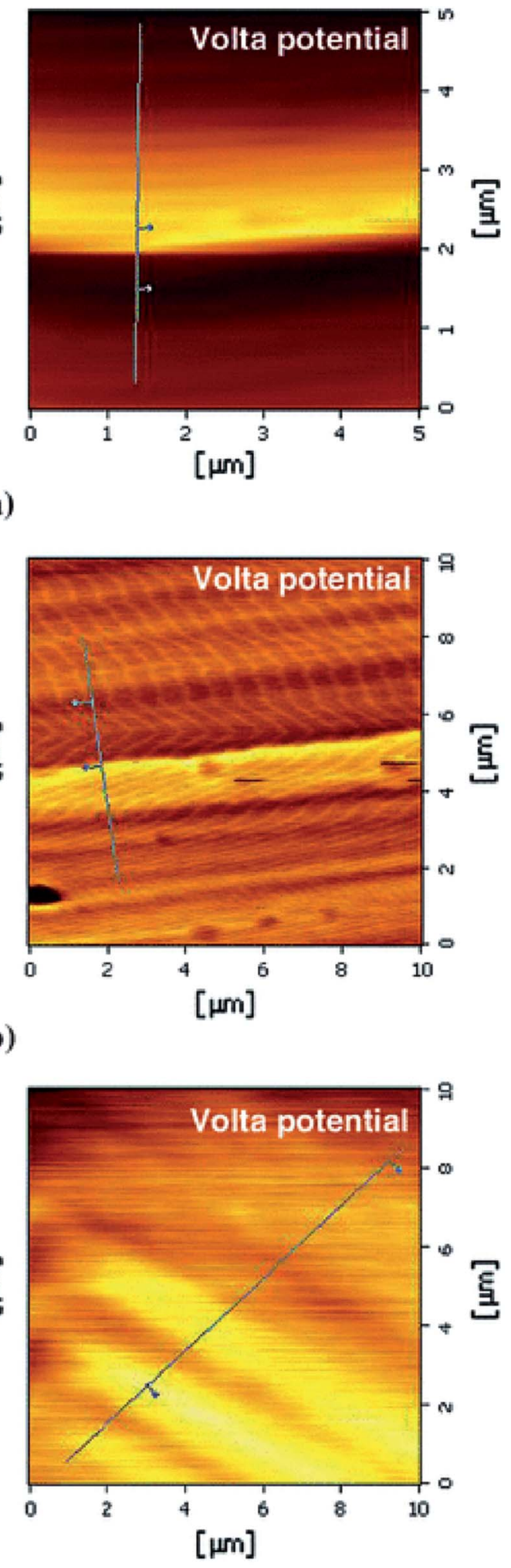

)

Fig. 16 KPFM image representing topography and Volta potential with different average roughness; (a) Ra $108.0 \mathrm{~nm}$, (b) Ra $39.3 \mathrm{~nm}$, and (c) Ra $16.7 \mathrm{~nm} .{ }^{152}$ Reprinted from ref. 152 with permission of Springer. Springer Science + Business Media Dordrecht 2013.

corrosion mechanisms. Establishment of a collaborative instrumental approach with the help use of KPFM to study the solid (base alloy or metal)-liquid (corrosive media) interface could be useful for corrosion scientists as well as theoreticians as the interface properties can be utilized in various aspects of mass transfer. 
(a)

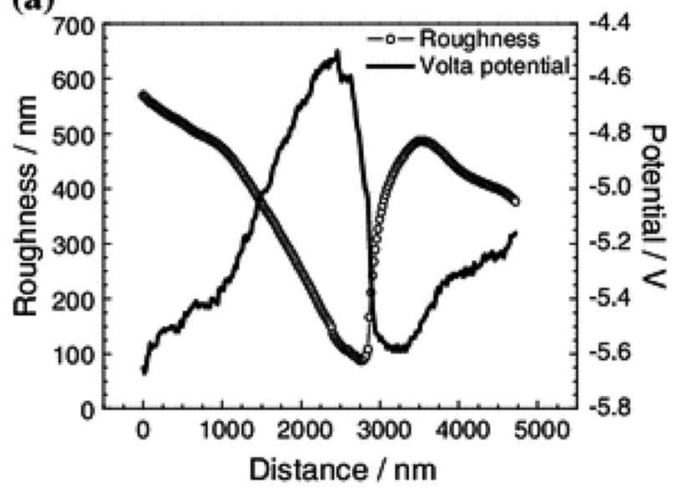

(c)

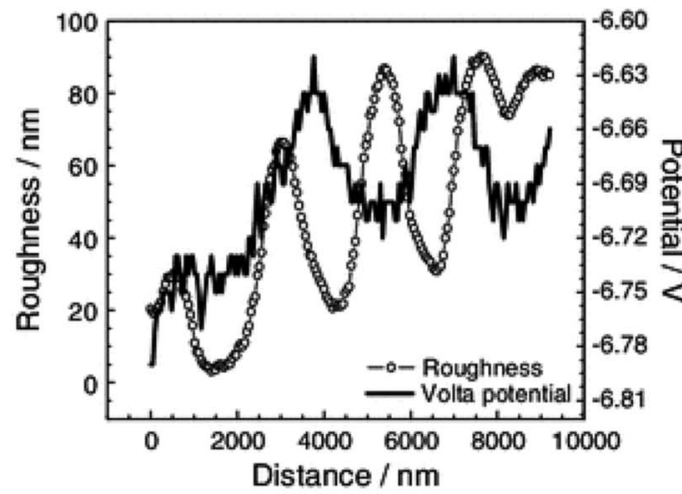

(b)

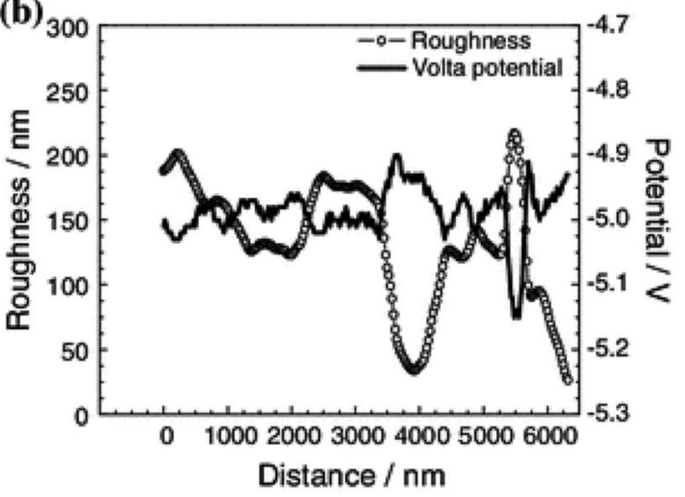

(d)

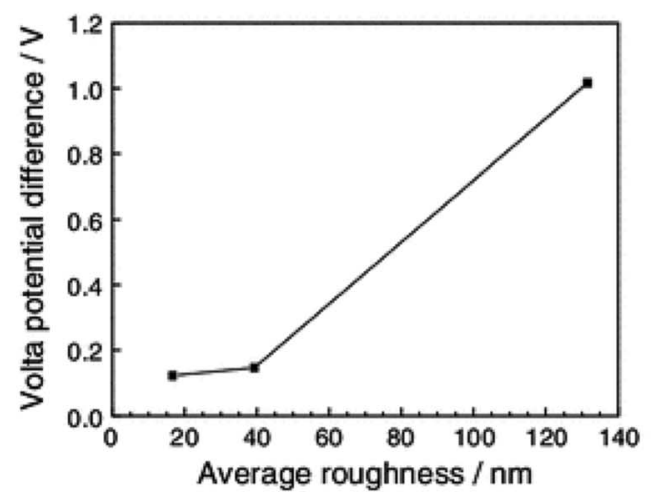

Fig. 17 Image shows line diagram (cross sectional) between roughness and Volta potential with average roughness of (a) Ra $108.0 \mathrm{~nm}$, (b) Ra $39.3 \mathrm{~nm}$, (c) Ra $16.7 \mathrm{~nm}$. (d) Shows Volta potential difference between peak and valley with respective average roughness. ${ }^{152}$ Reprinted from ref. 152 with permission of Springer. Springer Science + Business Media Dordrecht 2013.

4.2.2. Scanning tunnelling microscopy (STM). Local dissolution and electrochemical behaviour can be investigated with scanning tunnelling microscopy (STM). Therefore it has been considered as an important technique that provides information with atomic resolution and can be applied in corrosion research. ${ }^{153,154}$ The advantage of the STM technique is that it can operate in air, vacuum and in liquid (electrochemical study), which makes this instrument very popular for obtaining topographical and spectroscopic data from steel surfaces. ${ }^{155,156}$ The advantage of STM over scanning electron microscope (SEM), for example is that it can give information about the change in depth with potential change, which is not applicable for SEM. ${ }^{157}$

Sekine et al. ${ }^{158}$ studied the corrosion behaviour of mild steel with various hydroxyl acid solutions and used STM for the analysis of surface topography. As the bias voltage was applied, a shift was observed in glycolic acid with a step structure, whereas no shift was observed in malic acid solution. It was shown that the corrosion rate of mild steel by malic acid was higher than for tartaric acid, lactic acid and glycolic acid, respectively.

Zhou et al. ${ }^{159}$ studied intergranular corrosion of mild steel in combined $\mathrm{NaNO}_{2}$ and $\mathrm{CO}_{2}$ media with the application of STM to visualize the corroded grain boundary as well as to estimate the size of the dissolved grain (Fig. 18).
Topography of nano-coating of polyelectrolytes on mild steel with $1 \mathrm{mM}$ benzotriazole inhibitor was studied by Sabbaghi et al. ${ }^{\mathbf{1 6 0}}$ who showed a uniform nature of coating. Higher corrosion potentials were observed for the coated sample compared to the uncoated sample, and the corrosion potential increased with number of layers of the coating material on steel.

Presently, in situ STM is developed and represents a powerful technique for surface analysis of metallic substrates. MartinezLombardia et al. ${ }^{\mathbf{1 6 1}}$ studied grain dependent corrosion in microcrystalline copper. This material is out of scope of this review but will assist in understanding the multi-dimensional usage of STM. With the help of electrochemical STM (ECSTM), the authors showed the importance of surface defects in corrosion. Orientation of grains affects corrosion resistance and grains with large step linear density dissolve faster than the other grains and elucidate low corrosion resistance. The study concludes that the $\{111\}$ plane has higher reactivity and dissolves quicker than the $\{001\}$ plane. This is a very exciting observation as for FCC structures the $\{111\}$ plane is observed as close packed structure and should be stable, but due to the large grain misorientation with respect to terraces developed low coordination atoms. The analysis was combined with EBSD and texture analysis was combined with STM topography. This study established the importance of STM technique for fundamental and mechanistic corrosion study. Another scope of in situ STM 


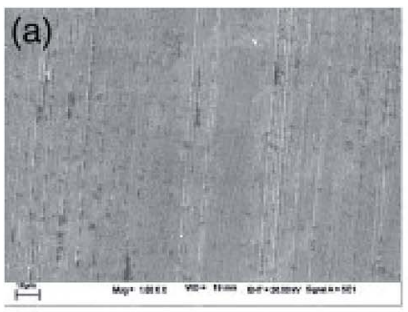

300 mV is $5 C E$

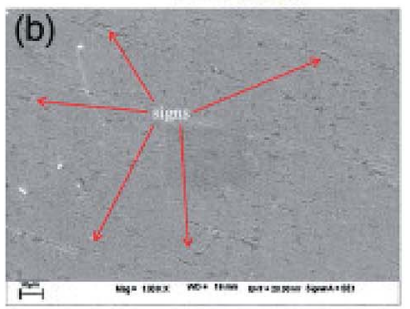

150 m $\mathrm{N}$ พ $5 \mathrm{CCE}$
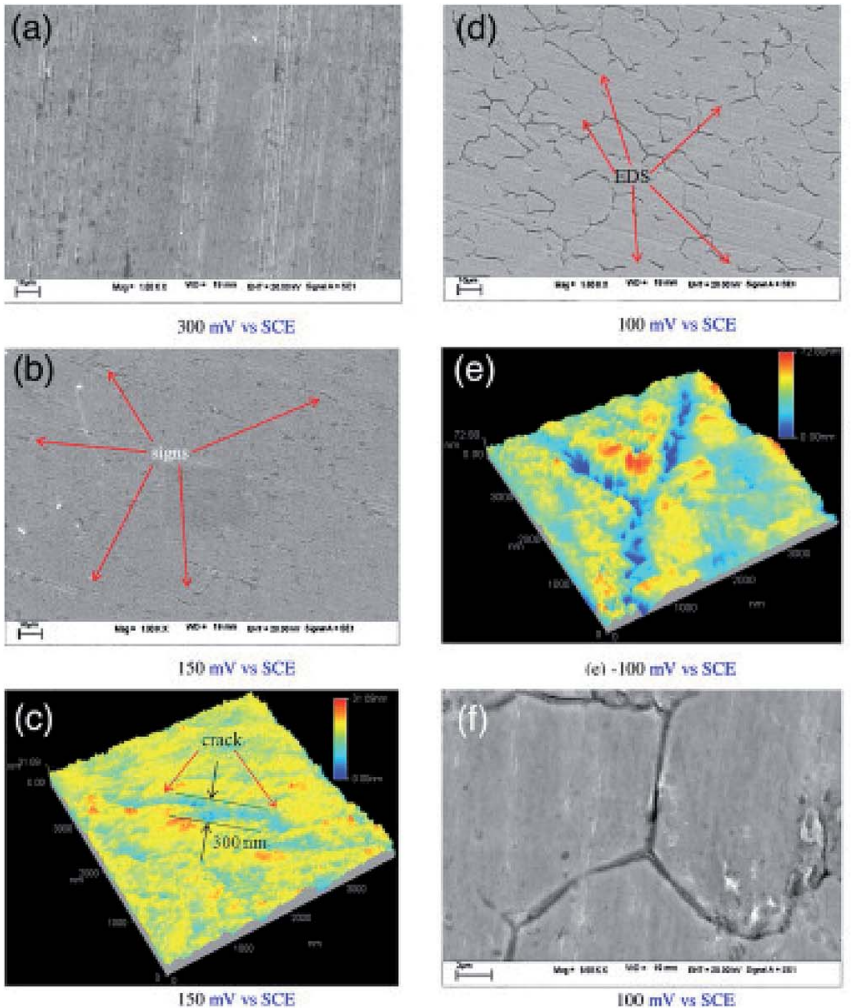

1000 H. W พS SCE

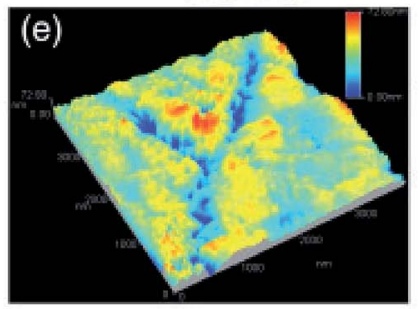

(6) $-100 \mathrm{mV}$ v $5 \mathrm{CE}$

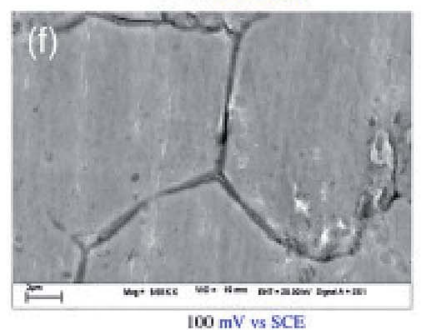

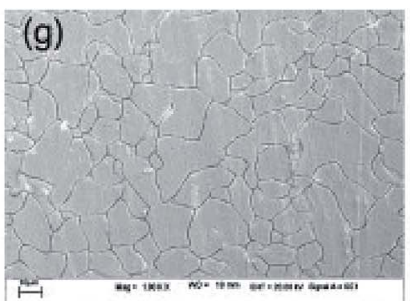

D mW ws SCE

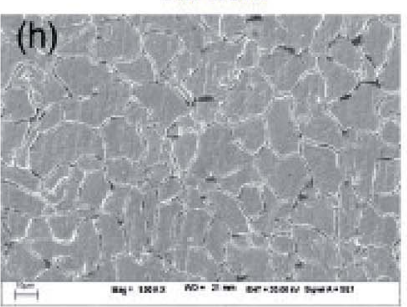

$600 \mathrm{mV}$ ys SCE

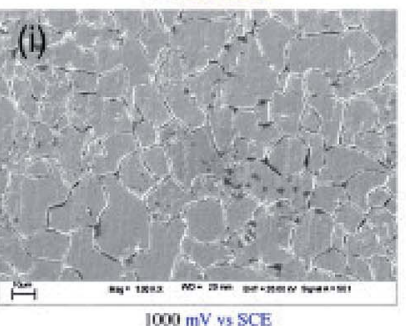

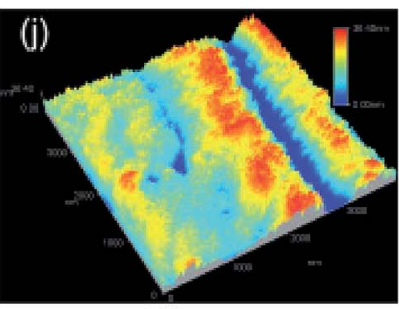

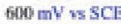

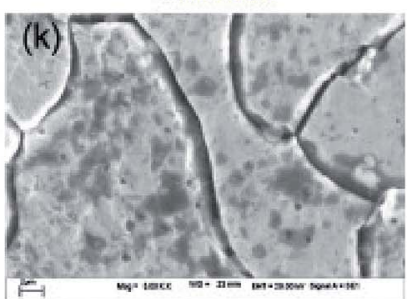

600) $\mathrm{mV}^{\mathrm{V}}$ v. $\mathrm{SCF}$

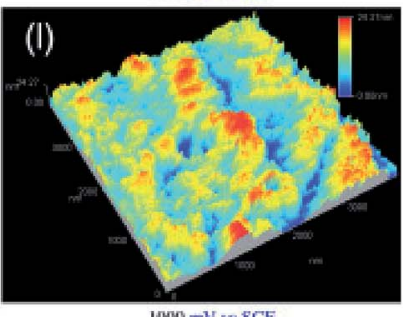

$1000 \mathrm{mV} \mathrm{xs} 3 \mathrm{CE}$

Fig. 18 SEM morphologies and STM topographies of mild steel polarized at (a) $-300 \mathrm{mV} v$ s. SCE, (b) $-150 \mathrm{mV}$ vs. SCE, (c) $-150 \mathrm{mV}$ vs. SCE, (d) $100 \mathrm{mV}$ vs. SCE, (e) $-100 \mathrm{mV}$ vs. SCE, (f) $-100 \mathrm{mV}$ vs. SCE, (g) $0 \mathrm{mV}$ vs. SCE, (h) $600 \mathrm{mV}$ vs. SCE, (i) $1000 \mathrm{mV}$ vs. SCE, (j) $600 \mathrm{mV}$ vs. SCE, (k) $600 \mathrm{mV}$ vs. SCE, (l) $1000 \mathrm{mV}$ vs. SCE (in $\mathrm{CO}_{2}+\mathrm{NaNO}_{2}$ solution). ${ }^{159}$ Reprinted with permission from ref. 159. Copyright 2015, Elsevier B. V.

application was defined by Lu et al. ${ }^{162}$ who studied the corrosion behaviour of $\mathrm{Cu}-20 \mathrm{Zr}$ film in $\mathrm{HCl}$ media and observed that due to the pitting corrosion and electron tunnelling $\mathrm{Zr}$ atoms dissolve, which leads to surface diffusion of $\mathrm{Cu}$ and generates defects. Although the study used $\mathrm{Cu}-20 \mathrm{Zr}$ alloy deposited on a glass substrate, the outcome of the study demonstrates the possibilities of the surface investigations using in situ STM that could possibly be applicable to carbon steel surfaces. Carbon steels can contain certain alloying elements, such as Mo or $\mathrm{Cr}$ and be susceptible to corrosion due to the selective dissolution of elements at certain regions at the surface. Such a corrosion phenomenon could be studied using STM. Zamborini et al. ${ }^{163}$ coated $n$-alkane thiol-Au (111) and naked Au (111) to study surface corrosion in $\mathrm{CN}^{-}$medium. The authors observed that the potential, not time, is the critical parameter defining the rate of corrosion. This study involved the use of electrochemical STM (ECSTM) and highlights the importance of the use of ECSTM as a characterizing tool for corrosion processes.

The reviewed literature elucidated that corrosion of carbon steel has not been extensively studied with STM or ECSTM. In fact, no studies have utilized these techniques in situ on carbon steels to date. STM analysis can however provide valuable information on the properties of the steel surfaces, as demonstrated for other alloys. STM thus represents a field of surface analysis that is yet to be explored for carbon steel substrates.

4.2.3. Scanning electrochemical microscopy (SECM). Scanning electrochemical microscopy can provide information about the interfacial phenomenon as well as mass transport at a solid-liquid interface. It is also a very important characterization tool for corrosion as it allows simultaneous measurement of chemical reactivity and electrochemical properties along with the surface kinetic properties. ${ }^{160,161}$ SECM can potentially identify the preferential sites for corrosion along with the information about the concentration of active species for corrosion, and thus can be applied to investigations of localized corrosion that occurs at specific sites. Interested readers could follow a review published by Szunerits et al. ${ }^{164}$ New developments in SECM such as alternating current SECM allow measurement of electrochemical impedance between the solid-liquid interface.

Electrochemical microscopy has only scarcely been applied in carbon steel corrosion investigations and the majority of studies involve corrosion of stainless steel or iron substrate. These include publications by Lister et al., ${ }^{165}$ who studied sulphur dissolution in stainless steel with SECM. Fushimi et al. ${ }^{166}$ investigated dissolution of $\mathrm{Fe}^{2+}$ or Fe $^{3+}$ in a poly-crystal iron electrode and showed that dissolution of ferrous iron from a thick film region was slower than the thinner film region. Similarly, localized corrosion of 316 LN stainless steel was observed through electrochemical microscopy by Tanabe et al. ${ }^{167}$

The only study involving application of SECM at carbon steel was presented by Völker et al. ${ }^{168}$ The authors studied $\mathrm{Fe}^{2+}$ at low carbon steel coated with tin and epoxy resin. This study 


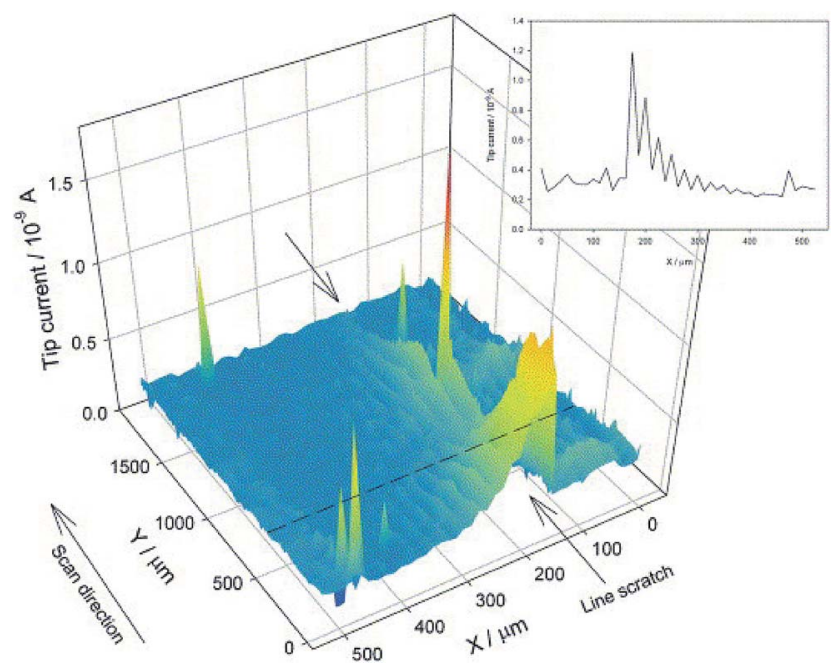

Fig. 19 SECM image of tinplate with a line scratch immersed in $10 \mathrm{mM}$ $\mathrm{H}_{2} \mathrm{SO}_{4}$. The current increase above the scratch shows the oxidation of $\mathrm{Fe}^{2+}$ to $\mathrm{Fe}^{3+} . E_{\text {tip }}=+600 \mathrm{mV}, E_{\text {sample }}=$ OCP (about $520 \mathrm{mV}$ ), SECM Pt tip radius: $10 \mu \mathrm{m} .{ }^{168}$ Reprinted with permission from ref. 168. Copyright 2006, Elsevier B. V.

established SECM as a powerful technique for localized corrosion detection with high lateral resolution. $\mathrm{Fe}\left(\mathrm{OH}_{2}\right)_{6}{ }^{2+}$ detection was difficult due to its oxidation product's limited solubility. This was one of the important limitations of experiment which restricted experimental conditions below pH 3 (Fig. 19 and 20). The tin plate is composed as $200 \mu \mathrm{m} \mathrm{Fe} / 1-2 \mu \mathrm{m} \mathrm{Sn} / 9-15 \mu \mathrm{m}$ epoxyphenolic coating. A line scan was performed in a direction perpendicular to the scratch (Fig. 19 inset) and the tip current increased as the tip crossed over the scratch. In Fig. 20, colour scale indicates tip current and numbers local concentrations.

\section{Inhibitors for plain carbon steels}

Carbon steel is the preferred material for many applications, including the oil and gas industry, where corrosion protection of carbon steels exposed to acidic conditions is a continuously developing field, aiming for improved performance of carbon steels that provide a more economical option compared to other alloys. Previous sections of this review discussed the importance of the properties of the carbon steels and the methodology applied or available for applications to thin films on carbon steel surfaces. It is however also important to consider the chemical composition of the corrosion inhibitors that are efficient in inhibiting carbon steel corrosion under specific conditions. This section focusses on summarizing the latest developments in inhibition of carbon steel corrosion under acidic conditions, such as $\mathrm{HCl}$-containing media. A specific focus is given to carbon dioxide corrosion, a type of acid corrosion that is the major issue in the oil and gas industry. Most equipment in the industry operations is exposed to an acidic atmosphere that results for example in corrosion of pipelines, casing and tanks leakage. ${ }^{\mathbf{1 6 9 , 1 7 0}}$ Acidizing is however an important procedure in which high pressure acid is inserted into the rock through its pores and allows it to chemically attack, resulting in the dissolution of rocks and generating channels for flow. ${ }^{171}$

In order to prevent corrosion, corrosion inhibitors are employed. It has been noticed that absence of corrosion inhibitors leads to an exponential increase in corrosion rate. ${ }^{\mathbf{1 7 2}}$ Corrosion inhibitors can either be a single component (organic)

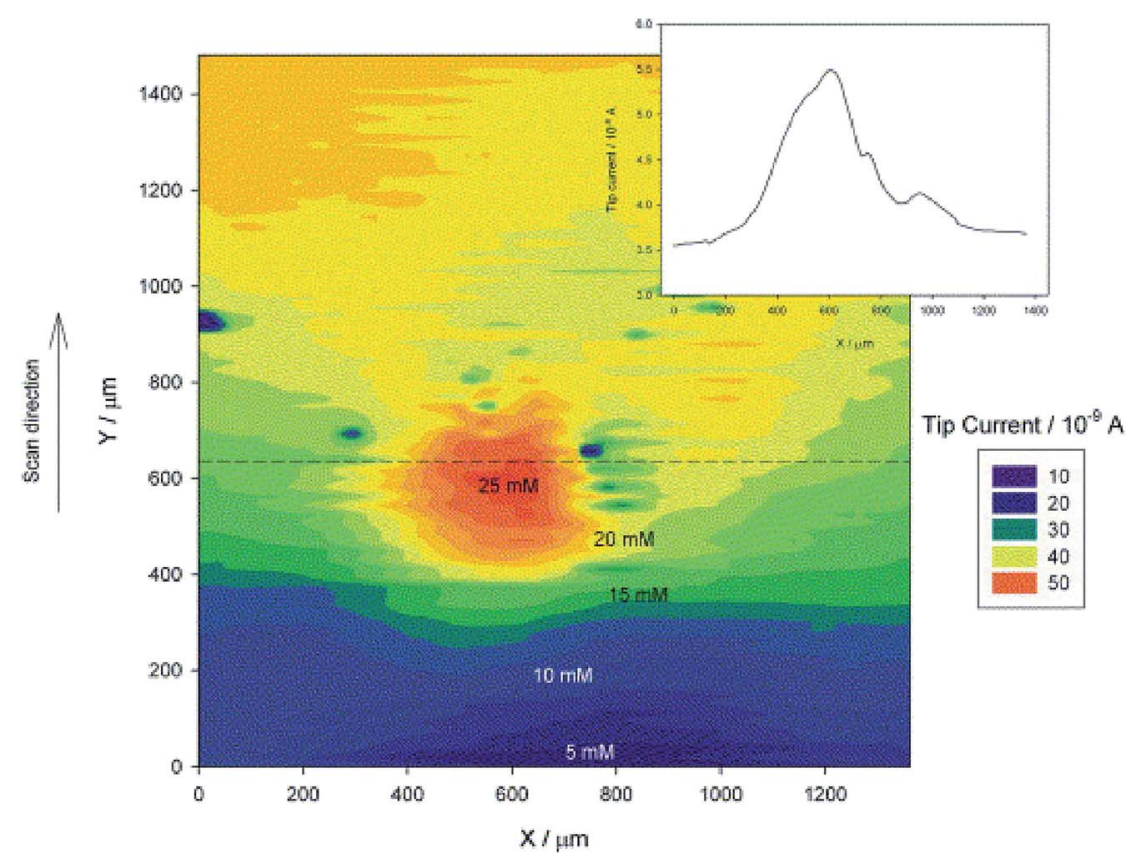

Fig. $20 \mathrm{SECM}$ contour plot exhibiting defect in tin plate which was immersed in $10 \mathrm{mM} \mathrm{H}_{2} \mathrm{SO}_{4}$. $E_{\text {tip }}=+600 \mathrm{mV}, E_{\text {sample }}=\mathrm{OCP}$ (about $520 \mathrm{mV}$ ), SECM Pt tip radius $=10 \mu \mathrm{m} .{ }^{168}$ Reprinted with permission from ref. 168. Copyright 2006, Elsevier B. V. 
or a mixture of solvents and compound, compound-surfactant or compound-co-solvents. ${ }^{173}$ Usually, mixtures are known as corrosion inhibitor formulation (CIF) or corrosion inhibitor package (CIP). ${ }^{\mathbf{1 7 4 , 1 7 5}}$ Surfactants are basically used for making emulsion with inhibitors as it increases the dispersibility of inhibitors in solution (incl. acids), ${ }^{176}$ but some of the surfactants also help controlling corrosion. Design of a surfactant molecule is an important aspect as far as performance of inhibitors is concerned. Studied surfactants are cationic surfactants such as ammonium salts and amines, which can perform at low $\mathrm{pH} .{ }^{177}$

Another important aspect of a corrosion inhibition package is the solvent. Solvents provide stability to the formulations or mixtures. Some important solvents are glycols, formic acids, dimethylsulphoxide etc. ${ }^{\mathbf{1 7 8 , 1 7 9}}$ In order to select a solvent, one should be aware of its flammability as well as its cost. Flammability is occasionally important for oil and gas industries. Nasr-El-Din et al. ${ }^{\mathbf{1 8 0}}$ and W. Durnie et al. ${ }^{\mathbf{1 8 1}}$ studied the joint application of alcohol-ether as a solvent and found all combinations generated a better acid penetration and clean-up. It is also noted that formic acid also serves as intensifier (inhibitor acid). Intensifiers help to protect steel (plain carbon steel) at high temperature.

Developments of novel corrosion inhibition measures are the focus of many research groups in the field of corrosion science. The research is generally conducted on carbon steels of different material properties. Few authors have addressed the performance of corrosion inhibitors in respect to the type of carbon steel used. For example, Tkachenko et al. ${ }^{182}$ observed a good corrosion resistance with AGMIB (a commercial agent) in sulphuric acid solution (20\%) for carbon steels. A comparison was made among some other additives such as thiourea, KPI, AGMIB, APB, PB, katapin and cetylpyridine, etc., by keeping the inhibitor amount constant $\left(3 \mathrm{~g} \mathrm{~L}^{-1}\right)$. Hydrogen embrittlement leads to brittle fractures and ductility loss in plastically deformed steel. This problem becomes severe in acidic corrosion media and therefore this study was designed to investigate the durability of plastically deformed steel. Sherif et al. ${ }^{183}$ utilized aminophenyl tetrazole (APTA) as corrosion inhibitor for maraging steel in $2 \mathrm{M} \mathrm{H}_{2} \mathrm{SO}_{4}$ solution and suggested that it has a good corrosion inhibition property for maraging steel in acid pickling condition and could be a potential future candidate for efficiency modification.

Corrosion inhibition research of carbon steels under acidic conditions focuses on utilizing alternative compounds to the organics typically used in the industrial applications. These alternative methods often offer more ecological value and can provide better protection to the steel. The latest developments in the main streams in the selection of alternative corrosioninhibitive compounds are further discussed in detail, and include the modification or synthesis of novel compounds, the use of biopolymers and so called 'green' corrosion inhibitors.

Alternating the chemical structure of the inhibitor molecules and thus improving their corrosion-inhibition efficiencies has been successful in many instances. The recent focus is mainly on, but not limited to, the synthesis of novel azole-based inhibitors. For example, 2-amino-4-methyl thiazole was utilized as a corrosion inhibitor for mild steel in acidic medium. The study concluded that a strong adsorption film formation on mild steel offers good corrosion resistance. Formations of feedback bond and dipole-dipole interactions were named as important factors for film formation on mild steels. ${ }^{\mathbf{1 8 4 , 1 8 5}}$ Yildiz et $a{ }^{\mathbf{1 8 6}}$ investigated corrosion inhibition properties of mild steel with 2-pyridinecarbonitrile (2-PCN) in acidic medium. Langmuir isotherm was the key feature for adsorption of 2-PCN on mild steel. Mert et al. investigated 2-amino-4-methyl pyridine (AMP) inhibitor for mild steel in $0.5 \mathrm{M} \mathrm{HCl}$ solution. An interesting outcome was the relation of inhibition efficiency with frontier orbital's energy band gap i.e. $5.357 \mathrm{eV}$ for neutral and $6.490 \mathrm{eV}$ for protonated AMP. ${ }^{187}$ 2-Amino-5-mercapto-1,3,4thiodiazole (2A5MT) and 2-mercapto-thiazoline (2MT) were investigated for carbon steel corrosion in $1 \mathrm{M} \mathrm{H}_{2} \mathrm{SO}_{4}$. The presence of deep holes and pores in mild steel surface was confirmed through SEM analysis. It was shown that the surface became smooth (low surface roughness) upon contact with the corrosion inhibitor. AFM depicted $329 \mathrm{~nm}$ as mean roughness of mild steel surface, whereas $18 \mathrm{~nm}$ with $10 \mathrm{mM} 2 \mathrm{~A} 5 \mathrm{MT}$ and $35 \mathrm{~nm}$ with 2 MT inhibitor. The AFM analysis confirmed adsorption of inhibitor molecules. ${ }^{188}$ 2,5-Bis(n-pyridyl)-1,3,4thiadiazole was used as a corrosion inhibitor for carbon steel in $1 \mathrm{M}$ perchloric acid $\left(\mathrm{HClO}_{4}\right)$ media. FTIR confirmed the $\mathrm{Fe}$ (II) complex $\left(\mathrm{Fe}\left(\mathrm{ClO}_{4}\right)_{2} \cdot 6 \mathrm{H}_{2} \mathrm{O}\right)$ on steel. However, the phenomenon of 2-PTH deterioration in $\mathrm{HClO}_{4}$ solution by precipitation of CuS was observed, indicated by a broad $\mathrm{S}$ peak in the FTIR spectrum. Higher efficiency (88.2\%) was observed for 3-PTH (12 $\left.\times 10^{-4} \mathrm{M}\right)$ than for 2 -PTH $\left(12 \times 10^{-4} \mathrm{M}\right) .{ }^{189} \mathrm{SEM}$ was used extensively in the surface examination of inhibitor film formation. 3-Pyridine carbozalde thio semicarbazone (3-PCT) ${ }^{\mathbf{1 9 0}}(89 \%$ efficiency $\left.\left(25^{\circ} \mathrm{C}\right)(1.5 \mathrm{mmol})\right)$, rhodanine- $N$-acetic acid (R-NA) ${ }^{212}$ (efficiency $98 \%\left(1.0 \times 10^{-2} \mathrm{M}\right.$ in $0.1 \mathrm{M} \mathrm{HCl}$ corrosive media)); 4,4-dimethyl-3-oxo-2-(1,2,4)-triazol-1-yl-pentanethionic acid phenylamide (DTP), ${ }^{191}$ 5-((E)-4-phenylbuta-1,3-dienylideneamino)-1,3,4-thiadiazole-2-thiol ${ }^{192}$ and $4-\{[((1 Z)$-2-chloroquinolin-3-yl) methylene]amino\}phenol (CAP) ${ }^{193}$ (efficiency $97 \%$ in $1 \mathrm{M} \mathrm{HCl}$ corrosive media). The corrosion inhibitor films were examined using SEM and all studies exhibited a decrease in roughness of the steel surface after inhibitor exposure. The 1,3-diocta decylimidazolium bromide and $N$-octadecyl pyridinium bromide film was studied through XRD, EDS and Mössbauer spectroscopy. ${ }^{194}$ SEM shows a flat film formation, while EDS confirmed the presence of $\mathrm{Fe}$ and $\mathrm{Cl}$. The XRD analysis provided information about mixed goethite, melanterite and rozenite phases.

The application of bio-polymers has recently been studied by Tawfik et al. ${ }^{195}$ This study established various alginate-derived bio-polymer as an efficient inhibitor for corrosion of carbon steel in acidic medium ( $1 \mathrm{M} \mathrm{HCl}$ ). It was observed that alginate molecules do not affect the reaction mechanism, but block the reaction sites on the surface of carbon steel. The efficiency was entirely based on the adsorption of alginate molecules on carbon steels and it followed the Langmuir isotherm for adsorption. Highest efficiency (95.51\%) was observed with $5 \times$ $10^{-3} \mathrm{M}$ concentration of alginate derivatives. He et al. ${ }^{196}$ studied the corrosion of carbon steel in re-circulating cooling water with polyaspartic acid. Polyepoxysuccinic acid, polyamino poly ether 
methylene phosphonate and sodium gluconate were used in combination and such mixture could be considered a composite. The resulting corrosion inhibition efficiency of this composite was $97.32 \%$ at low dosage $\left(30 \mathrm{mg} \mathrm{L}^{-1}\right)$ with low $\mathrm{P}$ content. Nam et al. ${ }^{197}$ studied 4-carboxyphenylboronic acid (CPBA) $(0.12 \mathrm{mM}, 0.60 \mathrm{mM}$ and $2.41 \mathrm{mM})$ as a corrosion inhibitor for $\mathrm{CO}_{2}$ corrosion in $0.01 \mathrm{M} \mathrm{NaCl}$ solution. It was suggested that the organic film formation prevented the inward diffusion of $\mathrm{Cl}^{-}$and outward diffusion of Fe ions and inhibition performance was increased with increasing concentration of CPBA.

Similarly, the use of rare-earth metal based compounds has been shown to effectively inhibit corrosion of carbon steel under acidic conditions (carbon dioxide corrosion). Nguyen et al. ${ }^{198}$ synthesized cerium 4-hydroxycinnamate $\left(\mathrm{Ce}(4 \mathrm{OHCin})_{3}\right)$, lanthanum 4-hydroxycinnamate $\left(\mathrm{La}(4 \mathrm{OHCin})_{3}\right)$ and praseodymium 4-hydroxycinnamate $\left(\operatorname{Pr}(4 \mathrm{OHCin})_{3}\right)$ and used them as inhibitor molecules $(0.0,0.02,0.16$ and $0.63 \mathrm{mM}$, respectively) for $\mathrm{CO}_{2}$ corrosion in $0.01 \mathrm{M} \mathrm{NaCl}$ solution at room temperature. Highest efficiency was observed at $0.63 \mathrm{mM}$ concentration of rare earth compounds and the most efficient inhibitor was praseodymium 4-hydroxycinnamate $\left(\operatorname{Pr}(4 \mathrm{OHCin})_{3}(0.063 \mathrm{mM})\right.$. It was concluded that the film formation on the surface of steel was the reason for the effective corrosion inhibition observed.

Green corrosion inhibitors are an important alternative for the use of organic corrosion inhibitors. Azadirachta indica, commonly known as "Neem tree", has been used as a corrosion inhibitor not only for plain carbon steel but also for aluminium and tin based systems. ${ }^{199}$ Methanol extract of Ligularia fischeri was investigated as corrosion inhibitor for carbon steel in $1 \mathrm{M}$ $\mathrm{HCl}$ corrosive solution and reached $92 \%$ inhibition efficiency at $500 \mathrm{ppm}$ of Ligularia fischeri. The study found that Ligularia fischeri acted as a mixed corrosion inhibitor. ${ }^{200}$ Similarly methanolic, aqueous methanolic and water extracts of Anthemis pseudocotula were utilized for mild steel corrosion inhibition in $1 \mathrm{M} \mathrm{HCl}$ corrosive media. The highest inhibition competency was observed for methanoic extract. ${ }^{201}$

Plant-extracted inhibitors have also been employed by several researchers for plain carbon steels. ${ }^{202}$ Carica papaya (leaves, seed, heart wood and bark) was also used for corrosion inhibition of carbon steels in $1 \mathrm{M} \mathrm{H}_{2} \mathrm{SO}_{4}$ corrosive media. Concentrations of inhibitors were varied as $0.1,0.2,0.5,1.0$ and $2.0 \mathrm{~g} \mathrm{~L}^{-1}$ and the highest efficiency was observed for leaves and the lowest for barks. It was noticed that inhibition efficiency was increased with extract concentration, but decreased with increasing temperature. ${ }^{203}$ Medicago sative proved as a good corrosion inhibitor for carbon steel in corrosive media of $2 \mathrm{M}$ $\mathrm{H}_{2} \mathrm{SO}_{4}$ containing $10 \% \mathrm{EtOH}$ and it was shown that inhibition was achieved through charge transfer. ${ }^{204}$ Cyamopsis tetragonaloba was utilized as a carbon steel inhibitor with $92 \%$ efficiency whereas the highest efficiency was observed for Ocimum sanctum, Aegle marmelos and Solanum trilobatum with 99\% efficiency for carbon steels. ${ }^{205,206}$ The use of plant based inhibitors has recently been reviewed by Singh et al. ${ }^{207}$ Mourya et al. ${ }^{208}$ studied the mild steel corrosion with Tagetes erecta (Marigold flower) as a corrosion inhibitor. In $0.5 \mathrm{M} \mathrm{H}_{2} \mathrm{SO}_{4}$ solution, the authors observed that performance of the inhibitor could be increased through adsorption of protonated Lutein than Lutein. It was noticed that the performance increased with marigold extract concentration and adsorption behaviour was found as Langmuir isotherm. Chidiebere et al. ${ }^{209}$ utilized phytic acid as an inhibitor for corrosion on mild steel (Q 235) in $0.5 \mathrm{M} \mathrm{H}_{2} \mathrm{SO}_{4}$ medium. In addition to this, iodide additives were used to support the inhibition properties of phytic acid. ${ }^{209,210}$ The use of phytic acid has certain advantages as it is nontoxic as well as soluble in water. Musa paradisica peel extract is another green inhibitor utilized for mild steel application. ${ }^{211}$ Zhang et al. ${ }^{212}$ used halogen substituted imidazoline derivative as 2-(2trifluoromethyl-4,5-dihydro-imidazol-1-yl)-ethylamine (1.1 M) and 2-(2-trichloromethyl-4,5-dihydro-amidazole-1-yl)ethylamine $(2.1 \mathrm{M})$ for mild steel in $\mathrm{HCl}(0.5 \mathrm{M})$ solution and observed better efficiency in chloride substituted compounds than fluoride one. The compound 4-6-diamino-2-pyrimidinethiol (4D2P) was also utilized for the mild steel corrosion inhibition in acidic $(0.1 \mathrm{M} \mathrm{HCl})$ medium..$^{213}$

Another approach in selecting 'green' compounds for corrosion inhibition is to utilize pharmaceutical-based compounds (drugs). Penicillins, ${ }^{\mathbf{2 1 4}, 215}$ which belong to the beta-lactom group of antibiotics were shown important in corrosion inhibition studies, including penicillin G (commonly used for septic arthritis), ampiciline (used for urinary tract infection), penicillin $\mathrm{V}$ (commonly used for skin infection). ${ }^{216,217}$ Interested readers can refer to a review published by Gece $e t a l$. on the use of drugs as corrosion inhibitors. ${ }^{218}$ Vitamin B1 was also utilized as a corrosion inhibitor for mild steel in $0.5 \mathrm{M} \mathrm{HCl}$ solution. It was observed that vitamin B1 protects carbon steel through formation of passive film by physical and chemical interaction. ${ }^{217}$ Another interesting approach was to use a ketosulfone drug for mild steel under $1 \mathrm{M} \mathrm{HCl}$ medium. Ketosulfone is considered as a mixed corrosion inhibitor. ${ }^{219,220}$

Similarly, in acidic solution (1 M HCl), cationic 1-dodecyl-1methyl-1 $H$-benzo[ $d]$-(1,2,3)-triazole-1-ium bromide (1-DMBT) was investigated as a potential corrosion inhibitor in $1 \mathrm{M} \mathrm{HCl}$ corrosive media for carbon steel. It was observed that 1-DMBT behaved as a mixed-type inhibitor and offers good corrosion inhibition efficiency $\left(91.2 \%\right.$ at $25{ }^{\circ} \mathrm{C}$ with $\left.5 \times 10^{-3} \mathrm{M}\right) \cdot{ }^{220}$ Recently, pyrazol derivatives such as 2-(3-amino-5-oxo-4,5dihydro-1H-pyrazol-1-yl), (P-toly)(methyl)malononitrile (P21) and 2-((3-amino-5-oxo-4,5-dihydro-1H-pyrazol-1-yl)(phenyl)methyl) malononitrite (P22) were utilized for corrosion prevention of N80 steel in $15 \% \mathrm{HCl}$ medium. The study concluded that P21 was better than P22 as far as corrosion inhibition is concerned. It should be mentioned that both P21 and P22 can be protonated. ${ }^{221}$ Further, indigo carmine was shown to provide 95\% inhibition efficiency when combined with benzyl trimethyl ammonium bromide. Other inhibitors incorporated in this study were triethanolamine and cetyltrimethyl ammonium bromide. ${ }^{222}$ Other drugs applied as corrosion inhibitors are torsemide and furosemide, that were studied in $1 \mathrm{M} \mathrm{HCl} \mathrm{solu-}$ tion. Inhibition efficiency of torsemide was higher than the furosemide because of its high electron density which supports the inhibitor adsorption. ${ }^{222}$

$\mathrm{CO}_{2}$ corrosion represents a specific type of acid corrosion encountered in the oil and gas industry. Inhibition of $\mathrm{CO}_{2}$ 


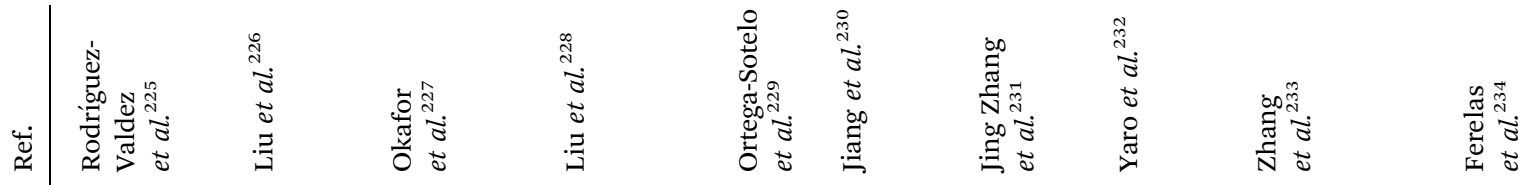

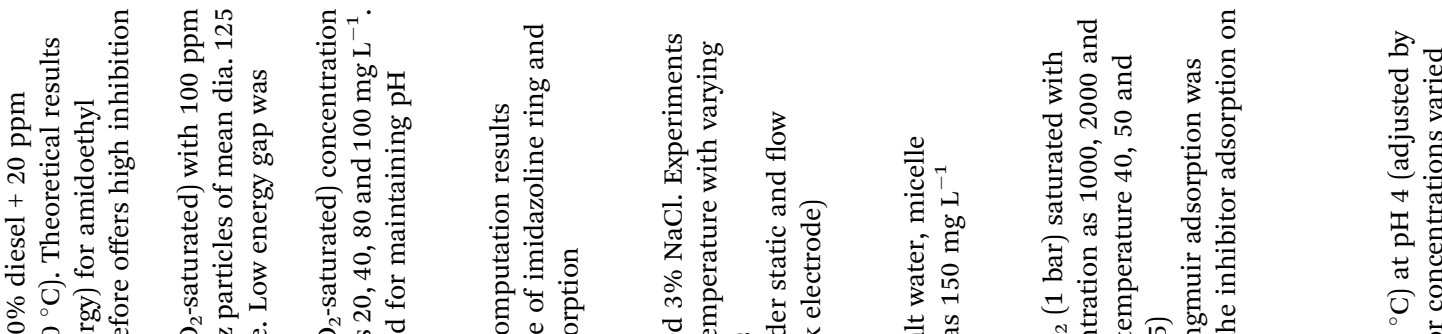

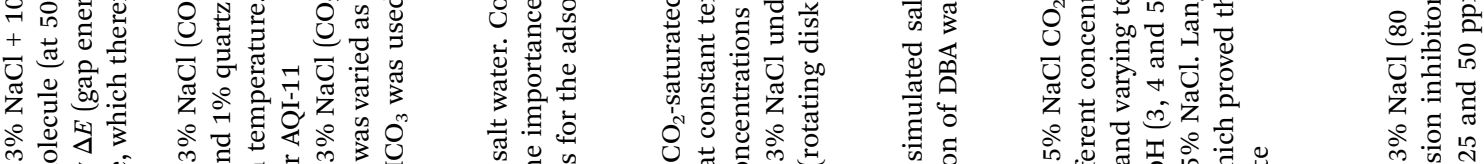

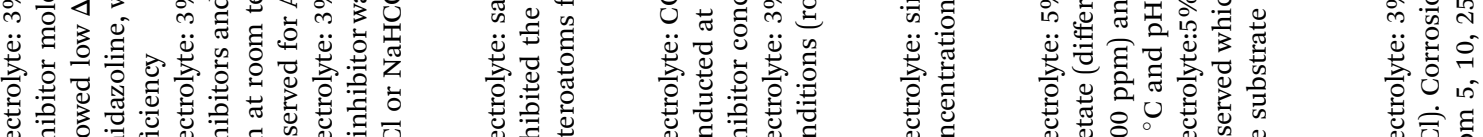

مे
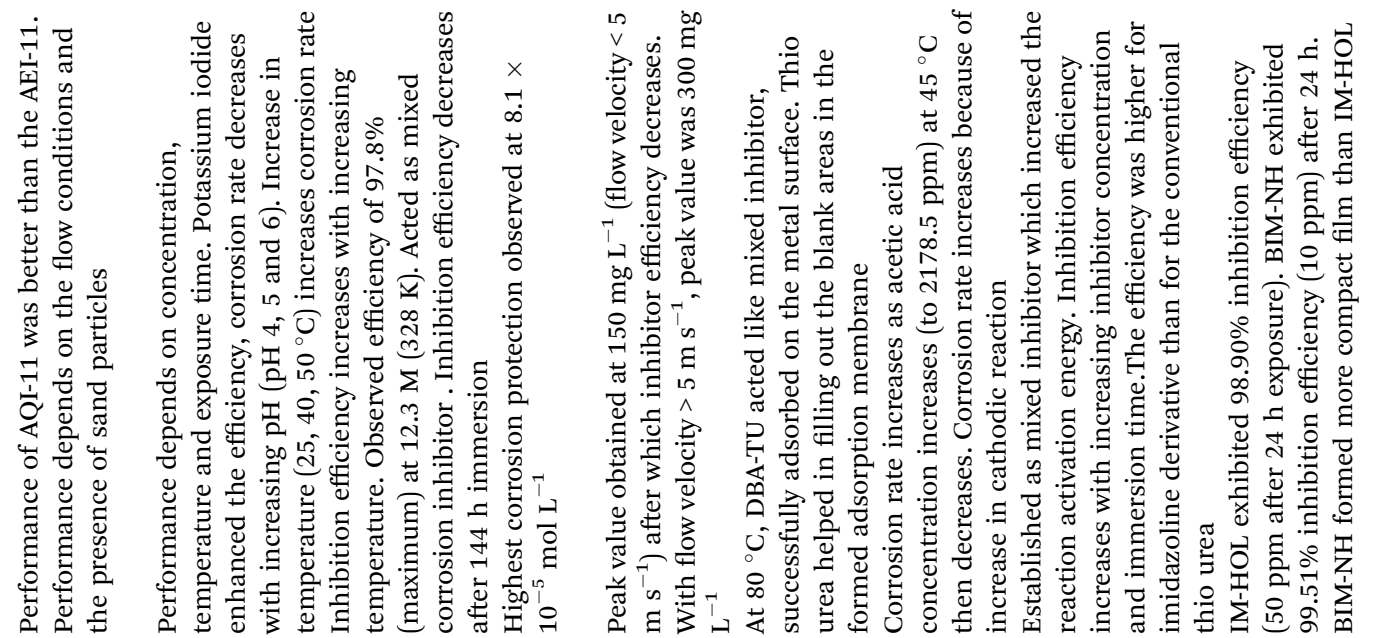

$\infty$ ळू

a

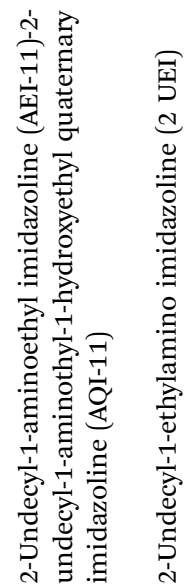

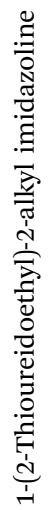
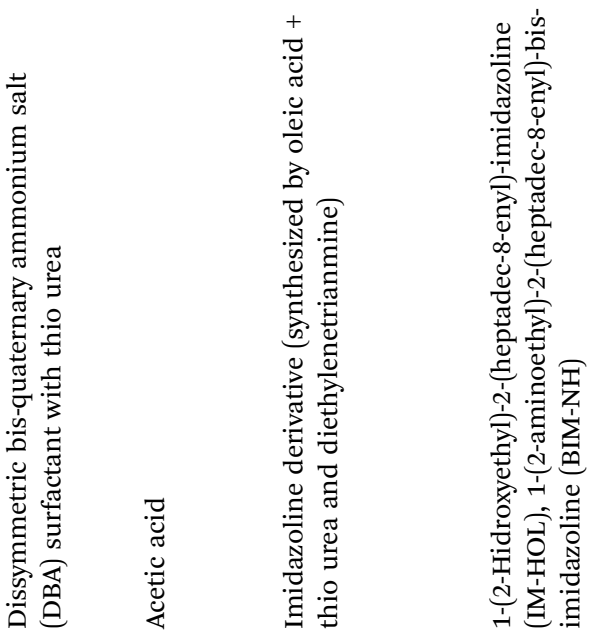
corrosion can be performed in two ways, either directly through crude oil or through use of corrosion inhibitor molecules. The former method involves two major phenomena known as wettability through constituents of crude oil. Sometimes crude oil does not allow water to encounter the steel surface and thus prevents corrosion. Nesic et al. ${ }^{223}$ studied the effect of aromatic resin, saturates, nitrogen and sulphur, etc. Another approach to $\mathrm{CO}_{2}$ corrosion inhibition is the application of corrosion inhibitors. Corrosion inhibitors are mostly organic compounds that adsorb on the metallic substrate (through changing the interfacial free energy) with the help of the active part of their molecule, characterized as hydrophilic head and hydrophobic tail. The adsorption occurs through the hydrophilic head whereas the hydrophobic tail helps in forming a hydrophobic barrier through self-assembly. ${ }^{224}$ The adsorption of inhibitor molecules changes the wettability of steel along with the oil water interfacial tension. Adsorption of inhibitors can be categorized as physical adsorption (electric force) or chemical adsorption (chemical bonding) as described earlier in this review (see also Durnie et al. ${ }^{\mathbf{1 8 1}}$ ).

Chemical compounds that are widely used as $\mathrm{CO}_{2}$ corrosion inhibitors in oil and gas industries are listed in Table 1.

\section{Conclusions and outlook}

This article addresses the importance of material properties, such as surface texture, energy, morphology and defects in carbon steels used under corrosive conditions, and provides a critical review of the current state of surface analytical methods available for the carbon steel surfaces. As carbon steel continues to be the preferred construction material across industry fields, understanding the corrosion mechanisms and the function of corrosion inhibitors, involving the reactions at the interfaces between the corrosive electrolyte and a steel surface, particularly at the initial stages of the corrosion process are required. Naturally, these reactions are strongly affected by the nature and properties of the steel surfaces. It is however noted that the majority of recent corrosion and corrosioninhibition investigations are limited to electrochemical testing, with ex situ analysis of the treated steels (post-exposure analysis). The characterization of materials and their surface properties, such as texture, energy and morphology, are not being considered in most studies. One of the gaps in surface investigations pointed out in this review is the fact that a low surface energy and hydrophobicity of the steel surface are not the only factors in the corrosion prevention and mechanistic studies into the understanding corrosion processes are required. Furthermore, the mechanism of surface chemical composition, surface texture and hierarchical surface behaviour in terms of hydrophobicity has not been extensively studied and the corrosion prevention mechanism of hydrophobic surface of carbon steels has not been universalized to date, to the best of our knowledge. Similarly, in situ investigations of the initial stages of the corrosion reactions using advanced surface characterization techniques are scarce. Existing surface characterization techniques need to be combined with various electrochemical methods in order to achieve deeper mechanistic insights. For example, the use of electrochemical microscopy and magnetic force microscopy in the corrosion of carbon steels and their combination with electrochemical methods such as cyclic voltammetry, electrochemical impedance spectroscopy, etc. could advance the investigations of the localized chemical behaviour of carbon steels.

Expanding corrosion studies on carbon steel surfaces with the currently used and the emerging surface analytical methods, and their combinations as identified in this review could fill the gaps in understanding corrosion and corrosioninhibition mechanisms. Such knowledge is necessary for the development of novel corrosion inhibition measures and synthesis of corrosion inhibitors that are non-toxic, environmentally friendly, inexpensive and provide adequate inhibition against corrosion. These investigations and surface analytical studies of thin films, such as those of film-forming corrosion inhibitors, on carbon steels can be extended to corrosion studies on other metallic and non-metallic substrates and mono-layer studies in general.

\section{Acknowledgements}

Financial support from Curtin University for D. D. (Curtin International Postgraduate Research Scholarship) is greatly appreciated.

\section{References}

1 F. U. Renner, A. Stierle, H. Dosch, D. M. Kolb, T. L. Lee and J. Zegenhagen, Nature, 2006, 707-710.

2 S. D. Cramer and B. S. Covino, Corrosion: fundamentals, testing and protection, ASM International Handbook, 2003, vol. 13A.

3 F. M. Song, D. W. Kirk, J. W. Graydon and D. E. Cormack, Corrosion, 2004, 60, 736-748.

4 W. Villamizar, M. Casales, J. G. Gonzalez-Rodriguez and L. Martinez, J. Solid State Electrochem., 2006, 11, 619-629.

$5 \mathrm{~J}$. L. Crolet, Predicting $\mathrm{CO}_{2}$ corrosion in oil and gas industry, European Federation of Corrosion Publications, Work. Party Report, Inst. Mater, London, 1994, SSN 1354-5116, No. 13.

6 A. Ikeda, M. Ueda and S. Mukai, Corrosion, 1983, 83.

7 L. A. I. Kestens and R. Petrov, Ceram. Trans., 2009, 200, 207216.

8 S. Nesic, Corros. Sci., 2007, 49, 4308-4338.

9 H. S. Hernandez, F. L. Linares, J. Bruzual and J. G. Luzon, NACE International, 2003, 1, 03330.

10 M. A. Migahed, Prog. Org. Coat., 2005, 54, 91-98.

11 S. Papavinasam, A. Doiron, T. Panneerselvam and R. W. Revie, Corrosion, 2007, 63, 704-712.

12 M. Godec and M. Jenko, Mater. Tehnol., 2000, 34, 359-364. 13 Z. N. Farhat, Wear, 2001, 250-251, 401-408.

14 M. Liu, D. Qiu, M.-C. Zhao, G. Song and A. Atrens, Scr. Mater., 2007, 58, 421-424.

15 R. Xin, Y. Luo, A. Zuo, J. Gao and Q. Liu, Mater. Lett., 2012, $72,1-4$. 
16 Y. S. Sato, H. Kokawa, K. Ikeda, M. Enomoto, S. Jogan and T. Hashimoto, Metall. Mater. Trans. A, 2001, 32, 941-948.

17 D. P. Field, T. W. Nelson, Y. Hovanski and K. V. Jata, Metall. Mater. Trans. A, 2001, 32, 2869-2877.

18 M. F. Suarez and R. G. Compton, J. Phys. Chem. B, 1998, 102, 7156-7162.

19 E. Hill, R. R. Lloyd-Williams, R. G. Compton and J. H. Atherton, J. Solid State Electrochem., 1999, 3, 327-330.

20 K. Y. Tam, R. G. Compton, J. H. Atherton, C. M. Brennan and R. Docherty, J. Am. Chem. Soc., 1996, 118, 4419-4426.

21 A. Y. Kandeil and M. Y. Mourad, Surf. Coat. Technol., 1989, 37, 237-250.

22 M. R. Bateni, J. A. Szpunar, X. Wang and D. Y. Li, Wear, 2005, 259, 400-404.

23 V. Venegas, F. Caleyo, T. Baudin, J. H. Espina-Hernandez and J. M. Hallen, Corros. Sci., 2011, 53, 4204-4212.

24 M. A. Arafin and J. A. Szpunar, Corros. Sci., 2009, 51, 119128.

25 Y. Baik and Y. Choi, Phys. Met. Metallogr., 2014, 115, 13181325.

26 N. M. Shkatulyak and O. M. Tkachuk, Mater. Sci., 2012, 48, 153-161.

27 D. Raabe, Crystallographic textures of hot rolled steels, 2003, http://pubman.mpdl.mpg.de/pubman/item/escidoc:2018381/ component/escidoc:2018380/Raabe\%20textures\%20of\% 20hot\%20rolled\%20steels.pdf.

$28 \mathrm{~J}$. M. Hallen, V. Venegas and F. Caleyo, International Conference on Fracture, Beijin, China, 16-21 June 2013.

29 S. A. Park, J. G. Kim, Y. S. He, K. S. Shin and J. B. Yoon, Phys. Met. Metallogr., 2014, 115, 1285-1294.

30 Y. B. Park, D. N. Lee and G. Gottstein, J. Mater. Process. Technol., 1994, 45, 471-476.

31 W. Xu and M. Ferry, Mater. Sci. Technol., 2010, 26, 1159-1172.

32 W. Ozgowicz, A. Grajcar and A. Kurc-Lisiecka, in Corrosion Behaviour of Cold-Deformed Austenitic Alloys, INTECH Open Access Publisher, 2012.

33 L. J. Oblonsky, G. R. Chesnut and T. M. Devine, Corrosion, 1995, 51, 891-900.

34 E. Naderi, A. H. Jafari, M. Ehteshamzadeh and M. G. Hosseini, Mater. Chem. Phys., 2009, 115(2-3), 852-858.

35 C. Herrera, N. B. Lima, A. Ferreira Filho, R. L. Plaut and A. F. Padilha, J. Mater. Process. Technol., 2009, 209(7), 3518-3524.

36 A. Y. Kandeil and M. Y. Mourad, Surf. Coat. Technol., 1989, 37(2), 237-250.

37 C. Y. Chao, L. F. Lin and D. D. Macdonald, J. Electrochem. Soc., 1981, 128, 1187-1194.

38 S. M. Moon and S. I. Pyun, Electrochim. Acta, 1998, 43, 31173126.

39 L. Jinlong and L. Hongyun, Surf. Coat. Technol., 2013, 235, 513-520.

40 Y. A. Perlovich, M. G. Isaenkova, P. N. Medvedev, V. A. Fesenko and S. San Thu, Inorganic Materials: Applied Research, 2015, 6, 259-266.

41 G. L. Song, R. Mishra and Z. Xu, Electrochem. Commun., 2010, 12, 1009-1012.

42 E. J. Song, H. Bhadeshia and D. W. Suh, Corros. Sci., 2013, 77, 379-384.
43 J. T. Woodward, H. Gwin and D. K. Schwartz, Langmuir, 2000, 16, 2957-2961.

44 M. Ma and R. M. Hill, Curr. Opin. Colloid Interface Sci., 2006, 11, 193-202.

45 P. Roach, N. J. Shirtcliffe and M. I. Newton, Soft Matter, 2008, 4, 224-240.

46 W. Xu, T. Ning, X. Yang and S. Lu, Appl. Surf. Sci., 2011, 257, 4801-4806.

47 R. N. Wenzel, Ind. Eng. Chem., 1936, 28, 988-994.

48 D. Yu and J. Tian, Colloids Surf., A, 2014, 445, 75-78.

49 H. Zhang, J. Yang, B. Chen, C. Liu, M. Zhang and C. Li, Appl. Surf. Sci., 2015, 359, 905-910.

50 Z. Yuan, J. Bin, X. Wang, M. Wang, C. Peng, S. Xing, J. Xiao, J. Zeng, X. Xiao and X. Fu, Surf. Topogr.: Metrol. Prop., 2014, 2, 25003.

51 L. K. Wu, X. F. Zhang and J. M. Hu, Corros. Sci., 2014, 85, 482-487.

52 R. Ramachandran and M. Nosonovsky, Phys. Chem. Chem. Phys., 2015, 17, 24988-24997.

53 W. Xu, J. Song, J. Sun, Y. Lu and Z. Yu, ACS Appl. Mater. Interfaces, 2011, 3, 4404-4414.

54 T. Liu, S. Chen, S. Cheng, J. Tian, X. Chang and Y. Yin, Electrochim. Acta, 2007, 52, 8003-8007.

55 W. Durnie, R. De Marco, B. Kinsella, A. Jefferson and B. Pejcic, J. Electrochem. Soc., 2005, 152, B1-B11.

56 S. Shahabi, P. Norouzi and M. R. Ganjali, Int. J. Electrochem. Sci., 2015, 10, 2646-2662.

57 L. Guo, X. Ren, Y. Zhou, S. Xu, Y. Gong and S. Zhang, Arabian J. Chem., 2015, DOI: 10.1016/j.arabjc.2015.01.005.

58 M. Yadav, S. Kumar, N. Kumari, I. Bahadur and E. E. Ebenso, Int. J. Electrochem. Sci., 2015, 10, 602-624.

59 K. F. Khaled and A. El-Maghraby, Arabian J. Chem., 2014, 7, 319-326.

60 M. Larouj, H. Lgaz, H. Serrar, H. Zarrouk, A. Elmidaoui, A. Guenbour, S. Boukhris and H. Oudda, J. Mater. Environ. Sci., 2015, 6(11), 3251-3267.

61 J. Tan, L. Guo, T. Lv and S. Zhang, Int. J. Electrochem. Sci., 2015, 10, 823-837.

62 J. Y. Lee, J. Han, J. Lee, J. S. Yeo, J. Y. Lee and J. Han, Nanoscale Res. Lett., 2015, 10(1), 505.

63 L. Li, V. Breedveld and D. W. Hess, ACS Appl. Mater. Interfaces, 2012, 4, 4549-4556.

64 S. Seal, K. Sapre, A. Kale, V. Desai, M. Gopal and P. Jepson, Corros. Sci., 2000, 42(9), 1623-1634.

65 K. Kowal, J. DeLuccia, J. Y. Josefowicz, C. Laird and G. C. Farrington, J. Electrochem. Soc., 1996, 143, 2471-2481.

66 J. Li and D. Lampner, Colloids Surf., A, 1999, 154, 227-237.

67 M. Ataeefard and S. Moradian, Appl. Surf. Sci., 2011, 257, 2320-2326.

68 W. R. Bowen and N. Hilal, Atomic force microscopy in process engineering: An introduction to AFM for improved processes and products, Butterworth-Heinemann, 2009.

69 M. Sababi, F. Zhang, O. Krivosheeva, M. Forslund, J. Pan, P. M. Claesson and A. Dedinaite, J. Electrochem. Soc., 2012, 159, C364-C371.

70 G. Ji, S. Anjum, S. Sundaram and R. Prakash, Corros. Sci., 2015, 90, 107-117. 
71 I. Jevremović, M. Singer, S. Nešić and V. Mišković-Stanković, Corros. Sci., 2013, 77, 265-272.

72 Z. Y. Chen, X. P. Guo, Q. Zhang and J. E. Qu, J. Mater. Sci., 2006, 41, 5033-5035.

73 A. Döppenschmidt and H. J. Butt, Langmuir, 2000, 16, 67096714.

74 Y. Xiong, B. Brown, B. Kinsella, S. Nešić and A. Pailleret, Corrosion, 2014, 70, 247-260.

75 F. Zhang, J. Pan, P. M. Claesson and T. Brinck, Thin Solid Films, 2012, 520, 7136-7143.

76 X. F. Yang and J. E. Castle, Surf. Interface Anal., 2002, 33, 894-899.

77 G. Bar, Y. Thomann and M. H. Whangbo, Langmuir, 1998, 14, 1219-1226.

78 A. Imanishi, M. Suzuki and Y. Nakato, Langmuir, 2007, 23, 12966-12972.

79 S. Paulson, P. Khalafpour, D. Cramb and V. Birss, 2016, http://www.researchgate.net/publication/268406800, accessed Nov. 2016.

80 J. Li, L. Ecco, M. Fedel, V. Ermini, G. Delmas and J. Pan, Prog. Org. Coat., 2015, 87, 179-188.

81 H. Ardelean, I. Frateur and P. Marcus, Corros. Sci., 2008, 50, 1907-1918.

82 M. F. Montemor, A. M. Simoes and M. G. S. Ferreira, Prog. Org. Coat., 2002, 44, 111-120.

83 V. Pandarinathan, K. Lepková, S. I. Bailey, T. Becker and R. Gubner, Ind. Eng. Chem. Res., 2014, 53, 5858-5865.

$84 \mathrm{~J}$. Li, L. Ecco, A. Ahniyaz, M. Fedel and J. Pan, J. Electrochem. Soc., 2015, 162, C610-C618.

85 J. Li, H. Huang, M. Fielden, J. Pan, L. Ecco, C. Schellbach, G. Delmas and P. M. Claesson, $R S C A d v ., 2016,6$, 1911119127.

86 S. Al-Hassan, B. Mishra, D. L. Olson and M. M. Salama, Corrosion, 1998, 54, 480-491.

87 W. Kautek, M. Geu, M. Sahre, P. Zhao and S. Mirwald, Surf. Interface Anal., 1997, 25, 548-560.

88 S. Sathiyanarayanan, M. Sahre and W. Kautek, Corros. Sci., 1999, 41, 1899-1909.

89 R. De Marco, Z. T. Jiang, B. Pejcic and E. Poinen, J. Electrochem. Soc., 2005, 152(10), B389-B392.

90 R. De Marco, Z. T. Jiang, D. John, M. Sercombe and B. Kinsella, Electrochim. Acta, 2007, 52, 3746-3750.

91 B. Ingham, M. Ko, G. Kear, P. Kappen, N. Laycock, J. A. Kimpton and D. E. Williams, Corros. Sci., 2010, 52, 3052-3061.

92 B. Ingham, M. Ko, N. Laycock, J. Burnell, P. Kappen, J. A. Kimpton and D. E. Williams, Corros. Sci., 2012, 56, 96-104.

93 M. Ko, N. J. Laycock, B. Ingham and D. E. Williams, Corrosion, 2012, 68, 1085-1093.

94 M. Ko, B. Ingham, N. Laycock and D. E. Williams, Corros. Sci., 2015, 90, 192-201.

95 R. De Marco, Z. T. Jiang, B. Pejcic and A. van Riessen, Electrochim. Acta, 2006, 51, 4886-4891.

96 J. H. Qiu and P. H. Chua, Surf. Interface Anal., 1999, 28, 119122.
97 Y. Xiang, M. Yan, Y. S. Choi, D. Young and S. Nesic, Int. J. Greenhouse Gas Control, 2014, 30, 125-132.

98 D. A. Lopez, W. H. Schreiner, S. R. De Sanchez and S. N. Simison, Appl. Surf. Sci., 2004, 236, 77-97.

99 P. Galicia, N. Batina and I. Gonzalez, J. Phys. Chem. B, 2006, 110, 14398-14405.

100 N. Ochoa, C. Vega, N. Pébère, J. Lacaze and J. L. Brito, Mater. Chem. Phys., 2015, 156, 198-205.

101 M. P. Seah, J. H. Qiu, P. J. Cumpson and J. E. Castle, Surf. Interface Anal., 1994, 21, 336-341.

102 I. L. Rosenfeld, Corrosion, 1981, 37, 371-377.

103 G. Trabanelli, Corrosion, 1991, 47, 410-419.

104 J. E. Castle and J. H. Qiu, Corros. Sci., 1989, 29, 591-603.

105 J. H. Qiu and J. E. Castle, J. Electrochem. Soc., 1991, 138, 1908-1911.

106 M. Tourabi, K. Nohair, M. Traisnel, C. Jama and F. Bentiss, Corros. Sci., 2013, 75, 123-133.

107 B. V. A. Rao, M. V. Rao, S. S. Rao and B. Sreedhar, J. Surf. Eng. Mater. Adv. Technol., 2013, 3(1), 28-42.

108 F. Bentiss, M. Outirite, M. Traisnel, H. Vezin, M. Lagrenee, B. Hammouti, S. S. Al-Deyab and C. Jama, Int. J. Electrochem. Sci., 2012, 7, 1699-1723.

109 H. Zarrok, A. Zarrouk, B. Hammouti, R. Salghi, C. Jama and F. Bentiss, Corros. Sci., 2012, 64, 243-252.

110 D. A. Lopez, W. H. Schreiner, S. R. De Sánchez and S. N. Simison, Appl. Surf. Sci., 2003, 207, 69-85.

111 R. Kelly, Surf. Sci., 1980, 100, 85-107.

112 S. Hajati and S. Tougaard, Anal. Bioanal. Chem., 2010, 396(8), 2741-2755.

113 J. W. Kim, B. Son, H. Yu, H. M. Park and Y. S. Lee, Surf. Interface Anal., 2014, 46(3), 193-196.

114 C. Gutiérrez and C. A. Melendres, Spectroscopic and diffraction techniques in interfacial electrochemistry, Springer Science \& Business Media, 2012, p. 320.

115 P. Fabis, C. Brown, T. Rockett and R. Heidersbach, Oxid. Met., 1981, 16, 399-407.

116 X. Nie, X. Li, C. Du, Y. Huang and H. Du, J. Raman Spectrosc., 2009, 40, 76-79.

117 B. W. A. Sherar, P. G. Keech and D. W. Shoesmith, Corros. Sci., 2013, 66, 256-262.

118 Y. S. Choi, S. Nesic and D. Young, Environ. Sci. Technol., 2010, 44, 9233-9238.

119 I. S. Molchan, G. E. Thompson, P. Skeldon, R. Lindsay, J. Walton, E. Kouvelos, G. E. Romanos, P. Falaras, A. G. Kontos, M. Arfanis, E. Siranidi, L. F. Zubeir, M. C. Kroon, J. Klockner, B. Iliev and T. J. S. Schubert, RSC Adv., 2015, 5, 35181-35194.

120 X. Kui, C. Dong, X. Li and F. Wang, J. Iron Steel Res. Int., 2008, 15, 42-48.

121 R. A. Antunes, R. U. Ichikawa, L. G. Martinez and I. Costa, Int. J. Corros., 2014, 419570, DOI: 10.1155/2014/419570.

122 S. Li and L. H. Hihara, J. Electrochem. Soc., 2015, 162, C495C502.

123 Y. El Mendili, A. Abdelouas and J. F. Bardeau, Phys. Chem. Chem. Phys., 2013, 15, 9197-9204.

124 P. Balamurugan, P. Chandramohan and T. S. Rao, RSC Adv., 2016, 6, 41122-41129. 
125 G. Genchev and A. Erbe, J. Electrochem. Soc., 2016, 163, C333-C338.

126 X. Zhang, K. Xiao, C. Dong, J. Wu, X. Li and Y. Huang, Eng. Failure Anal., 2011, 18, 1981-1989.

127 P. Cao, R. Gu and Z. Tian, Langmuir, 2002, 18, 7609-7615.

128 L. J. Oblonsky, T. M. Devine, J. W. Ager III, S. S. Perry, X. L. Mao and R. E. Russo, J. Electrochem. Soc., 1994, 141, 3312-3317.

129 H. Yamada and Y. Yamamoto, Surf. Sci., 1983, 134(1), 71-90.

130 K. Aramaki and J. Uehara, J. Electrochem. Soc., 1989, 136(5), 1299-1303.

131 K. Aramaki, M. Ohi and J. Uehara, J. Electrochem. Soc., 1992, 139(6), 1525-1529.

132 J. Uehara, H. Nishihara and K. Aramaki, J. Electrochem. Soc., 1990, 137(9), 2677-2683.

133 R. A. Gu, P. G. Cao, J. L. Yao, B. Ren, Y. Xie, B. W. Mao, et al., J. Electroanal. Chem., 2001, 505(1-2), 95-99.

134 K. K. Alaneme, S. J. Olusegun and O. T. Adelowo, Alexandria Eng. J., 2016, 55, 673-681.

135 F. E. Awe, S. O. Idris, M. Abdulwahab, E. E. Oguzie and A. M. Z. Slawin, Cogent Chem., 2015, 1, 1112676.

136 Y. Sangeetha, S. Meenakshi and C. Sairam Sundaram, J. Appl. Polym. Sci., 2016, 133.

137 E. E. Oguzie, C. B. Adindu, C. K. Enenebeaku, C. E. Ogukwe, M. A. Chidiebere and K. L. Oguzie, J. Phys. Chem. C, 2012, 116, 13603-13615.

138 L. Li, W. Xu, J. Lei, J. Wang, J. He, N. Li and F. Pan, RSC Adv., 2015, 5, 93724-93732.

139 J. M. Perez, L. Josephson, T. O'Loughlin, D. Högemann and R. Weissleder, Nat. Biotechnol., 2002, 20, 816-820.

140 A. V. Ramesh Kumar and N. Singh, Hyperfine Interact., 2009, 188(1-3), 51-58.

141 J. A. Jaen, J. Iglesias and C. Hernandez, Int. J. Corros., 2012, 162729, 11.

142 A. L. Chong, J. I. Mardel, D. R. MacFarlane, M. Forsyth and A. E. Somers, ACS Sustainable Chem. Eng., 2016, 4(3), 17461755.

143 R. Baskar, D. Kesavan, M. Gopiraman and K. Subramanian, Prog. Org. Coat., 2014, 77, 836-844.

144 A. M. Atta, G. A. El-Mahdy, H. A. Al-Lohedan and A. M. ElSaeed, Molecules, 2015, 20, 1244-1261.

145 K. Lepkova, W. Van Bronswijk, V. Pandarinathan and R. Gubner, Vib. Spectrosc., 2013, 68, 204-211.

146 V. Pandarinathan, K. Lepkova and W. Van Bronswijk, Corros. Sci., 2014, 85, 26-32.

147 K. Lepkova, W. Van Bronswijk, V. Pandarinathan and R. Gubner, J. Synchrotron Radiat., 2014, 21, 580-585.

148 http://www.bruker.com, Application note \#140, PeakForce Kelvin Probe Force Microscopy, accessed October 2016.

149 I. Apachitei, L. E. Fratila-Apachitei and J. Duszczyk, Scr. Mater., 2007, 57, 1012-1015.

150 P. Schmutz and G. S. Frankel, J. Electrochem. Soc., 1999, 146, 4461-4472.

151 V. Guillaumin, P. Schmutz and G. S. Frankel, J. Electrochem. Soc., 2001, 148, B163.
152 S. K. Kim, I. J. Park, D. Y. Lee and J. G. Kim, J. Appl. Electrochem., 2013, 43, 507-514.

153 P. K. Hansma and J. Tersoff, J. Appl. Phys., 1987, 61, R1-R24.

154 E. Martinez-Lombardia, Y. Gonzalez-Garcia, L. Lapeire, I. De Graeve, K. Verbeken, L. Kestens, J. M. C. Mol and H. Terryn, Electrochim. Acta, 2014, 116, 89-96.

155 K. Itaya, Prog. Surf. Sci., 1998, 58, 121-247.

156 E. Wang, Anal. Sci., 1994, 10, 155-156.

157 M. Moors, K. K. Adepalli, Q. Lu, A. Wedig, C. Bäumer, K. Skaja, B. Arndt, H. L. Tuller, R. Dittmann, R. Waser, B. Yildiz and I. Valov, ACS Nano, 2016, 10, 1481-1492.

158 I. Sekine, T. Hayakawa, T. Negishi and M. Yuasa, J. Electrochem. Soc., 1990, 137, 3029-3033.

159 Y. Zhou and Y. Zuo, Electrochim. Acta, 2015, 154, 157-165.

160 S. Sabbaghi, R. Bazargan Lari and M. Zeraatkar, International Journal of Nanoscience and Nanotechnology, 2011, 7, 72-77.

161 E. Martinez-Lombardia, V. Maurice, L. Lapeire, I. De Graeve, K. Verbeken, L. Kestens, P. Marcus and H. Terryn, J. Phys. Chem. C, 2014, 118, 25421-25428.

162 G. M. Haibo Lu, Y. LI and F. Wang, J. Mater. Sci. Technol., 2005, 21, 311-314.

163 F. P. Zamborini and R. M. Crooks, Langmuir, 1997, 13, 122126.

164 S. Szunerits, S. E. Pust and G. Wittstock, Anal. Bioanal. Chem., 2007, 389, 1103-1120.

165 T. E. Lister and P. J. Pinhero, Electrochim. Acta, 2003, 48, 2371-2378.

166 K. Fushimi and M. Seo, Electrochim. Acta, 2001, 47, 121-127.

167 H. Tanabe, K. Togashi, T. Misawa and U. K. Mudali, J. Mater. Sci. Lett., 1998, 17, 551-553.

168 E. Völker, C. G. Inchauspe and E. J. Calvo, Electrochem. Commun., 2006, 8, 179-183.

169 M. M. Osman and M. N. Shalaby, Mater. Chem. Phys., 2003, 77, 261-269.

170 P. C. Okafor, X. Liu and Y. G. Zheng, Corros. Sci., 2009, 51, 761-768.

171 M. A. Quraishi and D. Jamal, Corrosion, 2000, 56, 983-985.

172 E. Barmatov, J. Geddes, T. Hughes and M. Nagl, NACE International, 2012, C2012-0001573.

173 D. G. Hill and A. Jones, NACE International, 2003, paper no. 03121.

174 E. R. Fischer and J. E. Parker III, Corrosion, 1997, 53, 62-64. 175 D. I. Horsup, J. C. Clark, B. P. Binks, P. D. Fletcher and J. T. Hicks, Corrosion, 2010, 66, 36001.

176 D. G. Hill and H. Romijn, NACE International, 2000, paper no. 00342.

177 M. A. Malik, M. A. Hashim, F. Nabi, S. A. Al-Thabaiti and Z. Khan, Int. J. Electrochem. Sci., 2011, 6, 1927-1948.

178 S. Ali, J. S. Reyes, M. M. Samuel and F. M. Auzerais, US Pat. 20100056405 A1, 2010.

179 D. A. Williams, P. K. Holifield, J. R. Looney and L. A. McDougall, US Pat. 5209859 A, 1993.

180 H. A. Nasr-El-Din, A. M. Al-Othman, K. C. Taylor and A. H. Al-Ghamdi, J. Pet. Sci. Eng., 2004, 43, 57-73.

181 W. Durnie, R. De Marco, A. Jefferson and B. Kinsella, J. Electrochem. Soc., 1999, 146(5), 1751-1756. 
182 N. N. Tkachenko, I. I. Vasilenko and I. Y. Liskevich, Mater. Sci., 1968, 3, 268.

183 E. S. M. Sherif, Appl. Surf. Sci., 2014, 292, 190-196.

184 B. Dogru Mert, M. Erman Mert, G. Kardas and B. Yazıcı, Corros. Sci., 2011, 53, 4265-4272.

185 A. O. Yüce, B. D. Mert, G. Kardaş and B. Yazıcı, Corros. Sci., 2014, 83, 310-316.

186 R. Yildiz, A. Döner, T. Doğan and I. Dehri, Corros. Sci., 2014, 82, 125-132.

187 B. D. Mert, A. O. Yüce, G. Kardaș and B. Yazıcı, Corros. Sci., 2014, 85, 287-295.

188 A. Döner, R. Solmaz, M. Özcan and G. Kardaș, Experimental and theoretical studies of thiazoles as corrosion inhibitors for mild steel in sulphuric acid solution, Corros. Sci., 2011, 53, 2902-2913.

189 M. El Azhar, M. Traisnel, B. Mernari, L. Gengembre, F. Bentiss and M. Lagrenée, Appl. Surf. Sci., 2002, 185, 197-205.

190 B. Xu, Y. Liu, X. Yin, W. Yang and Y. Chen, Corros. Sci., 2013, 74, 206-213.

191 Z. Tao, S. Zhang, W. Li and B. Hou, Corros. Sci., 2009, 51, 2588-2595.

192 R. Solmaz, Corros. Sci., 2010, 52, 3321-3330.

193 R. A. Prabhu, T. V. Venkatesha, A. V. Shanbhag, G. M. Kulkarni and R. G. Kalkhambkar, Corros. Sci., 2008, 50, 3356-3362.

194 N. V. Likhanova, M. A. Domínguez-Aguilar, O. OlivaresXometl, N. Nava-Entzana, E. Arce and H. Dorantes, Corros. Sci., 2010, 52, 2088-2097.

195 S. M. Tawfik, RSC Adv., 2015, 5, 104535-104550.

196 C. He, Z. Tian, B. Zhang, Y. Lin, X. Chen, M. Wang and F. Li, Ind. Eng. Chem. Res., 2015, 54, 1971-1981.

197 N. D. Nam, Q. V. Bui, M. Mathesh, M. Y. J. Tan and M. A. Forsyth, Corros. Sci., 2013, 76, 257-266.

198 D. N. Nguyen, M. Mathesh, B. Hinton, M. J. Y. Tan and M. Forsyth, J. Electrochem. Soc., 2014, 161(12), C527-C534.

199 P. C. Okafor, E. E. Ebenso and U. J. Ekpe, Int. J. Electrochem. Sci., 2010, 5, 978-993.

200 M. Prabakaran, S. H. Kim, K. Kalaiselvi, V. Hemapriya and I. M. Chung, J. Taiwan Inst. Chem. Eng., 2016, 59, 553-562.

201 H. Z. Alkhathlan, M. Khan, M. M. S. Abdullah, A. M. AlMayouf, A. Y. Badjah-Hadj-Ahmed, Z. A. AlOthman, et al., RSC Adv., 2015, 5(67), 54283-54292. 202 J. Buchweishaija and G. S. Mhinzi, Port. Electrochim. Acta, 2008, 26, 257-265.

203 P. C. Okafor and E. E. Ebenso, Pigm. Resin Technol., 2007, 36, 134-140.

204 A. M. Al-Turkustani, S. T. Arab and L. S. S. Al-Qarni, J. Saudi Chem. Soc., 2011, 15, 73-82.

205 M. Shyamala and P. K. Kasthuri, Int. J. Corros., 2011, 2011, 11. 206 S. Subhashini, R. Rajalakshmi, A. Prithiba and A. Mathina, J. Chem., 2010, 7, 1133-1137.

207 A. Singh, E. E. Ebenso and M. A. Quraishi, Int. J. Corros., 2012, 2012.

208 P. Mourya, S. Banerjee and M. M. Singh, Corros. Sci., 2014, 85, 352-363.
209 M. A. Chidiebere, E. E. Oguzie, L. Liu, Y. Li and F. Wang, Ind. Eng. Chem. Res., 2014, 53, 7670-7679.

210 A. L. M. Daneluti and J. d. R. Matos, Braz. J. Pharm. Sci., 2013, 49, 275-283.

211 G. Ji, S. Anjum, S. Sundaram and R. Prakash, Corros. Sci., 2015, 90, 107-117.

212 K. Zhang, B. Xu, W. Yang, X. Yin, Y. Liu and Y. Chen, Corros. Sci., 2015, 90, 284-295.

213 R. Yıldız, Corros. Sci., 2015, 90, 544-553.

214 A. L. De Weck, in Allergic reactions to drugs 423-482, Springer, 1983.

215 P. M. Blumberg, Ann. N. Y. Acad. Sci., 1974, 235, 310-325.

216 N. O. Eddy, S. A. Odoemelam and P. Ekwumemgbo, Sci. Res. Essays, 2009, 4, 33-38.

217 N. O. Eddy and S. A. Odoemelam, Adv. Nat. Appl. Sci., 2008, 2, 225-233.

218 G. Gece, Corros. Sci., 2011, 53, 3873-3898.

219 P. B. Matad, P. B. Mokshanatha, N. Hebbar, V. T. Venkatesha and H. C. Tandon, Ind. Eng. Chem. Res., 2014, 53, 8436-8444.

220 K. R. Ansari, M. A. Quraishi, A. Singh, S. Ramkumar and I. B. Obote, $R S C$ Adv., 2016, 6, 24130-24141.

221 K. R. Ansari, M. A. Quraishi, A. Singh, S. Ramkumar and I. B. Obote, RSC Adv., 2016, 6(29), 24130-24141.

222 S. H. Kumar and S. Karthikeyan, Ind. Eng. Chem. Res., 2013, 52, 7457-7469.

223 C. Li, S. Richter and S. Nesic, Proceedings of $7^{\text {th }}$ International Corrosion Congress, Las Vegas, NV, 6-10 October 2008, paper no. 2662.

224 S. Ramachandran and V. Jovancicevic, Corrosion, 1999, 55(6), 631.

225 L. M. Rodríguez-Valdez, W. Villamisar, M. Casales, J. G. González-Rodriguez, A. Martínez-Villafañe, L. Martinez, et al., Corros. Sci., 2006, 48(12), 4053-4064.

226 X. Liu, P. C. Okafor and Y. G. Zheng, Corros. Sci., 2009, 51(4), 744-751.

227 P. C. Okafor, X. Liu and Y. G. Zheng, Corros. Sci., 2009, 51(4), 761-768.

228 F. G. Liu, M. Du, J. Zhang and M. Qiu, Corros. Sci., 2009, 51, 102-109.

229 D. M. Ortega-Sotelo, J. G. Gonzalez-Rodriguez, M. A. NeriFlores, M. Casales, L. Martinez and A. Martinez-Villafañe, J. Solid State Electrochem., 2011, 15, 1997-2004.

230 X. Jiang, Y. G. Zheng and W. Ke, Corrosion, 2005, 61(4), 326334.

231 J. Zhang, X. Sun, Y. Ren and M. Du, J. Surfactants Deterg., 2015, 18, 981-987.

232 A. S. Yaro, K. R. Abdul-Khalik and A. A. Khadom, J. Loss Prev. Process Ind., 2015, 38, 24-38.

233 G. Zhang, C. Chen, M. Lu, C. Chai and Y. Wu, Mater. Chem. Phys., 2007, 105(2-3), 331-340.

234 F. Ferelas and A. Ramirez, Int. J. Electrochem. Sci., 2010, 5, 797-814. 